\title{
Leitlinienreport zur aktualisierten S3-Leitlinie der Deutschen Gesellschaft für Gastroenterologie, Verdauungs- und Stoffwechselkrankheiten (DGVS) und der Deutschen Gesellschaft für Allgemein- und Viszeralchirurgie (DGAV) zur Prävention, Diagnostik und Behandlung von Gallensteinen
}

(AWMF-Register-Nr. 021/008)

\author{
Autoren \\ Frank Lammert ${ }^{1,5}$ \\ Institute \\ 1 Deutsche Gesellschaft für Gastroenterologie, Verdauungs- \\ und Stoffwechselerkrankungen, Berlin, Deutschland \\ 2 Klinik f. Allgemein-, Viszeral-, Gefäß- und Thoraxchirurgie, \\ Klinikum Memmingen, Deutschland \\ 3 Innere Medizin, Krankenhaus Märkisch Oderland $\mathrm{GmbH}$, \\ Wriezen, Deutschland \\ 4 Deutsche Stiftung Organtransplantation (DSO), Mainz, \\ Deutschland \\ 5 Klinik für Innere Medizin II, Universitätsklinikum des \\ Saarlandes, Universität des Saarlandes, Homburg, \\ Deutschland \\ 6 Abteilung Innere Medizin, Krankenhaus Maria Stern, \\ Remagen, Deutschland
}

Petra Lynen Jansen ${ }^{1}$, Carsten Gutt ${ }^{2}$, Christian Jenssen $^{3}$, Ana-Paula Barreiros ${ }^{4}$, Caroline S. Stokes ${ }^{5}$, Michael Neubrand ${ }^{6}$,

Bibliografie

DOI https://doi.org/10.1055/a-0643-4420

Z Gastroenterol 2018; 56: 116-180

(c) Georg Thieme Verlag KG, Stuttgart · New York

ISSN 0044-2771

Korrespondenzadresse

Prof. Dr. Frank Lammert

Klinik für Innere Medizin II

Universitätsklinikum des Saarlandes

Universität des Saarlandes

Kirrberger Straße 100, 66421 Homburg

Tel.: ++49/6841/1623201

frank.lammert@uks.eu

\begin{tabular}{|l|l|l|}
\hline \multicolumn{2}{|l|}{ Inhaltsverzeichnis } & Seite \\
\hline 1. & Hintergrund der Leitlinie & $\mathrm{e} 116$ \\
\hline 1.1 & Zielorientierung der Leitlinie & $\mathrm{e} 117$ \\
\hline 1.2 & Patientenzielgruppe & $\mathrm{e} 117$ \\
\hline 1.3 & Versorgungsbereich & $\mathrm{e} 117$ \\
\hline 1.4 & Anwenderzielgruppe & $\mathrm{e} 117$ \\
\hline 2. & Zusammensetzung der Leitliniengruppe und & $\mathrm{e} 117$ \\
\hline 3. & Meteiligung von Interessengruppen & $\mathrm{e} 118$ \\
\hline 3.1 & $\begin{array}{l}\text { Überarbeitungsstrategie und Priorisierung der } \\
\text { Empfehlungen }\end{array}$ & $\mathrm{e} 118$ \\
\hline 3.2 & Literaturrecherche und Auswahl der Evidenz & $\mathrm{e} 119$ \\
\hline 3.3 & $\begin{array}{l}\text { Formulierung der Empfehlungen und strukturierte } \\
\text { Konsensfindung }\end{array}$ & $\mathrm{e} 119$ \\
\hline 3.4 & Zeitplan & $\mathrm{e} 120$ \\
\hline 4. & Externe Begutachtung und Verabschiedung & $\mathrm{e} 120$ \\
\hline & & \\
\hline
\end{tabular}

\section{Hintergrund der Leitlinie}

Die Entwicklung und Implementierung von nationalen, hochwertigen evidenz- und konsensbasierten Leitlinien ist eine wesentliche Grundlage für eine optimierte und sichere Versorgung unse- 
rer Patienten. 15 - 20\% unserer Bevölkerung haben Gallensteine [1 -4], und jährlich werden in Deutschland mehr als 175000 Cholezystektomien aufgrund einer Cholelithiasis durchgeführt [5, 6]. Das Gallensteinleiden ist damit nach der Refluxerkrankung die gastroenterologische Erkrankung, die die höchsten Kosten verursacht [7]. Folgerichtig wurde bereits 2000 eine erste Leitlinie publiziert, um eine evidenzbasierte und einheitliche Behandlung des Gallensteinleidens zu gewährleisten. 2007 erfolgte eine erste Aktualisierung auf S3-Niveau, deren Gültigkeit 2012 endete. Inzwischen wurden weitere wichtige Leitlinien, Metaanalysen und randomisierte Studien veröffentlicht, die eine erneute Überarbeitung der Leitlinie erforderten.

Die Leitlinie zur Prävention, Diagnostik und Therapie dieser sehr häufigen Erkrankung wurde von der Deutschen Gesellschaft für Verdauungs- und Stoffwechselkrankheiten (DGVS) und der Deutschen Gesellschaft für Allgemein- und Viszeralchirurgie (DGAV) gemeinsam entwickelt. Die bisherigen Leitlinien, die auf die Diagnostik und die Therapie fokussierten, wurden hierbei auch um Empfehlungen zur Prävention des Gallensteinleidens erweitert.

Die Leitlinie ist eine systematisch entwickelte ärztliche Orientierungshilfe mit Handlungs- und Entscheidungsvorschlägen, von denen in begründeten Fällen abgewichen werden kann oder sogar muss. Die Entscheidung, ob einer bestimmten Empfehlung gefolgt wird, trifft der behandelnde Arzt unter Berücksichtigung der individuellen Situation seines Patienten.

\subsection{Zielorientierung der Leitlinie}

Ziel ist es, die neuen Erkenntnisse zur Definition, Epidemiologie und Resistenzlage sowie Fortschritte in der Diagnostik und Therapie zu bewerten und zu integrieren. Zu Beginn dieser vollständigen Leitlinienaktualisierung wurde daher zunächst der Überarbeitungsbedarf der Leitlinie in folgenden Schritten analysiert und festgelegt.

Festlegung des inhaltlichen Überarbeitungsbedarfs:

- Orientierende Literaturrecherche insbesondere nach Quellen aggregierter Evidenz

- Aufarbeitung der Kommentare und Korrekturvorschläge zur alten Leitlinie

- Expertenbefragung der Leitliniengruppe zum Änderungs- und Ergänzungsbedarf

- Priorisierung des Überarbeitungsbedarfs der alten Leitlinienempfehlung, Festlegung der Evidenzgrundlage und Ergänzung neuer Schlüsselfragen

- Konsentierung durch die Steuergruppe (Koordinator, AG-Leiter und Mandatsträger der eingeladenen Fachgesellschaften)

Dem Entwicklungsprozess lagen wie auch bei den Vorgängerversionen die Anforderungen des Deutschen Instruments zur methodischen Leitlinien-Bewertung (DELBI) zugrunde [8]. Die Methodik der Leitlinie beruht auf dem zurzeit gültigen Regelwerk der AWMF, dem Cochrane Manual Systematische Literaturrecherche für die Erstellung von Leitlinien und dem Leitlinienprogramm der DGVS [9-11], hierbei ergaben sich einige Änderungen, insbesondere in der Darstellung der angewandten Methodik.
Festlegung des methodischen Überarbeitungsbedarfs:

1. Systematische Literaturrecherche ab 2007, Auswahl und Bewertung der Literatur für prioritäre Fragestellungen

2. Klassifizierung von Studien und Empfehlungen nach den Kriterien der evidenzbasierten Medizin, Erstellen von Evidenztabellen

3. Dokumentation der Evidenzrecherche (Suchstrategien, Trefferquoten, Auswahl der Evidenz und Dokumentation der Ausschlussgründe)

4. Änderung der Empfehlungsgraduierung nach A („soll“), B (,sollte“) und 0 (,kann“)

5. Formulierung von Qualitätszielen für die Versorgung

6. Dokumentation und Bewertung potenzieller Interessenskonflikte im Leitlinienreport, Offenlegung im Leitlinienreport

\subsection{Patientenzielgruppe}

Die Leitlinie richtet sich an Erwachsene mit Gallensteinen sowie deren Folgekrankheiten.

\subsection{Versorgungsbereich}

Die Leitlinie gilt sowohl für die ambulante als auch die stationäre medizinische Versorgung und behandelt Prävention, Diagnostik und Therapie in der primärärztlichen und der spezialfachärztlichen Versorgung.

\subsection{Anwenderzielgruppe}

Die Leitlinie richtet sich insbesondere an alle an der Beratung, Diagnostik und Therapie der Erkrankung beteiligten Internisten, Gastroenterologen und Chirurgen. Sie soll darüber hinaus aber andere Institutionen und Organisationen wie zum Beispiel Medizinisch-Wissenschaftlichen Fachgesellschaften und Berufsverbänden, Interessenvertretungen der Patienten, Gesundheitspolitischen Einrichtungen und Entscheidungsträgern, Kostenträgern sowie der Öffentlichkeit zur Information über gute medizinische Vorgehensweise dienen.

\section{Zusammensetzung der Leitliniengruppe und Beteiligung von Interessengruppen}

Die Leitlinie wurde federführend durch die Deutsche Gesellschaft für Gastroenterologie, Verdauungs- und Stoffwechselkrankheiten (DGVS) erstellt, die als Koordinator Herrn Prof. Dr. med. Lammert, Homburg, beauftragte. Frau PD Dr. med. Lynen-Jansen, DGVSGeschäftsstelle (Berlin), stand bei methodischen Fragestellungen beratend zur Seite und übernahm organisatorische Aufgaben.

Bei der Zusammenstellung der Arbeitsgruppen wurde auf eine für die klinischen Fragestellungen repräsentative Besetzung geachtet. Die für das Fachgebiet relevanten Fachgesellschaften wurden angeschrieben und gebeten, Mandatsträger für ihre Organisationen zu benennen. Die Anmeldung der Leitlinie wurde am 20.11.2012 auf der Webseite der AWMF veröffentlicht, sodass weitere Fachgesellschaften/Vertreter sich zur Mitarbeit melden konnten. Experten und Anwender aus den verschiedenen Versorgungsstufen wurden berücksichtigt. 
Folgende Fachgesellschaften/Organisationen nahmen teil:

- Deutsche Gesellschaft für Innere Medizin e. V. (DGIM)

- Österreichische Gesellschaft für Gastroenterologie und Hepatologie (ÖGGH)

- Schweizer Gesellschaft für Gastroenterologie (SGH)

- Deutsche Gesellschaft für Allgemein- und Viszeralchirurgie (DGAV)

- Gesellschaft für Humangenetik (GfH)

- Deutsche Gesellschaft für Ultraschall in der Medizin (DEGUM)

- Deutsche Gesellschaft für Chirurgie (DGCH)

- Institut für Qualitätssicherung und Transparenz im Gesundheitswesen (IQTIG)

- Deutsche Arbeitsgemeinschaft zum Studium der Leber (GASL)

- Deutsche Röntgengesellschaft (DRG)

- Deutsche Leberhilfe e. V. als Patientenorganisation

Die Deutsche Gesellschaft für Allgemein- und Familienmedizin (DEGAM) wurde zur Mitarbeit eingeladen, konnte aber aus personellen Gründen die Leitlinienarbeit nicht unterstützen. Das IQTIG stand beratend und ohne Stimmrecht bei der Erstellung der Leitlinie beiseite.

Bei der personellen Besetzung der einzelnen Arbeitsgruppen wurden, wenn möglich, Fachkompetenz, eine interdisziplinäre Verteilung und der jeweilige Tätigkeitsbereich (niedergelassen und stationär) berücksichtigt. Die inhaltliche Arbeit wurde $4 \mathrm{Ar}$ beitsgruppen zugeordnet, Qualitätssicherungsempfehlungen wurden in den jeweiligen Arbeitsgruppen in Anlehnung an die alte Leitlinie mit erarbeitet.

Herr von Thiel arbeitete als Patientenvertreter arbeitsgruppenübergreifend.

Besetzung der Arbeitsgruppen (AGs):

AG1: Prävention und konservative Therapie der Gallenblasensteine

- Frank Lammert, Homburg: DGVS, DGIM

- Jochen Hampe, Dresden: DGVS

- Michael Sackmann, Bamberg: DGVS

- Thomas P. Hüttl, München: DGAV

- Erdmute Kunstmann, Würzburg: GfH

- Christoph Dietrich, Stolberg: DGVS

- Birgit Kallinowski, Schwetzingen: DGVS

AG2: Diagnostik der Gallenblasen- und Gallengangsteine

- Ana-Paula Barreiros, Regensburg: DEGUM, GASL

- Michael Schepke, Siegburg: DGVS

- Siegbert Faiss, Hamburg: DGVS

- Steffen Rickes, Oschersleben: DGVS, DEGUM

- Klaus Dirks, Winnenden: DEGUM

- Thomas Frieling, Krefeld: ALGK

- Christian Jenssen, Strausberg: DEGUM

- Reinhard Kubale, Pirmasens: DEGUM

- Matthias Glanemann, Homburg: DGAV

- Andreas Schreyer, Regensburg: DRG

\section{AG3: Chirurgische Therapie der Gallenblasensteine}

- Carsten Gutt, Memmingen: DGAV

- Tilman Sauerbruch, Bonn: DGVS

- Thorsten Götze, Frankfurt: DGAV

- Jens Encke, Neuss: DGVS
- Jochen Schuld, Homburg: DGAV

- Jürgen Pauletzki, Göttingen: IQTIG

- Stephan Miehlke, Hamburg: DGVS

- Albrecht Stier, Erfurt: DGCH

- Marty Zdichavsky, Tübingen: GASL

AG4: Therapie der Gallengangsteine

- Michael Neubrand, Remagen: DGVS

- Hubertus Feussner, München: DGAV

- Ralf Jakobs, Ludwigshafen: DGVS

- Matthias Maier, Püttlingen: DGVS

- Peter Sauer, Heidelberg: DGVS

- Christiane Bruns, München: DGAV

- Walter Asperger, Halle: DGVS

- Florian Schreiber, Graz: ÖGGH

- Hermann Helmberger, München: DRG

\section{Patientenvertretung}

- Ingo van Thiel, Köln: Deutsche Leberhilfe e. V.

\section{Methodologische Exaktheit}

\section{1 Überarbeitungsstrategie und Priorisierung der Empfehlungen}

Am 10.07.2014 erfolgte ein erstes Treffen (Kick-off-Treffen) der Koordinatoren, Mandatsträger und der Arbeitsgruppenleiter, in dem die Arbeitsgruppen und der Überarbeitungsbedarf festgelegt wurden. Vorab wurde eine Recherche nach aktuellen Leitlinien über die Datenbank der Arbeitsgemeinschaft der Wissenschaftlichen Medizinischen Fachgesellschaften (AWMF), die Datenbank der National Guideline Clearinghouse (NGC), sowie über die Webseiten des National Institute for Health and Clinical Excellence (NICE) und des Scottish Intercollegiate Guidelines Network (SIGN), der European Association for the Study oft the Liver (EASL) durchgeführt. Per Handsuche wurde die Richtlinie Gallensteine der Nederlandse Vereniging voor Heelkunde ergänzt. Metaanalysen, systematische Reviews und randomisierte Studien, deren Aussage eine inhaltliche Änderung der Leitlinie erforderten, wurden unter den Experten abgefragt oder über die Cochrane Library recherchiert.

Folgende Leitlinien und Studien waren für die Planung von besonderer Relevanz

- DGVS-Leitlinien 2000 und 2007 [12, 13]

- TG13: Updated Tokyo Guidelines for the management of acute cholangitis and cholecystitis [14]

- NICE Clinical Guideline 1882014 [15]

- Neederlandse richtlijn Galsteenlijden 2016 [16]

- EASL Clinical Practice Guidelines on the prevention, diagnosis and treatment of gallstones 2016 [17]

- British guidelines on the management of common bile duct stones 2017 [18]

Als weitere relevante Quelle wurde die IQWIG Gesundheitsinformation Gallensteine 2012 berücksichtigt (http://www.iqwig.de/). 
Auf Basis dieser Vorabrecherche wurden die Empfehlungen der alten Leitlinie diskutiert und priorisiert. Es wurde festgelegt, welche Empfehlungen unverändert übernommen, überarbeitet oder gestrichen werden sollten. Neue Empfehlungen wurden auf Vorschlag der Teilnehmenden, auf Basis der Vorabrecherche oder auf Basis der seit 2009 dokumentierten Kommentare, Fragen und Vorschläge zur alten Leitlinie ergänzt. Literatur, Präsentationen und Arbeitsmaterialien wurden über ein onlinebasiertes Leitlinienportal allen Mitarbeitern zur Verfügung gestellt. Zur Evidenzbewertung wurde auf die Primärliteratur zurückgegriffen und von einer Leitlinienadaptation wurde abgesehen. Die Evidenzbewertung erfolgte anhand des Oxford-Schemas von 2011 (siehe Anhang IV). Anhang V zeigt das Schema zur Graduierung der Empfehlungsstärke. Abweichungen der Empfehlungsstärke wurden im Hintergrundtext begründet. Anhang III fasst die Evidenztabellen zusammen; bei hier nicht aufgeführten Empfehlungen gab es gegenüber der bisherigen Leitlinienversion keine neue Evidenz. Nach der Leitlinienkonferenz wurde die Literaturrecherche von 04/2015 bis 12/2017 ergänzt; dieses Literatur-Update führte mit einer Ausnahme (Empfehlung IIIC.7) nicht zu Veränderungen der Evidenzlevel der Leitlinienempfehlungen. Das neue Evidenzlevel für die Empfehlung III.C7 durch die Studie von Da Costa et al. [19] war schon aufgrund der Veröffentlichungen bei der Leitlinienkonferenz berücksichtigt worden.

\subsection{Literaturrecherche und Auswahl der Evidenz}

Im Anschluss an das Kick-off-Treffen wurde die Literatur durch eine systematische Recherche innerhalb der Arbeitsgruppen ergänzt. Diese Recherche erfolgte über die Literaturdatenbanken Cochrane (über das Cochrane Central Register of Controlled Trials in der Cochrane Library) und Medline (über die Pubmed-Suchoberfläche) mit den Limits 01/2007 - 03/2015, human, German, English. Literatur zur Prävention von Gallensteinen wurde ohne zeitliche Begrenzung gesucht, da die bisherigen Leitlinien hierzu keine Empfehlungen enthielten. Zusätzlich erfolgte eine Handsuche und Ergänzung relevanter Arbeiten durch die Mitglieder der Arbeitsgruppen. Weitere Artikel und Studien konnten bis zur Konsensuskonferenz ergänzt werden.

Die Suchstrategien basierten auf den Suchstrategien der britischen NICE Clinical Guideline Gallstone Disease [15]. Sie sind zusammen mit den Trefferzahlen im Anhang II dargestellt. Nach einer Vorsichtung der Abstracts durch die Arbeitsgruppenleiter, Ausschluss von nicht in englischer oder deutscher Sprache erhältlichen und inhaltlich nicht relevanten Arbeiten (anderer thematischer Fokus, anderer Publikationstyp/Abstract ohne weitere Informationen, nicht hinsichtlich Alter, Geschlecht oder klinischen Charakteristika spezifizierte Patientengruppen, fehlende Vergleichsgruppen, Duplikate, Fallserien) wurden insgesamt 142 von 372 Quellen zur Bewertung ausgewählt (siehe Anhang II).

\subsection{Formulierung der Empfehlungen und strukturierte Konsensfindung}

Auf Grundlage der Literatur wurden die Empfehlungen durch die AG-Leiter aktualisiert bzw. neu erarbeitet und zunächst im E-MailUmlaufverfahren innerhalb der einzelnen AGs abgestimmt. Die Graduierung der Empfehlungen erfolgte über die Formulierung
- Tab. 1 Schema zur Graduierung von Empfehlungen.

\begin{tabular}{|l|l|l|}
\hline Syntax & Symbol & Beschreibung \\
\hline soll & A & $\begin{array}{l}\text { starke Empfeh- } \\
\text { lung }\end{array}$ \\
\hline sollte & B & Empfehlung \\
\hline kann & 0 & Empfehlung offen \\
\hline Negative Empfehlungen werden entsprechend formuliert.
\end{tabular}

- Tab. 2 Konsensfindung.

\begin{tabular}{|l|l|}
\hline Konsens & \% Zustimmung \\
\hline starker Konsens & $\geq 95$ \\
\hline Konsens & $\geq 75-95$ \\
\hline mehrheitliche Zustimmung & $\geq 50-75$ \\
\hline kein Konsens & $<50$ \\
\hline
\end{tabular}

„soll, sollte, kann“ ( $\triangleright$ Tab. 1). Die Empfehlungen wurden in einem Delphi-Verfahren von allen Leitlinienmitarbeitern mithilfe einer dreistufigen Entscheidungsskala abgestimmt (ja, unentschieden, nein). Zu Empfehlungen, die nicht mit ja abgestimmt wurden, musste ein begründender Kommentar hinterlegt werden. Empfehlungen, die zu über $95 \%$ mit ja abgestimmt wurden, wurden bereits zu diesem Zeitpunkt verabschiedet ( $\bullet$ Tab. 2 ).

Die Kommentare und Änderungsvorschläge der Delphi-Runde wurden von den Koordinatoren gesichtet und ausgewertet. Alle Empfehlungen, die in der ersten Abstimmung weniger als $95 \%$ Zustimmung erhalten hatten, wurden innerhalb der AGs überarbeitet und auf der abschließenden Konsensuskonferenz erneut diskutiert. Frau PD Dr. med. Lynen-Jansen übernahm die unabhängige Moderation der Konsensuskonferenz. Die Empfehlungen wurden durch die vorbereitenden AG-Leiter präsentiert, erläutert und nach den Prinzipien der NIH-Konferenz besprochen und abgestimmt. Dazu wurden Änderungsvorschläge gesammelt, dokumentiert und mittels TED-System von allen Anwesenden bis zur Konsentierung (Konsens > 75\%) abgestimmt. Das Ergebnis der Abstimmung wurde dokumentiert und die Konsensusstärke gemäß > Tab. 2 festgelegt. Im Anschluss an die Konsensuskonferenz erfolgte die finale Überarbeitung der Kommentare durch die AGLeiter und die redaktionelle Zusammenstellung der Leitlinie durch den Koordinator. 


\subsection{Zeitplan}

\begin{tabular}{|l|l|}
\hline $\begin{array}{l}\text { Oktober } \\
2012\end{array}$ & Beauftragung der Koordinatoren durch die DGVS \\
\hline $\begin{array}{l}\text { Dezember } \\
2012\end{array}$ & Anmeldung bei der AWMF \\
\hline $\begin{array}{l}\text { Juni } \\
2014\end{array}$ & Kick-off-Treffen in Berlin \\
\hline $\begin{array}{l}\text { Oktober } \\
2014\end{array}$ & AG-Treffen in Leipzig \\
\hline $\begin{array}{l}\text { Februar } \\
2015\end{array}$ & Delphi-Verfahren \\
\hline $\begin{array}{l}\text { April } \\
2015\end{array}$ & Konsensuskonferenz in Mannheim \\
\hline $\begin{array}{l}\text { Dezember } \\
2017\end{array}$ & Literatur-Update und Freigabeverfahren \\
\hline
\end{tabular}

\section{Externe Begutachtung und Verabschiedung}

Die Leitlinie wurde allen beteiligten Fachgesellschaften zur Stellungnahme vorgelegt und von diesen verabschiedet. Durch die AWMF erfolgte eine externe formale Beurteilung.

\section{Redaktionelle Unabhängigkeit und Um- gang mit potenziellen Interessenkonflikten}

Die Leitlinie wurde von der DGVS finanziert. Vertreter der pharmazeutischen Industrie wurden nicht am Prozess der Leitlinienentwicklung beteiligt, um Neutralität und Unabhängigkeit zu wahren.

Vor Beginn der Konsensuskonferenz legten alle Teilnehmer ihre potenziellen Interessenkonflikte offen (siehe Anhang I). Hierfür wurden Interessenkonflikte schriftlich mithilfe eines Formblattes der Arbeitsgemeinschaft der Wissenschaftlichen Medizinischen Fachgesellschaften e. V. (AWMF), das materielle und immaterielle Interessen umfasst, erfasst und der Leitliniengruppe tabellarisch zur Verfügung gestellt und diskutiert. Die Interessenkonflikte wurden in „moderat“ und „schwer“ unterteilt (siehe Anhang I). Potenzielle „moderate“ Interessenkonflikte betrafen die Empfehlungen I.2a und I.2b; hierzu finden sich spezifische Hinweise in den beiden Kommentaren. Ein einziger potenzieller "schwerer“ Interessenkonflikt betraf den Aktienbesitz von zwei pharmazeutischen Unternehmen, deren Medikamente jedoch nicht Gegenstand dieser Leitlinie sind (siehe Anhang I). Es wurde einstimmig festgestellt, dass keine weiteren Interessenkonflikte vorlagen, die eine Stimmenthaltung erforderlich machten.

\section{Verbreitung und Implementierung}

Die Leitlinie sowie der Leitlinienreport werden auf der Homepage der DGVS (http://www.dgvs.de/) und der AWMF (http://www. awmf.de/) zum freien Download zur Verfügung gestellt. Die Langversion der Leitlinie wird in der „Zeitschrift für Gastroenterologie“ in deutscher Sprache publiziert. Unterstützend wird eine Leitlinien-App zur Verfügung gestellt. Die Leitlinienempfehlungen wer- den darüber hinaus auf den Kongressen und themenbezogenen Fortbildungsveranstaltungen der DGVS vorgestellt.

\section{Lernziele für Studierende der Medizin}

Der 2015 durch den Medizinischen Fakultätentag verabschiedete Nationale Kompetenzbasierte Lernzielkatalog Medizin (NKLM) beschreibt das Absolventenprofil von Ärztinnen und Ärzten nach einer universitären Ausbildung im Sinne eines Kerncurriculums Medizin (http://www.nklm.de/) [20]. Neben den Kompetenzen in der wissenschaftlichen Analyse, der Erhebung und Bewertung von Daten und Fakten der biologischen, physiologischen und psychosozialen Interdependenzen des Patienten werden Kompetenzen und Fertigkeiten in der Anwendung von diagnostischen und therapeutischen Verfahren sowie in der Kommunikation, der Interaktion und der Teamarbeit definiert.

Die Inhalte der aktuellen S3-Leitlinie wurden mit dem NKLM abgeglichen ( $\triangleright$ Tab.3). Der Vergleich beider Instrumente soll den Übergang von der ärztlichen Aus- zur Weiterbildung verbessern und einen Beitrag zur Sicherstellung einer bestmöglichen patientenzentrierten Prävention und Behandlung des Gallensteinleidens leisten. Ziel der Analyse war es, die Empfehlungen der Leitlinie den Lernzielen und Kompetenzen des NKLM zuzuordnen. Die in $>$ Tab. 3 aufgelisteten Empfehlungen wurden in der Leitlinie mit dem Hinweis NKLM versehen. Es fiel u. a. auf, dass der NKLM im Kap. 21 keinen Hinweis zur Prävention beim Gallensteinleiden allgemein und zur Behandlung der akuten Cholangitis spezifiziert; umgekehrt enthalten die Leitlinien keine Empfehlung zur im NKLM explizit genannten Nahrungskarenz bei Gallenkolik ( $\vee$ Tab. 3).

\section{Gültigkeitsdauer und \\ Aktualisierungsverfahren}

Die Gültigkeit der Leitlinie beträgt 5 Jahre (November 2022). Eine Überarbeitung der Leitlinie bei veränderter Datenlage erfolgt gegebenenfalls auch früher. Das Aktualisierungsverfahren wird koordiniert durch die DGVS-Geschäftsstelle.

$\begin{array}{ll}\text { ABKÜRZUnGSVERZICHNIS } \\ \text { AP } & \text { alkalische Phosphatase } \\ \text { ASA } & \text { American Society of Anesthesiologists } \\ \text { ASGE } & \text { American Society for Gastrointestinal Endoscopy } \\ \text { ASS } & \text { Acetylsalicylsäure } \\ \text { ATC } & \text { Anatomisch-Therapeutisch-Chemische Klassifikation } \\ \text { AWMF } & \text { Arbeitsgemeinschaft der Wissenschaftlichen } \\ & \text { Medizinischen Fachgesellschaften } \\ \text { ÄZQ } & \text { ärztliches Zentrum für Qualität in der Medizin } \\ \text { BÄK } & \text { Bundesärztekammer } \\ \text { BDE } & \text { Bile duct exploration } \\ \text { BIOSIS } & \text { BioSciences Information Service of Biological } \\ & \text { Abstracts } \\ \text { BMI } & \text { Body-Mass-Index } \\ \text { bng } & \text { Bundesverband Niedergelassener Gastroenterolo- } \\ & \text { gen Deutschlands } \\ \text { BQS } & \text { Bundesgeschäftsstelle Qualitätssicherung }\end{array}$


- Tab. 3 Abbildung von Lernzielen des NKLM in der Leitlinie.

\section{Lernziel/Teilkompetenz des NKLM}

Anwendungsbeispiele/Querverweise im NKLM

\section{Kompetenzebene des} NKLM $^{1}$
Relevante Empfehlung der S3-Leitlinie

12 Prinzipien normaler Struktur und Funktion

\begin{tabular}{|c|c|c|c|}
\hline 12.8.2 Orientierung am Körper & 12.8.2.4 Schmerzprojektion bei Cholezystitis & GL2 & II.1 \\
\hline \multirow[t]{2}{*}{$\begin{array}{l}12.15 .2 \text { Nahrungsverdauung und } \\
\text {-resorption }\end{array}$} & $\begin{array}{l}\text { 12.15.2.4 Hydroylse durch Verdauungsenzyme, } \\
\text { Pankreatitis }\end{array}$ & GL2 & II. 11 \\
\hline & $\begin{array}{l}\text { 12.15.2.6 Cholestase, obstruierende Gallensteine, } \\
\text { Cholezystitis }\end{array}$ & GL2 & $\begin{array}{l}11.4 \\
11.7\end{array}$ \\
\hline $\begin{array}{l}\text { 12.15.3 Leber als zentrales Organ } \\
\text { des Stoffwechsels }\end{array}$ & $\begin{array}{l}\text { 12.15.3.5 Bildung und Ausscheidung von Gallen- } \\
\text { farbstoffen und Gallensäuren, } \\
\text { ABC-Transporter, Gallensteine, Cholangitis }\end{array}$ & GL2 & 11.3 \\
\hline \multicolumn{4}{|c|}{13 Prinzipien der Pathogenese und Pathomechanismen } \\
\hline $\begin{array}{l}\text { 13.3.10 Pathophysiologische Me- } \\
\text { chanismen der Störungen des Ver- } \\
\text { dauungstraktes und Ableitung von } \\
\text { Diagnostik und Therapieansätzen }\end{array}$ & $\begin{array}{l}\text { 13.3.10.7 Cholestasen, Cholelithiasis, bildgebende } \\
\text { Verfahren, Strahlenschutz }\end{array}$ & GL1, BK2 & $\begin{array}{l}11.7 \\
11.8\end{array}$ \\
\hline \multicolumn{4}{|l|}{15 Diagnostische Verfahren } \\
\hline $\begin{array}{l}\text { 15.3.1 Indikations-gerechte, pa- } \\
\text { tientenbezogene und situations- } \\
\text { gerechte Auswahl der Sonografie }\end{array}$ & $\begin{array}{l}\text { 15.3.1.1 Indikationen und Kontraindikationen der } \\
\text { Sonografie } \\
\text { 14b.3.1.8/15.3.1.2 Nutzung zur Unterstützung } \\
\text { klinischer Basisuntersuchungen und für weitere } \\
\text { diagnostische und therapeutische Entscheidungen } \\
\text { 15.3.1.3 B-Bild-Sonografie durchführen, Focused } \\
\text { Assessment with Sonography for Trauma }\end{array}$ & $\begin{array}{l}\text { BK2, WK3b } \\
\text { BK2, PJ2-3a, WK3a } \\
\text { PJ2, WK3a }\end{array}$ & $\begin{array}{l}11.2 \\
11.4 \\
I 1.8\end{array}$ \\
\hline \multicolumn{4}{|l|}{16 Therapeutische Prinzipien } \\
\hline $\begin{array}{l}16.2 \text { Prinzipien der Ernährungs- } \\
\text { und Substitutionstherapie }\end{array}$ & $\begin{array}{l}\text { 16.2.1.4 Nahrungskarenz: Hemmung der Motilität } \\
\text { der Gallenwege bei Gallenkolik, akute Pankreatitis }\end{array}$ & BK2 & - \\
\hline \multirow[t]{2}{*}{$\begin{array}{l}16.3 \text { Prinzipen der interventionellen } \\
\text { Therapie }\end{array}$} & $\begin{array}{l}\text { 16.3.1.21 Prinzipien der endoskopischen Therapie, } \\
\text { ERCP, PTCD, Choledocho- und Cholezystolithiasis }\end{array}$ & BK2 & $\begin{array}{l}\text { IIIC. } 1 \\
\text { IIIC.2 } \\
\text { IIIC.3 } \\
\text { IIIC.4 } \\
\text { IIIC. } 5\end{array}$ \\
\hline & 16.3.1.30 Extrakorporale Stoßwellenlithotripsie & BK2 & $\begin{array}{l}\text { IIIA.2. } \\
\text { IIIC.4 }\end{array}$ \\
\hline $\begin{array}{l}\text { 16.4 Prinzipien der operativen } \\
\text { Therapie, der präoperativen Vor- } \\
\text { bereitung und der postoperativen } \\
\text { Nachbetreuung }\end{array}$ & $\begin{array}{l}\text { 16.4.1.61 Prinzipien der operativen Therapie bei } \\
\text { Cholezystolithiasis und akuter Cholezystitis, } \\
\text { Choledocho- und Cholezystolithiasis }\end{array}$ & BK2 & $\begin{array}{l}\text { II. } 6 \\
\text { IIIB. } 1 \\
\text { IIIB. } 3 \\
\text { IIIB. } 8 \\
\text { IIIB. } 13\end{array}$ \\
\hline $\begin{array}{l}16.5 \text { Kritische Bewertung von Arz- } \\
\text { neimitteln und adäquate Arznei- } \\
\text { therapie }\end{array}$ & $\begin{array}{l}\text { 16.5.1.77 Prinzipien der konkrementlösenden The- } \\
\text { rapie, Gallenstein, Gallensäure-haltige Zubereitun- } \\
\text { gen (ATC-Code A05AA) }\end{array}$ & BK2 & IIIA.1 \\
\hline \multicolumn{4}{|l|}{17 Notfallmaßnahmen } \\
\hline $\begin{array}{l}17.6 \text { Relevante Leitsymptome und } \\
\text { wichtige Differenzial-diagnosen }\end{array}$ & 17.6.1.10 Kolikschmerzen & $\mathrm{BK} 1, \mathrm{PJ} 2$ & II.1 \\
\hline \multicolumn{4}{|l|}{20 Anlässe für ärztliche Konsultation } \\
\hline 20.15 Bauchschmerzen & Cholelithiasis, Pankreatitis & & $\begin{array}{l}\text { II.1 } \\
11.2 \\
I I .11\end{array}$ \\
\hline 20.34 Gelbsucht & Choledocholithiasis & & 11.7 \\
\hline 20.110 Übelkeit und Erbrechen & Cholezystitis, Pankreatitis & & II.1 \\
\hline
\end{tabular}


- Tab. 3 (Fortsetzung)

Lernziel/Teilkompetenz des NKLM
Anwendungsbeispiele/Querverweise im NKLM
Kompetenzebene des NKLM ${ }^{1}$
Relevante Empfehlung der S3-Leitlinie

21 Erkrankungsbezogene Prävention, Diagnostik, Therapie, Versorgungs- und Notfallmanagement

21.1.7 Verdauungssystem: Wissen bzw. Handlungskompetenz zu ...
21.1.7.2 Cholezystitis: Diagnostik und Therapie

IIIA.3

21.1.7.3 Choledocho- und Cholezystolithiasis:

Diagnostik und Therapie

21.1.7.6 Akute Pankreatitis: Diagnostik, Therapie

und Notfallmaßnahmen
II. 4
IIIA. 3
IIIA. 4
IIIB. 8
II. 7
II. 8
IIIB. 1
IIIC. 1
IIIC. 2
IIIC. 3
IIIC. 4
II. 11
IIIC. 8
IIIC. 9

1 GL: Grundlagenkompetenz, BK: ärztliche Basiskompetenz, PJ: PJ-Kompetenz, WK: Weiterbildungskompetenz;

Kompetenzebene 1: Faktenwissen, Kompetenzebene 2: Handlungs- und Begründungswissen; Kompetenzebene 3: Handlungskompetenz

(a: unter Anleitung durchführen und demonstrieren; b: selbstständig und situationsadäquat in Kenntnis der Konsequenzen durchführen)

CAES Chirurgische Arbeitsgemeinschaft für Endoskopie und Sonografie der DGAV

CBD Common bile duct

$\mathrm{Cl}$ Konfidenzintervall

CINAHL Cumulative Index to Nursing and Allied Health Literature

CRP C-reaktives Protein

CSI Cholesterinsättigungsindex

CT Computertomografie

DCCV Deutsche Morbus Crohn / Colitis ulcerosa -Vereinigung

DEGEA Deutsche Gesellschaft für Endoskopiefachberufe

DELBI Deutsches Leitlinien-Bewertungs-Instrument

DGAV Deutsche Gesellschaft für Allgemein- und Viszeralchirurgie

DGVS Deutsche Gesellschaft für Gastroenterologie, Verdauungs- und Stoffwechselerkrankungen

Embase Excerpta Medica Database

EPT endoskopische Papillotomie

ERC endoskopische retrograde Cholangiographie

EUS endoskopischer Ultraschall

GBP Gallenblasenpolyp

GCP Good Clinical Practice

GIN Guidelines International Network

GIQLI Gastrointestinal Quality of Life Index

GPRG Gesellschaft für Recht und Politik im Gesundheitswesen

HDL High Density Lipoprotein

HR Hazard Ratio

HRQoL Health-Related QoL

IOES intraoperative endoskopische Sphinkterotomie

$\begin{array}{ll}\text { IOC } & \text { intraoperative Cholangiographie } \\ \text { is } & \text { in situ } \\ \text { i.v. } & \text { intravenös } \\ \text { lap. } & \text { laparoskopisch } \\ \text { LC } & \text { laparoskopische Cholezystektomie } \\ \text { LCBDE } & \text { laparoskopische Gallengangrevision } \\ \text { LILACS } & \text { Latin American and Caribbean Health Sciences } \\ & \text { Literature } \\ \text { MRCP } & \text { Magnetresonanzcholangiografie } \\ \text { MRT } & \text { Magnetresonanztomografie } \\ \text { N } & \text { Anzahl } \\ \text { NKLM } & \text { Nationaler Kompetenz-basierter Lernzielkatalog } \\ & \text { Medizin } \\ \text { NNT } & \text { Number needed to treat } \\ \text { NPV } & \text { negativer prädiktiver Wert } \\ \text { NSAID } & \text { nichtsteroidale Antiphlogistika } \\ \text { OP } & \text { Operation } \\ \text { OR } & \text { Odds Ratio } \\ \text { P } & \text { P-Wert } \\ \text { POES } & \text { postoperative endoskopische Sphinkterotomie } \\ \text { PPV } & \text { positiver prädiktiver Wert } \\ \text { PTCD } & \text { perkutane Choledochusdrainage } \\ \text { QoL } & \text { Lebensqualität } \\ \text { r } & \text { Korrelationskoeffizient } \\ \text { RCT } & \text { randomisierte kontrollierte Studie } \\ \text { RR } & \text { relatives Risiko } \\ \text { SCI } & \text { Science Citation Index } \\ \text { SF } & \text { Short Form } \\ \text { SILC } & \text { Single-incision Laparoscopic Cholecystectomy } \\ \text { SIR } & \text { standardisierte Inzidenzrate } \\ \text { UDCA } & \text { Ursodeoxycholsäure } \\ & \\ & \end{array}$




\section{Begriffsdefinitionen}

Akute Cholangitis Das klinische Bild der akuten steinbedingten obstruktiven Cholangitis ist geprägt durch die Charcot-Trias: Fieber, Ikterus, Oberbauchschmerz. Insbesondere bei alten oder immuninkompetenten Patienten kann die entzündliche Komponente (Fieber, Entzündungsparameter, Schmerz) fehlen oder schwächer ausgeprägt sein [21-24]. In $10-20 \%$ kann es gleichzeitig zu Bewusstseinsstörungen und in bis zu 30 \% zu einer Hypotension kommen [25, 26]. Die Kombination dieser Symptome mit der Charcot-Trias wird auch als Reynolds-Pentade bezeichnet [27].

Akute Cholezystitis Die akute kalkulöse (lithogene) Cholezystitis wird durch biliäre Schmerzen, die länger als $6 \mathrm{~h}$ anhalten, Fieber bzw. Leukozytose und Gallenblasenwandödem (Ultraschall) in Kombination mit lokalem Druckschmerz (klinisches oder sonografisch-palpatorisches Murphy-Zeichen) definiert [28, 29].

Biliäre Pankreatitis Ein biliärer Ursprung einer Pankreatitis kann angenommen werden, wenn Gallensteine in einem bildgebenden Verfahren erkannt werden und ein Transaminasenanstieg beobachtet wird [30-33].

Biliäre Schmerzen Akut einsetzende, gut erinnerliche Schmerzen im Epigastrium oder rechten Oberbauch, die länger als 15 min, aber kürzer als $5 \mathrm{~h}$ anhalten [34-36].

Komplikationen der Cholezystolithiasis Im vorliegenden Leitlinientext werden unter dem Begriff Komplikationen die akute Cholezystitis, die Gallenblasenperforation, die akute Cholangitis und die biliäre Pankreatitis, die die häufigsten klinisch relevanten Komplikationen darstellen, zusammengefasst.

Leitlinie Systematisch unter Berücksichtigung der Strategien und Methoden der evidenzbasierten Medizin entwickelte, wissenschaftlich begründete und praxisorientierte Entscheidungshilfe für Ärzte, andere Gesundheitsberufe und Patienten über die angemessene Vorgehensweise bei speziellen Gesundheitsproblemen [37, 38].

Pankreatitis Die Diagnose einer akuten Pankreatitis ist bei akuten Bauchschmerzen, kombiniert mit eindeutiger Erhöhung der Serumaktivitäten der Pankreasenzyme (zumeist initial mehr als das Dreifache der oberen Normgrenze) zu stellen [39].

Sentinel Event Sehr seltene, schwerwiegende Komplikation, der in einer differenzierten Einzelfallanalyse nachgegangen werden soll. Ziel ist es, diese Komplikation vollständig zu vermeiden.

Sepsis Lebensbedrohliche Organdysfunktion, die durch eine inadäquate Wirtsantwort auf eine Infektion hervorgerufen wird; die Organdysfunktion wird definiert als akute Änderung von mindestens 2 Punkten im SOFA-Score im Rahmen einer Infektion [40].

\section{Anhänge}

Anhang I: Interessenkonflikt-Erklärungen - Tabellarische Zusammenfassung Stand: 08.12.2017

1. *Berater- bzw. Gutachtertätigkeit oder bezahlte Mitarbeit in einem wissenschaftlichen Beirat eines Unternehmens der Gesundheitswirtschaft (z. B. Arzneimittelindustrie, Medizinproduktindustrie), eines kommerziell orientierten Auftragsinstituts oder einer Versicherung

2. *Honorare für Vortrags- und Schulungstätigkeiten oder bezahlte Autoren- oder Co-Autorenschaften im Auftrag eines Unternehmens der Gesundheitswirtschaft, eines kommerziell orientierten Auftragsinstituts oder einer Versicherung

3. * Finanzielle Zuwendungen (Drittmittel) für Forschungsvorhaben oder direkte Finanzierung von Mitarbeitern der Einrichtung von Seiten eines Unternehmens der Gesundheitswirtschaft, eines kommerziell orientierten Auftragsinstituts oder einer Versicherung

4. **Eigentümerinteresse an Arzneimitteln/Medizinprodukten (z. B. Patent, Urheberrecht, Verkaufslizenz)

5. **Besitz von Geschäftsanteilen, Aktien, Fonds mit Beteiligung von Unternehmen der Gesundheitswirtschaft

6. ** Persönliche Beziehungen zu einem Vertretungsberechtigten eines Unternehmens der Gesundheitswirtschaft

7. Mitglied von in Zusammenhang mit der Leitlinienentwicklung relevanten Fachgesellschaften/ Berufsverbänden, Mandatsträger im Rahmen der Leitlinienentwicklung

8. Politische, akademische (z. B. Zugehörigkeit zu bestimmten „Schulen“), wissenschaftliche oder persönliche Interessen, die mögliche Konflikte begründen könnten

9. Gegenwärtiger Arbeitgeber, relevante frühere Arbeitgeber der letzten 3 Jahre

moderate Interessenkonflikte

** schwere Interessenkonflikte 


\begin{tabular}{|c|c|c|c|c|}
\hline & Asperger, Walter & Barreiros, Ana-Paula & Bruns, Christiane & Dietrich, Christoph G. \\
\hline 1 & nein & nein & $\begin{array}{l}\text { ja, Sirtex (Beratertätigkeit, } \\
\text { Vorträge), Celgene (Vorträge), } \\
\text { Excellence in Oncology (Steering } \\
\text { Board), Novartis (Vorträge, } \\
\text { Beratung) }\end{array}$ & $\begin{array}{l}\text { ja: Beratungshonorare von der Firma } \\
\text { Dres. Schlegel und Schmidt und von } \\
\text { der Clinical Research Organization Dr. } \\
\text { Kottmann }\end{array}$ \\
\hline 2 & nein & ja: Honorar für Vortrag durch Falk & Nein & $\begin{array}{l}\text { ja: Vortragshonorare von der Firma } \\
\text { Norgine und der Falk Foundation }\end{array}$ \\
\hline 3 & nein & nein & $\begin{array}{l}\text { ja, Celgene (Forschungsvorha- } \\
\text { ben), Sirtex (Forschungsvorha- } \\
\text { ben) }\end{array}$ & nein \\
\hline 4 & nein & nein & nein & nein \\
\hline 5 & nein & nein & nein & nein \\
\hline 6 & nein & nein & nein & nein \\
\hline 7 & $\begin{array}{l}\text { ja: Deutsche Gesellschaft } \\
\text { für Chirurgie, Deutsche } \\
\text { Gesellschaft für Allgemein- } \\
\text { und Viszeralchirurgie }\end{array}$ & nein & nein & $\begin{array}{l}\text { ja: Mitglied der DGVS, des BVGD, des } \\
\text { ALGK und der EASL. Mitglied des } \\
\text { wissenschaftlichen Beirats der Gastro- } \\
\text { Liga. }\end{array}$ \\
\hline 8 & nein & nein & nein & nein \\
\hline 9 & $\begin{array}{l}\text { Rentner, bis } 10 / 17 \text { Kranken- } \\
\text { haus St. Elisabeth und St. } \\
\text { Barbara in Halle/Saale }\end{array}$ & $\begin{array}{l}\text { aktuell: Klinik und Poliklinik für In- } \\
\text { nere Medizin I Universitätsklinikum } \\
\text { Regensburg Franz-Josef-Strauß- } \\
\text { Allee } 11 \text { Regensburg zuvor: Univer- } \\
\text { sitätsmedizin Mainz der Johannes } \\
\text { Gutenberg-Universität Mainz I. } \\
\text { Medizinische Klinik und Poliklinik } \\
\text { Langenbeckstr } 1 \text { Mainz }\end{array}$ & $\begin{array}{l}\text { Uniklinik Köln, Uniklinik Magde- } \\
\text { burg, Uniklinik München LMU }\end{array}$ & $\begin{array}{l}\text { Bethlehem-Gesundheitszentrum } \\
\text { gGmbH Stolberg/Rhld. }\end{array}$ \\
\hline & Dirks, Klaus & Dorta, Gian & Encke, Jens & Faiss, Siegbert \\
\hline 1 & nein & $\begin{array}{l}\text { ja: Novigenix SA Biopole IV Route de } \\
\text { la Corniche, } 31066 \text { Epalinges Swit- } \\
\text { zerlandhttp://www.novigenix.com: } \\
\text { Entwicklung eines Screeningtests } \\
\text { auf Blutbasis für kolorektale Neopla- } \\
\text { sien }\end{array}$ & nein & nein \\
\hline 2 & $\begin{array}{l}\text { ja: Vortragstätigkeit bei } \\
\text { Veranstaltungen durch } \\
\text { Ultraschall-Gerätehersteller } \\
\text { (GE) Ultraschallkurse }\end{array}$ & nein & nein & $\begin{array}{l}\text { ja: Vortragshonorare diverser Firmen } \\
\text { (Olympus, Falk, Abbvie, ...) }\end{array}$ \\
\hline 3 & nein & nein & nein & nein \\
\hline 4 & nein & nein & nein & nein \\
\hline 5 & nein & nein & nein & nein \\
\hline 6 & nein & nein & nein & nein \\
\hline 7 & $\begin{array}{l}\text { ja: DEGUM DGIM DGVS } \\
\text { DGE-BV }\end{array}$ & nein & nein & $\begin{array}{l}\text { ja: Vorstands und Beiratsmitglied } \\
\text { DGVS und DGEBV. }\end{array}$ \\
\hline 8 & nein & nein & nein & nein \\
\hline 9 & $\begin{array}{l}\text { Klinikum Stuttgart Rems- } \\
\text { Murr-Kliniken, Winnenden } \\
\text { (seit 2013) }\end{array}$ & $\begin{array}{l}\text { CHUV (Universitätsspital Lausanne } \\
\text { CH-1011 Lausanne Schweiz }\end{array}$ & $\begin{array}{l}\text { Johanna Etienne Krankenhaus } \\
\text { Neuss }\end{array}$ & Asklepios Klinik Barmbek \\
\hline
\end{tabular}




\begin{tabular}{|c|c|c|c|c|}
\hline & Feussner, Hubertus & Frieling, Thomas & Glanemann, Matthias & Gutt, Carsten \\
\hline 1 & nein & $\begin{array}{l}\text { ja: Advisory Board: Almirall, Shire, } \\
\text { Steigerwald, Schwabe, Astra }\end{array}$ & nein & nein \\
\hline 2 & $\begin{array}{l}\text { ja: Vorträge für die Firma } \\
\text { MSD zum Thema Relaxation }\end{array}$ & $\begin{array}{l}\text { ja: Voträge: Almirall, Shire, Falk, } \\
\text { Steigerwald, Schwabe, Recordati }\end{array}$ & nein & nein \\
\hline 3 & nein & nein & nein & nein \\
\hline 4 & nein & nein & nein & nein \\
\hline 5 & nein & ja: Aktien: Bayer, Fresenius & nein & nein \\
\hline 6 & nein & nein & nein & nein \\
\hline 7 & ja: CTAC, CURAC & $\begin{array}{l}\text { ja: BVGD, DGVS, ALGK, Gastro-Liga, } \\
\text { RWGIM, BDI, DGIM, Gesellschaft für } \\
\text { Gastroenterologie in NRW, AGA }\end{array}$ & $\begin{array}{l}\text { ja: DGAV-S3 Leitlinie Pankreas- } \\
\text { karzinom }\end{array}$ & nein \\
\hline 8 & nein & nein & nein & nein \\
\hline \multirow[t]{2}{*}{9} & $\begin{array}{l}\text { Klinikum rechts der Isar der } \\
\text { Technischen Universität } \\
\text { München }\end{array}$ & HELIOS Klinikum Krefeld & $\begin{array}{l}\text { Universitätsklinikum des } \\
\text { Saarlandes }\end{array}$ & Klinikum Memmingen \\
\hline & Götze, Thorsten & Hampe, Jochen & Helmberger, Hermann & Hüttl, Thomas P. \\
\hline 1 & nein & $\begin{array}{l}\text { ja, Berater oder Advisory Boards bei } \\
\text { Pfizer, Takeda, BBraun }\end{array}$ & nein & nein \\
\hline 2 & nein & $\begin{array}{l}\text { ja, Vortragshonorare und Reisekos- } \\
\text { ten von Falk Foundation, Abbvie, } \\
\text { MSD, Pfizer, Takeda, GWT TU } \\
\text { Dresden, BBraun }\end{array}$ & nein & $\begin{array}{l}\text { ja: Referent/Kursleiter an der Aescu- } \\
\text { lap-Akademie Tuttlingen für zertifi- } \\
\text { zierte Operations-Kurse Gelegentlich } \\
\text { Vorträge mit Reisekostenübernahme } \\
\text { durch Dritte z. B. im Rahmen von } \\
\text { Qualitätszirkeln }\end{array}$ \\
\hline 3 & nein & $\begin{array}{l}\text { ja, gemeinsame Drittmittel mit } \\
\text { Bayer AG }\end{array}$ & nein & nein \\
\hline 4 & nein & nein & nein & nein \\
\hline 5 & nein & nein & nein & nein \\
\hline 6 & nein & nein & nein & nein \\
\hline 7 & $\begin{array}{l}\text { ja: Mitglied der DGCH DGAV } \\
\text { Mandatsträger der DGAV }\end{array}$ & nein & $\begin{array}{l}\text { ja: Mitglied der Deutschen } \\
\text { Röntgengesellschaft (DRG) Vor- } \\
\text { standsmitglied im Berufsverband } \\
\text { der Deutschen Radiologen (BDR) }\end{array}$ & $\begin{array}{l}\text { ja: Mitverfasser der } 2010 \text { verabschie- } \\
\text { deten S3-LL zur Adipositaschirurgie } \\
\text { Mitglied in Gesellschaft für Chirurgie, } \\
\text { DGAVC, Adipositaschirurgie, etc. }\end{array}$ \\
\hline 8 & nein & nein & nein & nein \\
\hline \multirow[t]{2}{*}{9} & $\begin{array}{l}\text { Krankenhaus Nordwest } \\
\text { gGmbH UCT - Universitäres } \\
\text { Centrum für Tumorerkran- } \\
\text { kungen Frankfurt Steinba- } \\
\text { cher Hohl 2 - } 2660488 \\
\text { Frankfurt } \\
\text { Fon: } 00496976014187 \\
\text { Fax: } 00496976013655 \\
\text { Mail: Goetze.Thorsten } \\
\text { Oliver@khnw.de }\end{array}$ & Universitätsklinikum Dresden, AöR & $\begin{array}{l}\text { Klinikum Dritter Orden Menzin- } \\
\text { ger Str. } 4480638 \text { München }\end{array}$ & Fachkliniken München AG \\
\hline & Jakobs, Ralf & Jenssen, Christian & Kallinowski, Birgit & Kubale, Reinhard \\
\hline 1 & $\begin{array}{l}\text { ja: Boston Scientific: } \\
\text { Beratertätigkeit Celegene: } \\
\text { Expertenkommission }\end{array}$ & nein & nein & nein \\
\hline 2 & $\begin{array}{l}\text { ja: Boston Scientific: Unter- } \\
\text { stützung bei Stentworkshop }\end{array}$ & $\begin{array}{l}\text { ja: Vortragshonorare für Fortbil- } \\
\text { dungs-Vorträge zu sonografischen, } \\
\text { endoskopischen und endosonogra- } \\
\text { fischen Themen von Hitachi Medical } \\
\text { Systems, Bracco, Covidien, Novartis, } \\
\text { Falk Foundation und Mediglobe, } \\
\text { jährlich < } 2000 \text { Euro }\end{array}$ & nein & $\begin{array}{l}\text { ja: Entwicklung Ultraschalltechnik } \\
\text { (Siemens, Samsung/Frauenhofer } \\
\text { Institut) }\end{array}$ \\
\hline
\end{tabular}




\begin{tabular}{|c|c|c|c|c|}
\hline 3 & nein & nein & nein & nein \\
\hline 4 & nein & nein & nein & nein \\
\hline 5 & nein & nein & nein & nein \\
\hline 6 & nein & nein & nein & nein \\
\hline 7 & ja: DGVS, DGE-BV, DGIM & $\begin{array}{l}\text { ja: Mandatsträger DGE-BV Leitlinie } \\
\text { Qualität Endoskopie, Mandatsträger } \\
\text { DEGUM in LL Gallensteine und Ma- } \\
\text { genkarzinom, Mandatsträger DEGUM } \\
\text { in Leitlinien der EFSUMB zum inter- } \\
\text { ventionellen Ultraschall, kontrastver- } \\
\text { stärkten Ultraschall und Elastografie. } \\
\text { MemberExecutive Board EFSUMB, } \\
\text { Member publications committee } \\
\text { WFUMB, Mitglied Beirat DGE-BV }\end{array}$ & nein & ja: DEGUM, DRG, AIUM \\
\hline 8 & nein & nein & nein & nein \\
\hline \multirow[t]{2}{*}{9} & $\begin{array}{l}\text { Klinikum der Stadt Ludwigs- } \\
\text { hafen }\end{array}$ & $\begin{array}{l}\text { Krankenhaus Märkisch-Oderland } \\
\text { GmbH Prötzeler Chaussee } 5 \\
15344 \text { Strausberg }\end{array}$ & $\begin{array}{l}\text { Ich bin seit } 2004 \text { in eigener Praxis } \\
\text { (Gastroenterologische Schwer- } \\
\text { punktpraxis mit Onkolog. } \\
\text { Tagesklinik) in Schwetzingen } \\
\text { niedergelassen }\end{array}$ & $\begin{array}{l}\text { 1) Selbstständige Praxis (Radiologie } \\
50 \% \text { ) 2) Universitätsklinikum } \\
\text { Homburg/Saar } 50 \%\end{array}$ \\
\hline & Kunstmann, Erdmute & Lammert, Frank & Lynen-Jansen, Petra & Maier, Matthias \\
\hline 1 & nein & nein & nein & nein \\
\hline 2 & nein & $\begin{array}{l}\text { ja: Falk Foundation e. V. } \\
\text { (Vortragstätigkeiten) }\end{array}$ & nein & ja: Vortragshonorar Falk Foundation \\
\hline 3 & nein & nein & nein & nein \\
\hline 4 & nein & nein & nein & nein \\
\hline 5 & nein & nein & nein & nein \\
\hline 6 & nein & nein & nein & nein \\
\hline 7 & ja: DGVS, GfH, DGIM & $\begin{array}{l}\text { ja: Deutsche Gesellschaft für Gas- } \\
\text { troenterologie, Verdauungs- und } \\
\text { Stoffwechselkrankheiten (DGVS), } \\
\text { Präsident; Deutsche Gesellschaft für } \\
\text { Innere Medizin (DGIM), Ausschuss }\end{array}$ & ja: DGVS & $\begin{array}{l}\text { ja: Mitglied: DGVS, DGE-BV, DGIM, } \\
\text { BDI, ENDOakademie }\end{array}$ \\
\hline 8 & nein & nein & nein & nein \\
\hline \multirow[t]{2}{*}{9} & in eigener Praxis tätig & Universität des Saarlandes & DGVS & Knappschaftsklinikum Saar GmbH \\
\hline & Miehlke, Stephan & Neubrand, Michael & Pauletzki, Juergen & Rickes, Steffen \\
\hline 1 & nein & nein & nein & nein \\
\hline 2 & $\begin{array}{l}\text { ja: Falk, Shire, Aptalis, } \\
\text { Olympus }\end{array}$ & nein & $\begin{array}{l}\text { ja: } 2015 \text { keine } 2016 \text { Vortrag } \\
\text { „Ethische Aspekte der Qualitäts- } \\
\text { offensive“ auf dem Bundeskon- } \\
\text { gress des VLK (Verband der Lei- } \\
\text { tenden Krankenhausärzte), Berlin } \\
2016 \text { Vortrag „Das neue Quali- } \\
\text { tätssicherungsverfahren: Noso- } \\
\text { komiale Infektionen - Postopera- } \\
\text { tive Wundinfektionen“ auf dem } \\
\text { Freiburger Infektiologie- und } \\
\text { Hygienekongress des Beratungs- } \\
\text { zentrums für Hygiene, Freiburg } \\
2017 \text { keine }\end{array}$ & $\begin{array}{l}\text { ja: Bracco Kontrastmittelsonografie } \\
\text { bei Lebertumoren }\end{array}$ \\
\hline 3 & nein & nein & nein & nein \\
\hline 4 & nein & nein & nein & nein \\
\hline
\end{tabular}




\begin{tabular}{|c|c|c|c|c|}
\hline 5 & nein & nein & nein & nein \\
\hline 6 & nein & nein & nein & nein \\
\hline 7 & ja: DGVS, BNG & nein & $\begin{array}{l}\text { ja: Mitglied GQMG - Gesellschaft } \\
\text { für Qualitätsmanagement im Ge- } \\
\text { sundheitswesen, Mitglied DDG - } \\
\text { Deutsche Diabetes Gesellschaft }\end{array}$ & ja: DGVS, DEGUM \\
\hline 8 & nein & nein & nein & nein \\
\hline \multirow[t]{2}{*}{9} & selbstständig & $\begin{array}{l}\text { In den letzten } 3 \text { Jahren keine be- } \\
\text { zahlten Vorträge oder Anstellung } \\
\text { bei relevanten Arbeitgebern. Seit } 16 \\
\text { Jahren Chefarzt eines konfessionel- } \\
\text { len Krankenhauses. }\end{array}$ & $\begin{array}{l}\text { IQTIG - Institut für Qualitätssi- } \\
\text { cherung und Transparenz im } \\
\text { Gesundheitswesen, Berlin } \\
\text { (unabhängiges Institut nach } \\
\text { §137a SGB V), ab 5/2015 AQUA- } \\
\text { Institut, Göttingen (unabhängige } \\
\text { Institution nach §137a SGB V), } \\
2011 \text {-4/2015 }\end{array}$ & $\begin{array}{l}\text { AMEOS Klinikum Halberstadt GmbH } \\
\text { bis } 31.12 .13 \\
\text { Helios Bördeklinik GmbH seit 1.1.14 }\end{array}$ \\
\hline & Sackmann, Michael & Sauer, Peter & Sauerbruch, Tilman & Schepke, Michael \\
\hline 1 & nein & nein & nein & nein \\
\hline 2 & $\begin{array}{l}\text { ja: Honorare für Vorträge, } \\
\text { Arzt- und Patientenbroschü- } \\
\text { ren: Falk Foundation. Hono- } \\
\text { rar für Vortragstätigkeit: } \\
\text { Abbvie }\end{array}$ & nein & nein & nein \\
\hline 3 & nein & nein & nein & nein \\
\hline 4 & nein & nein & nein & nein \\
\hline 5 & nein & nein & nein & nein \\
\hline 6 & nein & nein & nein & nein \\
\hline 7 & $\begin{array}{l}\text { ja: DGVS, Ges. für Gastroen- } \\
\text { terologie in Bayern, AGA, } \\
\text { European Board of Gastro- } \\
\text { enterology, Dt ges. für En- } \\
\text { doskopie und Bildgebende } \\
\text { Verfahren }\end{array}$ & ja: DGVS, DGEBV & ja: Mitglied der DGVS & $\begin{array}{l}\text { ja: Mitglied DGVS, kein Interessen- } \\
\text { konflikt }\end{array}$ \\
\hline 8 & nein & nein & nein & nein \\
\hline \multirow[t]{2}{*}{9} & Sozialstiftung Bamberg & Klinikum der Universität Heidelberg & Emeritus & Helios Klinikum Siegburg \\
\hline & Schreiber, Florian & Schreyer, Andreas & Schuld, Jochen & Stier, Albrecht \\
\hline 1 & nein & nein & nein & nein \\
\hline 2 & $\begin{array}{l}\text { ja: Honorar für Schulung/ } \\
\text { Vortragstätigkeit von Olym- } \\
\text { pus Europe, Honorar für Vor- } \\
\text { trags-/ Schulungstätigkeit } \\
\text { von Cook Medical Europe }\end{array}$ & $\begin{array}{l}\text { ja: Vortrags- und Schulungstätigkeit } \\
\text { für: Bayer Healthcare (Primovist) Ta- } \\
\text { keda }\end{array}$ & nein & nein \\
\hline 3 & $\begin{array}{l}\text { ja: Drittmittelaquisition aus } \\
\text { dem Forschungsförde- } \\
\text { rungsfonds des Landes Stei- } \\
\text { ermark - Projekt EBIDAV- } \\
\text { ROS }\end{array}$ & nein & nein & nein \\
\hline 4 & nein & nein & nein & nein \\
\hline 5 & nein & nein & nein & nein \\
\hline 6 & nein & nein & nein & nein \\
\hline 7 & ja: ÖGGH, ESGE & nein & nein & $\begin{array}{l}\text { ja: DGAV DGCH Verband der Itd. } \\
\text { Krankenhauschirurgen Berufsverband } \\
\text { deutscher Chirurgen }\end{array}$ \\
\hline 8 & nein & nein & nein & nein \\
\hline 9 & $\begin{array}{l}\text { Medizinische Universität } \\
\text { Graz }\end{array}$ & Universitätsklinikum Regensburg & $\begin{array}{l}\text { Universitätsklinikum des } \\
\text { Saarlandes } 66421 \text { Homburg }\end{array}$ & Helios Klinikum Erfurt \\
\hline
\end{tabular}




\begin{tabular}{|c|c|c|c|}
\hline & Stokes, Caroline & Zdichavsky, Marty & van Thiel, Ingo \\
\hline 1 & nein & nein & nein \\
\hline 2 & nein & nein & nein \\
\hline 3 & $\begin{array}{l}\text { ja: Forschungsstipendium } \\
\text { von Lallemand Inc. für eine } \\
\text { „Investigator-Initiated“-Stu- } \\
\text { die mit Probiotika für Patien- } \\
\text { ten mit HCV-Infektion }\end{array}$ & nein & nein \\
\hline 4 & nein & nein & nein \\
\hline 5 & nein & nein & nein \\
\hline 6 & nein & nein & nein \\
\hline 7 & nein & nein & ja: Deutsche Leberhilfe e. V. \\
\hline 8 & nein & nein & nein \\
\hline 9 & N/A & $\begin{array}{l}\text { Universitätsklinikum Tübingen Abtei- } \\
\text { lung für Allgemeine, Viszerale und } \\
\text { Transplantationschirurgie Hoppe-Sey- } \\
\text { ler-Str. } 372076 \text { Tübingen }\end{array}$ & $\begin{array}{l}\text { Deutsche Leberhilfe e. V. Krieler } \\
\text { Str. } 10050935 \text { Köln } \\
\text { Tel.: } 0221 / 2829980 \\
\text { E-Mail (allgemein): info@leberhilfe. } \\
\text { org } \\
\text { Internet: www.leberhilfe.org }\end{array}$ \\
\hline
\end{tabular}


Anhang II: Suchbegriffe für die Literaturrecherche

\section{AG 1: Prävention}

\section{Cochrane}

\#1 MeSH descriptor: Ultrasonography explode all trees

\#2 ultrasonograph* OR ultrasound* OR ecograph*

\#3 \#1 OR \#2

\#4 MeSH descriptor: Ursodeoxycholic Acid explode all trees

\#5 ursodeoxycholic acid* OR ursodiol OR UDCA

\#6 \#4 OR \#5

\#7 MeSH descriptor: Anti-Inflammatory Agents, Non-Steroidal explode all trees

\#8 (non-steroid* anti-inflammatory AND (drug* OR agent*))

OR ibuprofen OR aspirin

\#9 \#7 OR \#8

\#10 MeSH descriptor: Obesity explode all trees

\#11 obesity

\#12 \#10 OR \#11

\#13 MeSH descriptor: Bariatric Surgery explode all trees

\#14 bariatric surger*

\#15 \#13 OR \#14

\#16 MeSH descriptor: Weight Loss explode all trees

\#17 weight loss*

\#18 \#16 OR \#17

\#19 MeSH descriptor: Diet Therapy explode all trees

\#20 diet therap* OR caloric restriction OR low calorie diet*

OR liquid diet* OR fat* OR protein* OR carbohydrate* OR fibre

\#21 \#19 OR \#20

\#22 MeSH descriptor: Micronutrients explode all trees

\#23 micronutrient*

\#24 \#22 OR \#23

\#25 MeSH descriptor: Exercise explode all trees

\#26 physical activit* OR exercise*

\#27 \#25 OR \#26

\#28 \#3 OR \#6 OR \#9 OR \#12 OR \#15 OR \#18 OR \#21 OR \#24 OR \#27

\#29 MeSH descriptor: Cholelithiasis explode all trees

\#30 cholelithiasis OR gallstone* OR gall* stone* OR 'black pigment stone*

\#31 \#29 OR \#30

\#32 \#28 AND \#31

\section{AG 2: Diagnostik}

\section{Cochrane}

\#1 MeSH descriptor: [Cholelithiasis] explode all trees

\#2 MeSH descriptor: [Choledocholithiasis] explode all trees

\#3 MeSH descriptor: [Cholecystitis] explode all trees

\#4 cholelithiasis or cholecystitis or choledocholithiasis or cholecystolit-

hiasis:ti,ab,kw (Word variations have been searched)

\#5 gallstone* or gall stone*:ti,ab,kw (Word variations have been searched)

\#6 ((gallbladder or gall bladder) near/3 inflam*):ti,ab,kw (Word variations have been searched)

\#7 \#1 or \#2 or \#3 or \#4 or \#5 or \#6

\#8 MeSH descriptor: [Abdominal Pain] explode all trees

\#9 ((right upper quadrant near/3 pain*) or (epigast* near/3 pain*) or

(abdom* near/3 pain*)):ti,ab,kw (Word variations have been searched) \#10 MeSH descriptor: [Dyspepsia] explode all trees

\#11 dyspepsia or indigestion:ti,ab,kw (Word variations have been searched) \#12 MeSH descriptor: [Colic] explode all trees

\#13 MeSH descriptor: [Biliary Tract Diseases] explode all trees \#14 \#12 and \#13

\#15 colic near/3 biliary*:ti,ab,kw (Word variations have been searched) \#16 MeSH descriptor: [Pancreatitis] explode all trees

\#17 (pancreatitis or (pancrea* near/3 inflam*)):ti,ab,kw (Word variations have been searched)

\#18 MeSH descriptor: [Jaundice, Obstructive] explode all trees
\#19 ((obstructive* near/3 jaundice) or (post-hepatic near/3 jaundice) or (post hepatic near/3 jaundice)):ti,ab,kw (Word variations have been searched)

\#20 MeSH descriptor: [Cholangitis] explode all trees

\#21 (cholangitis or (bil* near/3 inflam*)):ti,ab,kw (Word variations have been searched)

\#22 MeSH descriptor: [Heart] explode all trees

\#23 MeSH descriptor: [Pain] explode all trees

\#24 \#22 and \#23

\#25 ((heart or cardiac) near/3 pain*):ti,ab,kw (Word variations have been searched)

\#26 \#8 or \#9 or \#10 or \#11 or \#14 or \#15 or \#16 or \#17 or \#18 or \#19 or \#20 or \#21 or \#24 or \#25

\#27 \#7 and \#26

\#28 sensitiv* or diagnos*:ti,ab,kw (Word variations have been searched) \#29 Any MeSH descriptor with qualifier(s): [Diagnosis - DI]

\#30 incidence:ti,ab,kw (Word variations have been searched)

\#31 MeSH descriptor: [Mortality] explode all trees

\#32 follow-up studies or prognos* or predict* or course*:ti,ab,kw (Word variations have been searched)

\#33 \#28 or \#29 or \#30 or \#31 or \#32

\#34 \#27 and \#33

Medline

1. exp Cholelithiasis/ or Choledocholithiasis/

2. cholelithiasis.tw.

3. $\exp$ Cholecystitis/

4. (gall stone* or gallstone*).tw.

5. (cholecystitis or choledocholithiasis or cholecystolithiasis).tw.

6. ((gallbladder or gall bladder) adj3 inflam*).tw.

7. 1 or 2 or 3 or 4 or 5 or 6

8. exp abdominal pain/

9. ((right upper quadrant adj3 pain*) or (epigast* adj3 pain*)

or (abdom* adj 3 pain*)).tw.

10. exp dyspepsia/

11. (dyspepsia or indigestion).tw.

12. colic/and exp biliary tract diseases/

13. (colic adj3 biliary*).tw.

14. exp pancreatitis/

15. (pancreatitis or (pancrea* adj3 inflam*)).tw.

16. jaundice,obstructive/

17. ((obstructive* adj3 jaundice) or (post-hepatic adj3 jaundice)

or (post hepatic adj3 jaundice)).tw.

18. exp cholangitis/

19. (cholangitis or (bil* adj3 inflam*)).tw.

20. exp heart/ and exp pain/

21. ((heart or cardiac) adj3 pain*).tw.

22. or $/ 8-21$

23. 22 and 7

24. (sensitiv: or diagnos:).mp. or di.fs.

25. incidence.sh. or exp mortality/

26. follow-up studies.sh. or prognos:.tw. or predict:.tw. or course:.tw.

27. or $/ 24-26$

28. 23 and 27

29. animals/ not humans/

30. 28 not 29

\section{Cochrane}

\#1 MeSH descriptor: [Cholelithiasis] explode all trees

\#2 „cholelithiasis“:ti,ab,kw (Word variations have been searched)

\#3 „gall stone“ or „gall stones“ or gallstone*:ti,ab,kw (Word variations have been searched)

\#4 MeSH descriptor: [Cholecystitis] explode all trees

\#5 cholecystitis:ti,ab,kw (Word variations have been searched) 
\#6 ((gallbladder or „gall bladder“) near/3 inflam*):ti,ab,kw (Word variations have been searched)

\#7 \#1 or \#2 or \#3 or \#4 or \#5 or \#6

\#8 murphy* near/3 test*:ti,ab,kw

\#9 MeSH descriptor: [Hematologic Tests] explode all trees

\#10 MeSH descriptor: [Blood Chemical Analysis] explode all trees

\#11 MeSH descriptor: [Serologic Tests] explode all trees

\#12 ((test* or analy*) near/3 blood):ti,ab,kw (Word variations have been searched)

\#13 ((test* or analy*) near/3 (hematolog* or haematolog*)):ti,ab,kw

(Word variations have been searched)

\#14 ((test * or analy*) near/3 serolog*):ti,ab,kw (Word variations have been searched)

\#15 MeSH descriptor: [X-Rays] explode all trees

\#16 x*ray*:ti,ab,kw (Word variations have been searched)

\#17 MeSH descriptor: [Ultrasonography] explode all trees

\#18 ultrasonograph*:ti,ab,kw (Word variations have been searched)

\#19 MeSH descriptor: [Tomography, X-Ray Computed] explode all trees

\#20 computer* near/3 tomograph*:ti,ab,kw (Word variations have been searched)

\#21 CT near/3 scan*:ti,ab,kw (Word variations have been searched)

\#22 ((hepatobiliary or hepato-bilary or HIDA) near/3 scan*):ti,ab,kw

(Word variations have been searched)

\#23 ((DISIDA or diisopropyl*) near/3 scan*):ti,ab,kw (Word variations have been searched)

\#24 (gall* near/3 („radionuclide scan or radionuclide scans“)):ti,ab,kw (Word variations have been searched)

\#25 ((„gall bladder“ or gallbladder or chole*) near/3 scintigraph*):

ti,ab,kw (Word variations have been searched)

\#26 cholescintigraph*:ti,ab,kw (Word variations have been searched)

\#27 MeSH descriptor: [Magnetic Resonance Imaging] explode all trees

\#28 „magnetic resonance imag* “:ti,ab,kw (Word variations have been searched)

\#29 ((imag* or scan*) near/3 MRI):ti,ab,kw (Word variations have been searched)

\#30 ((magnetic near/3 resonance near/3 cholangiopancreatograph*) or MRCP):ti,ab,kw (Word variations have been searched)

\#31 MeSH descriptor: [Cholangiopancreatography, Endoscopic Retrograde] explode all trees

\#32 endoscopic near/3 retrograde near/3 cholangiopancreatograph*:

ti,ab,kw (Word variations have been searched)

\#33 MeSH descriptor: [Diagnosis] this term only

\#34 diagnos*:ti,ab,kw (Word variations have been searched)

\#35 Any MeSH descriptor with qualifier(s): [Diagnosis - DI]

\#36 \#33 or \#34 or \#35

\#37 \#31 or \#32

\#38 \#36 and \#37

\#39 \#8 or \#9 or \#10 or \#11 or \#12 or \#13 or \#14 or \#15 or \#16 or \#17 or $\# 18$ or \#19 or \#20 or \#21 or \#22 or \#23 or \#24 or \#25 or \#26 or \#27 or \#28 or \#29 or \#30 or \#38 \#40 \#7 and \#39

\section{Medline}

1. $\exp$ Cholelithiasis/

2. (cholelithiasis or choledochlithiasis or cholecystolthiasis).tw.

3. (gall stone\$ or gallstone\$).tw.

4. exp Cholecystitis/

5. cholecystitis.tw.

6. ((gall bladder or gallbladder) adj3 inflam\$).tw.

7. 1 or 2 or 3 or 4 or 5 or 6

8. ((sign\$ or test\$) adj3 murphy\$).tw.

9. exp Hematologic Tests/

10. exp Blood Chemical Analysis/
11. exp Serologic Tests/

12. ((test\$ or analy\$) adj3 blood).tw.

13. ((test\$ or analy\$) adj3 hematolog\$).tw.

14. ((test\$ or analy\$) adj3 haematolog\$).tw.

15. ((test\$ or analy\$) adj3 serolog\$).tw.

16. exp X-Rays/

17. $x \$$ ra $\$ . t w$.

18. exp Ultrasonography/

19. ultrasonograph\$.tw.

20. exp Tomography, X-Ray Computed/

21. (computer\$ adj3 tomograph\$).tw.

22. (CT adj3 scan\$).tw.

23. ((hepatobiliary or hepato-bilary or HIDA) adj3 scan\$).tw.

24. ((DISIDA or diisopropyl\$) adj3 scan\$).tw.

25. (gall\$ adj3 radionuclide scan\$).tw.

26. ((gall bladder or gallbladder or chole\$) adj3 scintigraph\$).tw.

27. cholescintigraph\$.tw.

28. exp Magnetic Resonance Imaging/

29. magnetic resonance imag $\$$.tw.

30. ((imag\$ or scan\$) adj3 MRI).tw.

31. ((magnetic adj3 resonance adj3 cholangiopancreatograph\$) or MRCP).tw.

32. exp Cholangiopancreatography, Endoscopic Retrograde/

33. ((endoscopic adj3 retrograde adj3 cholangiopancreatograph\$) or ERCP).tw.

34. di.fs. or Diagnosis/ or diagnos\$.tw.

35. (32 or 33 ) and 34

36. (or/8-31) or 35

37. exp Cross-Sectional Studies/

38. cross-sectional.tw.

39. exp Cohort Studies/

40. ((cohort adj study) or studies).tw.

41. cohort analy\$.tw.

42. ((follow up adj study) or studies).tw.

43. longitudinal.tw.

44. prospective.tw.

45. retrospective.tw.

46. or/37- 45

47. animals/ not humans/

48. 46 not 47

49. Meta-Analysis.pt.

50. Meta-Analysis as Topic/

51. Review.pt.

52. exp Review Literature as Topic/

53. (metaanaly\$ or metanaly\$ or (meta adj2 analy\$)).tw.

54. (review\$ or overview\$).ti.

55. (systematic\$adj4 (review\$ or overview\$)).tw.

56. ((quantitative\$ or qualitative\$) adj4 (review\$ or overview\$)).tw.

57. ((studies or trial\$) adj1 (review\$ or overview\$)).tw.

58. (integrat\$ adj2 (research or review\$ or literature)).tw.

59. (pool\$adj1 (analy\$ or data)).tw.

60. (handsearch\$ or (hand adj2 search\$)).tw.

61. (manual\$ adj2 search\$).tw.

62. or/49-61

63. animals/ not humans/

64. 62 not 63

65. Randomized Controlled Trial.pt.

66. Controlled Clinical Trial.pt.

67. Clinical Trial.pt.

68. exp Clinical Trials as Topic/

69. Placebos/

70. Random Allocation/ 


\author{
71. Double-Blind Method/ \\ 72. Single-Blind Method/ \\ 73. Cross-Over Studies/ \\ 74. ((random\$ or control\$ or clinical\$) adj2 (trial\$ or stud\$)).tw. \\ 75. (random\$ adj2 allocat\$).tw. \\ 76. placebo\$.tw. \\ 77. ((singl\$ or doubl\$ or trebl\$ or tripl\$) adj (blind\$ or mask\$)).tw. \\ 78. (crossover\$ or (cross adj over\$)).tw. \\ 79. or $/ 65-78$ \\ 80. animals/ not humans/ \\ 81.79 not 80 \\ 82.48 or 64 or 81 \\ 83.7 and 36 and 82
}

\section{AG 3: Therapie der Cholezystolithiasis}

\section{Cochrane}

\#1 MeSH descriptor: [Cholelithiasis] explode all trees

\#2 cholelithiasis or choledocholithiasis or cholecystolithiasis:ti,ab,kw

(Word variations have been searched)

\#3 gall stone* or gallstone*:ti,ab,kw (Word variations have been searched)

\#4 MeSH descriptor: [Cholecystitis] explode all trees

\#5 cholecystitis:ti,ab,kw (Word variations have been searched)

\#6 ((gallbladder or gall bladder) near/4 inflam*):ti,ab,kw (Word variations have been searched)

\#7 \#1 or \#2 or \#3 or \#4 or \#5 or \#6

\#8 MeSH descriptor: [Asymptomatic Diseases] explode all trees

\#9 (asymptomatic or incidental or silent or ((without or absen ${ }^{*}$ ) near/4

symptom*)):ti,ab,kw (Word variations have been searched)

\#10 \#80r\#9

$\# 11$ \#7 and \#10

\#12 MeSH descriptor: [Mortality] explode all trees

\#13 incidence or follow-up studies or prognos* or predict* or course*:

$\mathrm{ti}, \mathrm{ab}, \mathrm{kw}$ (Word variations have been searched)

\#14 \#12 or \#13

\#15 \#14 and \#7

\#16 \#15 or \#11

Medline

1. exp Cholelithiasis/ or Choledocholithiasis/ or Cholecystolithiasis/

2. (cholelithiasis or choledocholithiasis or cholecystolithiasis).tw.

3. (gall stone* or gallstone*).tw.

4. exp Cholecystitis/

5. cholecystitis.tw.

6. ((gallbladder or gall bladder) adj4 inflam*).tw.

7. 1 or 2 or 3 or 4 or 5 or 6

8. exp Asymptomatic Diseases/

9. (asymptomatic or incidental or silent or ((without or absen*) adj4 symptom*)).tw.

10.8 or 9

11.7 and 10

12. incidence.sh. or exp mortality/

13. follow-up studies.sh.

14. prognos:.tw.

15. predict:.tw.

16. course:.tw.

17. 12 or 13 or 14 or 15 or 16

18. 7 and 17

19. 11 or 18

20. animals/not humans/

21. 19 not 20

22. Epidemiologic Studies/

23. exp Case-Control Studies/

24. exp Cohort Studies/

25. Cross-Sectional Studies/

26. Comparative Study.pt.

27. case control\$.tw.

28. case series.tw.
29. (cohort adj (study or studies)).tw.

30. cohort analy\$.tw.

31. (follow up adj (study or studies)).tw

32. (observational adj (study or studies)).tw. 33. longitudinal.tw.

34. prospective.tw.

35. retrospective.tw.

36. cross sectional.tw.

37. or $/ 22-36$

38. animals/not humans/

39. 37 not 38

40. Meta-Analysis.pt.

41. Meta-Analysis as Topic/

42. Review.pt.

43. exp Review Literature as Topic/

44. (metaanaly\$ or metanaly\$ or (meta adj2 analy\$)).tw.

45. (review\$ or overview\$).ti.

46. (systematic\$ adj4 (review\$ or overview\$)).tw.

47. ((quantitative $\$$ or qualitative $\$$ ) adj4 (review\$ or overview\$)).tw.

48. ((studies or trial\$) adj1 (review\$ or overview\$)).tw.

49. (integrat\$ adj2 (research or review\$ or literature)).tw.

50. (pool\$ adj1 (analy\$ or data)).tw.

51. (handsearch\$ or (hand adj2 search\$)).tw.

52. (manual\$ adj2 search\$).tw.

53. or $/ 40-52$

54. animals/ not humans/

55.53 not 54

56. Randomized Controlled Trial.pt.

57. Controlled Clinical Trial.pt.

58. Clinical Trial.pt.

59. exp Clinical Trials as Topic/

60. Placebos/

61. Random Allocation/

62. Double-Blind Method/

63. Single-Blind Method/

64. Cross-Over Studies/

65. ((random\$ or control\$ or clinical\$) adj2 (trial\$ or stud\$)).tw.

66. (random\$ adj2 allocat\$).tw.

67. placebo\$.tw.

68. ((singl\$ or doubl\$ or trebl\$ or tripl\$) adj (blind\$ or mask\$)).tw.

69. (crossover\$ or (cross adj over\$)).tw.

70. or/56-69

71. animals/not humans/

72.70 not 71

73. 39 or 55 or 72

74. 21 and 73

\section{AG 4: Therapie der Choledocholithiasis}

\section{Cochrane}

\#1 MeSH descriptor: [Cholelithiasis] explode all trees

\#2 MeSH descriptor: [Choledocholithiasis] explode all trees

\#3 MeSH descriptor: [Cholecystitis] explode all trees

\#4 MeSH descriptor: [Cholecystolithiasis] explode all trees

\#5 \#1 or\#2or\#3or\#4

\#6 gall stone* or gallstone*:ti,ab,kw (Word variations have been searched) \#7 ((gallbladder or gall bladder) near/4 inflam*) .:ti,ab,kw (Word variations have been searched)

\#8 cholelithiasis or choledocholithiasis or cholecystitis or cholecystolithiasis:ti,ab,kw (Word variations have been searched)

\#9 \#50r\#6or\#7or\#8

\#10 MeSH descriptor: [Gallbladder] explode all trees and with qualifiers: [Surgery - SU]

\#11 MeSH descriptor: [Bile Ducts] explode all trees and with qualifiers: [Surgery - SU]

\#12 MeSH descriptor: [Biliary Tract Surgical Procedures] explode all trees \#13 MeSH descriptor: [Bile Ducts] explode all trees

\#14 MeSH descriptor: [Common Bile Duct] explode all trees 
\#15 MeSH descriptor: [Biliary Tract] explode all trees \#16 MeSH descriptor: [Pancreatic Ducts] explode all trees $\# 17$ \#13 or \#14 or \#15 or \#16

\#18 MeSH descriptor: [Laparoscopy] explode all trees \#19 MeSH descriptor: [Endoscopy] explode all trees \#20 MeSH descriptor: [Stents] explode all trees \#21 MeSH descriptor: [Drainage] explode all trees

\#22 MeSH descriptor: [Biliary Tract] explode all trees and with qualifiers: [Ultrasonography - US]

\#23 \#18 or \#19 or \#20 or \#21 or \#22

\#24 \#17 and \#23

\#25 ((bile duct* or biliary tract or pancreatic duct*) near/4 (laparoscop* or endoscop* ${ }^{*}$ or stent ${ }^{*}$ or drain* or ultraso* or celioscop $\left.{ }^{*}\right)$ ):ti,ab,kw (Word variations have been searched)

\#26 MeSH descriptor: [Cholecystectomy] explode all trees

\#27 cholecystectom* or choledochoscop*:ti,ab,kw (Word variations have been searched)

\#28 MeSH descriptor: [Cholangiography] explode all trees

\#29 MeSH descriptor: [Cholecystography] explode all trees

\#30 cholangiogra* or cholecystograph*:ti,ab,kw (Word variations have been searched)

\#31 (bile duct * near/4 explor*):ti,ab,kw (Word variations have been searched)

\#32 ((endoscopic near/1 retrograde near/1 cholangiopancreatograph*) or ercp):ti,ab,kw (Word variations have been searched)

\#33 (balloon sphincteroplast* or transduodenal sphinteroplast* or ts): $\mathrm{ti}, \mathrm{ab}, \mathrm{kw}$ (Word variations have been searched)

\#34 MeSH descriptor: [Lithotripsy] explode all trees

\#35 lithotripsy:ti,ab,kw (Word variations have been searched)

\#36 MeSH descriptor: [Cholecystostomy] explode all trees

\#37 cholecystostom*:ti,ab,kw (Word variations have been searched)

\#38 (percutaneous near/4 biliary intervention*):ti,ab,kw (Word variations have been searched)

\#39 pthc or ptc.:ti,ab,kw (Word variations have been searched) \#40 MeSH descriptor: [Sphincterotomy, Endoscopic] explode all trees \#41 (endoscop* near/4 (sphincterotom* or papilllotom*)):ti,ab,kw (Word variations have been searched)

\#42 MeSH descriptor: [Sphincterotomy, Transhepatic] explode all trees \#43 ((transhepatic or transduodenal) near/4 (sphinctertom* or sphincteroplast* $)$ ).:ti,ab,kw (Word variations have been searched) \#44 transampullary septectom*.:ti,ab,kw (Word variations have been searched)

\#45 MeSH descriptor: [Ursodeoxycholic Acid] explode all trees

\#46 ((ursodeoxychol* near/1 acid) or ursodiol or ((dissolve* near/4 therap) or treat $\left.{ }^{*}\right)$ ).:ti,ab,kw (Word variations have been searched)

\#47 MeSH descriptor: [Anti-Bacterial Agents] explode all trees

\#48 antibiotic*:ti,ab,kw (Word variations have been searched)

\#49 MeSH descriptor: [Analgesics] explode all trees

\#50 analgesic ${ }^{*}$ :ti,ab,kw (Word variations have been searched)

\#51 (watch* near/2 wait*):ti,ab,kw (Word variations have been searched)

\#52 MeSH descriptor: [Watchful Waiting] explode all trees

$\# 53 \# 10$ or \#11 or \#12 or \#24 or \#25 or \#26 or \#27 or \#28 or \#29 or \#30 or \#31 or \#32 or \#33 or \#34 or \#35 or \#36 or \#37 or \#38 or \#39 or \#40 or $\# 41$ or \#42 or \#43 or \#44 or \#45 or \#46 or \#47 or \#48 or \#49 or \#50 or \#51 or \#52

\#54 \#9 and \#53

\section{Medline}

1. exp Cholelithiasis/ or Choledocholithiasis/ or exp Cholecystitis/ or Cholecystolithiasis|

2. exp Cholecystitis/

3. (gall stone* or gallstone*).tw.

4. ((gallbladder or gall bladder) adj4 inflam*).tw.

5. (cholelithiasis or choledocholithiasis or cholecystitis or cholecystolithiasis).tw.

6. 1 or 2 or 3 or 4 or 5

7. exp Gallbladder/su or exp Bile Ducts/su
8. exp Biliary Tract Surgical Procedures/

9. Bile Ducts/ or Common Bile Duct/ or Biliary Tract/ or exp Pancreatic Ducts/

10. exp Laparoscopy/ or Endoscopy/ or exp Stents/or exp Drainage/ or exp Biliary Tract/us

11.9 and 10

12. ((bile duct* or biliary tract or pancreatic duct*) adj4 (laparoscop* or endoscop* ${ }^{*}$ or stent* or drain* or ultraso* or celioscop*)).tw.

13. exp Cholecystectomy/

14. cholecystectom*.tw.

15. choledochoscop*.tw.

16. exp Cholangiography/ or Cholecystography/

17. (cholangiogra* or cholecystograph*).tw.

18. (bile duct * adj4 explor*).tw.

19. ((endoscopic adj1 retrograde adj1 cholangiopancreatograph*) or ercp).tw.

20. (balloon sphincteroplast* ${ }^{*}$ or transduodenal sphinteroplast* or ts).tw. 21. exp Lithotripsy/

22. lithotripsy.tw.

23. Cholecystostomy/

24. cholecystostom*.tw.

25. (percutaneous adj4 biliary intervention*).tw.

26. (pthc or ptc).tw.

27. Sphincterotomy ,Endoscopic/

28. (endoscop* adj4 (sphincterotom* or papilllotom*)).tw.

29. Sphincterotomy, Transhepatic/

30. ((transhepatic or transduodenal) adj4 (sphinctertom* or sphincteroplast*)).tw.

31. transampullary septectom*.tw.

32. exp Ursodeoxycholic Acid/

33. ((ursodeoxychol* adj1 acid) or ursodiol or ((dissolve* adj4 therap) or treat $\left.\left.{ }^{*}\right)\right)$.tw.

34. exp Anti-Bacterial Agents/

35. antibiotic*.tw.

36. $\exp$ Analgesics/

37. analgesic*.tw.

38. Watchful Waiting/

39. (watch* adj2 wait*).tw.

40.7 or 8 or 11 or 12 or 13 or 14 or 15 or 16 or 17 or 18 or 19 or 20 or 21 or 22 or 23 or 24 or 25 or 26 or 27 or 28 or 29 or 30 or 31 or 32 or 33 or

34 or 35 or 36 or 37 or 38 or 39

41.6 and 40

42. Randomized Controlled Trial.pt.

43. Controlled Clinical Trial.pt.

44. Clinical Trial.pt.

45. exp Clinical Trials as Topic/

46. Placebos/

47. Random Allocation/

48. Double-Blind Method/

49. Single-Blind Method/

50. Cross-Over Studies/

51. ((random\$ or control\$ or clinical\$) adj2 (trial\$ or stud\$)).tw.

52. (random\$ adj2 allocat\$).tw.

53. placebo $\$ . t w$.

54. ((singl\$ or doubl\$ or trebl\$ or tripl\$) adj (blind\$ or mask\$)).tw.

55. (crossover\$ or (cross adj over\$)).tw.

56. or $/ 42-55$

57. animals/not humans/

58.56 not 57

59. Epidemiologic Studies/

60. exp Case-Control Studies/

61. exp Cohort Studies/

62. Cross-Sectional Studies/

63. Comparative Study.pt.

64. case control\$.tw.

65. case series.tw. 
66. (cohort adj (study or studies)).tw.

67. cohort analy\$.tw.

68. (follow up adj (study or studies)).tw.

69. (observational adj (study or studies)).tw.

70. longitudinal.tw.

71. prospective.tw.

72. retrospective.tw.

73. cross sectional.tw.

74. or $/ 59-73$

75. animals/not humans/

76. 74 not 75

77. Meta-Analysis.pt.

78. Meta-Analysis as Topic/

79. Review.pt.

80. exp Review Literature as Topic/

81. (metaanaly\$ or metanaly\$ or (meta adj2 analy\$)).tw.

82. (review\$ or overview\$).ti.

83. (systematic\$adj4 (review\$ or overview\$)).tw.

84. ((quantitative\$ or qualitative\$) adj4 (review\$ or overview\$)).tw.

85. ((studies or trial\$) adj1 (review\$ or overview\$)).tw.

86. (integrat\$ adj2 (research or review\$ or literature)).tw.

87. (pool\$ adj1 (analy\$ or data)).tw.

88. (handsearch\$ or (hand adj2 search\$)).tw.

89. (manual\$ adj2 search\$).tw.

90. or/77-89

91. animals/ not humans/

92. 90 not 91
Trefferzahlen der Literaturrecherche

\begin{tabular}{|l|l|l|}
\hline AG/Themenkomplex & $\begin{array}{l}\text { identifizierte } \\
\text { Referenzen }\end{array}$ & $\begin{array}{l}\text { bewertete } \\
\text { Referenzen }\end{array}$ \\
\hline AG 1: Prävention & 85 & 37 \\
\hline AG 2: Diagnostik & 107 & 19 \\
\hline $\begin{array}{l}\text { AG 3: Therapie der } \\
\text { Cholezystolithiasis }\end{array}$ & 79 & 68 \\
\hline $\begin{array}{l}\text { AG4: Therapie der } \\
\text { Choledocholithiasis }\end{array}$ & 101 & 26 \\
\hline
\end{tabular}




\section{Anhang III: Evidenztabellen}

\section{Empfehlung I.1}

\begin{tabular}{|c|c|c|c|c|c|c|c|}
\hline Referenz & Studientyp & Intervention & Teilnehmer & $\begin{array}{l}\text { Index- und } \\
\text { Referenztest }\end{array}$ & Zielgröße und Ergebnis & Bemerkungen & Evidenzgrad \\
\hline \multicolumn{8}{|c|}{ Kohlenhydrate } \\
\hline $\begin{array}{l}\text { Misciagna } \\
1999[41]\end{array}$ & $\begin{array}{l}\text { prospektive } \\
\text { Kohortenstudie }\end{array}$ & & $\begin{array}{l}\mathrm{N}=100 \mathrm{~Pa}- \\
\text { tienten mit } \\
\text { Gallensteinen } \\
\text { (durch Sono- } \\
\text { grafie diag- } \\
\text { nostiziert), } \\
\mathrm{N}=290 \text { Kon- } \\
\text { trollen (Alter } \\
30-69 \text { Jahre) }\end{array}$ & $\begin{array}{l}\text { OR für energie- } \\
\text { adjustierte Nähr- } \\
\text { stoff-Quartile im } \\
\text { Vergleich zur nied- } \\
\text { rigsten Quartile } \\
\text { mit Kontrolle für } \\
\text { Störeinflüsse } \\
\text { (Alter, Geschlecht, } \\
\text { BMI, Gesamtener- } \\
\text { gie- und Nähr- } \\
\text { stoffaufnahme) } \\
\text { multivariate Ana- } \\
\text { lyse zur Kontrolle } \\
\text { von Alter und } \\
\text { Geschlecht }\end{array}$ & $\begin{array}{l}\text { inverse Korrelation zwi- } \\
\text { schen einfach ungesät- } \\
\text { tigtem Fett und Gallen- } \\
\text { steinrisiko } \\
\text { Assoziation zwischen } \\
\text { raffiniertem Zucker und } \\
\text { Steinrisiko } \\
\text { BMI, raffinierter Zucker } \\
\text { und gesättiges Fett asso- } \\
\text { ziiert mit erhöhtem } \\
\text { Steinrisiko, körperliche } \\
\text { Aktivität und gesättigtes } \\
\text { Fett mit verringertem } \\
\text { Steinrisiko } \\
\text { geschlechtsspezifisches } \\
\text { Risiko für gesättigtes Fett } \\
\text { (allgemein bei Frauen hö- } \\
\text { her, in der höchsten } \\
\text { Quartile jedoch bei Män- } \\
\text { nern) }\end{array}$ & & III \\
\hline $\begin{array}{l}\text { Tsai } 2004 \\
\text { [42] }\end{array}$ & $\begin{array}{l}\text { prospektive } \\
\text { Kohortenstudie }\end{array}$ & & $\begin{array}{l}\mathrm{N}=69778 \\
\text { Frauen } \\
\text { (35-61 Jahre) }\end{array}$ & $\begin{array}{l}\text { RR für höchste } \\
\text { Quintile des } \\
\text { Verzehrs von Bal- } \\
\text { laststoffen im Ver- } \\
\text { gleich zur niedrigs- } \\
\text { ten Quintile mit } \\
\text { multivariater Ana- } \\
\text { lyse für Störeinflüs- } \\
\text { se (Alter, BMI, Ge- } \\
\text { wichts-änderungen } \\
\text { in den letzten } 2 \\
\text { Jahren, Hormon- } \\
\text { therapie, körperli- } \\
\text { che Aktivität, Thia- } \\
\text { ziddiuretika, } \\
\text { NSAID, Rauchen, } \\
\text { Alkohol, Koffein, } \\
\text { Eiweiß, Transfette, } \\
\text { gesättigte Fettsäu- } \\
\text { ren, Gesamtener- } \\
\text { gieaufnahme) }\end{array}$ & $\begin{array}{l}\mathrm{N}=5771 \text { Cholezystekto- } \\
\text { mien während } 16 \text { Jahre } \\
\text { Follow-up mit } 932675 \\
\text { Personen-Jahren } \\
\text { RR: } 0,87(95 \% \mathrm{Cl} 0,78 \text { - } \\
0,96), \mathrm{P}=0,005 \\
\text { bei } 5 \mathrm{~g} \text { Steigerung der } \\
\text { täglichen Ballaststoff- } \\
\text { menge Reduktion des RR } \\
\text { für Cholezystektomie auf } \\
0,94(95 \% \mathrm{Cl} 0,90-0,98)\end{array}$ & $\begin{array}{l}\text { Risiko für Bias, } \\
\text { keine Sonogra- } \\
\text { fie zur Baseline } \\
\text { durchgeführt }\end{array}$ & III \\
\hline $\begin{array}{l}\text { Tsai } 2005 \\
{[43]}\end{array}$ & $\begin{array}{l}\text { prospektive } \\
\text { Kohortenstudie }\end{array}$ & & $\begin{array}{l}\mathrm{N}=44525 \\
\text { Männer } \\
\text { (40-75 Jahre) }\end{array}$ & $\begin{array}{l}\text { RR für höchste } \\
\text { Quintile des Ver- } \\
\text { zehrs von Kohlen- } \\
\text { hydraten, glykämi- } \\
\text { sche Last und } \\
\text { glykämischen } \\
\text { Index im Vergleich } \\
\text { zur niedrigsten } \\
\text { Quintile mit multi- } \\
\text { variater Analyse } \\
\text { für Störeinflüsse } \\
\text { (Alter, BMI, Ge- } \\
\text { wichtsänderungen } \\
\text { in den letzten } 2\end{array}$ & $\begin{array}{l}\mathrm{N}=1810 \text { Fälle symptoma- } \\
\text { tischer Gallensteine (da- } \\
\text { von } 1025 \text { Cholezystekto- } \\
\text { mien) während } 457699 \\
\text { Personen-Jahren Follow-up } \\
\text { RR: } 1,59 \text { ( } 95 \% \mathrm{Cl} 1,25 \text { - } \\
2,02), \mathrm{P}=0,002 \\
\text { RR: } 1,50 \text { ( } 95 \% \mathrm{Cl} 1,20 \text { - } \\
1,88), \mathrm{P}=0,001 \\
\text { RR: } 1,18(95 \% \mathrm{Cl} 1,01 \text { - } \\
1,39), \mathrm{P}=0,04\end{array}$ & $\begin{array}{l}\text { Risiko für Bias, } \\
\text { keine Sonogra- } \\
\text { fie zur Baseline } \\
\text { durchgeführt } \\
\text { keine Analyse } \\
\text { der Steinzu- } \\
\text { sammenset- } \\
\text { zung } \\
\text { (Annahme: } \\
80 \% \text { Choleste- } \\
\text { rinsteine) }\end{array}$ & III \\
\hline
\end{tabular}




\begin{tabular}{|c|c|c|c|c|c|c|c|}
\hline Referenz & Studientyp & Intervention & Teilnehmer & $\begin{array}{l}\text { Index- und } \\
\text { Referenztest }\end{array}$ & Zielgröße und Ergebnis & Bemerkungen & Evidenzgrad \\
\hline & & & & $\begin{array}{l}\text { Jahren, körperliche } \\
\text { Aktivität, Thiazid- } \\
\text { diuretika, NSAID, } \\
\text { Rauchen, Alkohol, } \\
\text { Koffein, Ballast- } \\
\text { stoffe, Eiweiß, } \\
\text { Transfette, gesät- } \\
\text { tigte Fettsäuren, } \\
\text { Gesamtenergie- } \\
\text { aufnahme) }\end{array}$ & & & \\
\hline $\begin{array}{l}\text { Tsai } 2005 \\
{[44]}\end{array}$ & $\begin{array}{l}\text { prospektive } \\
\text { Kohortenstudie }\end{array}$ & & $\begin{array}{l}\mathrm{N}=70408 \\
\text { Frauen } \\
(35-61 \text { Jahre })\end{array}$ & $\begin{array}{l}\text { RR für höchste } \\
\text { Quintile des Ver- } \\
\text { zehrs von Kohlen- } \\
\text { hydraten, glykämi- } \\
\text { sche Last und } \\
\text { glykämischen } \\
\text { Index im Vergleich } \\
\text { zur niedrigsten } \\
\text { Quintile mit multi- } \\
\text { variater Analyse } \\
\text { für Störeinflüsse } \\
\text { (Alter, BMl, Ge- } \\
\text { wichtsänderungen } \\
\text { in den letzten 2 } \\
\text { Jahren, Hormon- } \\
\text { therapie, körperli- } \\
\text { che Aktivität, } \\
\text { Thiazid- diuretika, } \\
\text { NSAID, Rauchen, } \\
\text { Alkohol, Koffein, } \\
\text { Ballaststoffe, } \\
\text { Eiweiß, Transfette, } \\
\text { gesättigte Fett- } \\
\text { säuren, Gesamt- } \\
\text { energieaufnahme) }\end{array}$ & $\begin{array}{l}\mathrm{N}=5771 \text { Cholezystekto- } \\
\text { mien während } 16 \text { Jahre } \\
\text { Follow-up mit } 932676 \\
\text { Personen-Jahren } \\
\text { RR: } 1,35(95 \% \mathrm{Cl} 1,17 \text { - } \\
1,55), \mathrm{P}<0,0001 \\
\text { RR: } 1,50(95 \% \mathrm{Cl} 1,32 \text { - } \\
1,71), \mathrm{P}<0,0001 \\
\text { RR: } 1,32(95 \% \mathrm{Cl} 1,20 \text { - } \\
1,45), \mathrm{P}<0,0001\end{array}$ & $\begin{array}{l}\text { Risiko für Bias, } \\
\text { keine Sonogra- } \\
\text { fie zur Baseline } \\
\text { durchgeführt }\end{array}$ & III \\
\hline $\begin{array}{l}\text { Tsai } 2006 \\
\text { [45] }\end{array}$ & $\begin{array}{l}\text { prospektive } \\
\text { Kohortenstudie }\end{array}$ & & $\begin{array}{l}\mathrm{N}=77090 \\
\text { Frauen } \\
\text { ( } 37-64 \text { Jahre) } \\
\text { ohne Gallen- } \\
\text { steine }\end{array}$ & $\begin{array}{l}\text { Relatives Risiko } \\
\text { (RR) für Frauen in } \\
\text { der höchsten } \\
\text { Quintile des Ver- } \\
\text { zehrs von Obst } \\
\text { und Gemüse im } \\
\text { Vergleich zur nied- } \\
\text { rigsten Quintile }\end{array}$ & $\begin{array}{l}\mathrm{N}=6608 \text { Cholezystekto- } \\
\text { mien während } 1060033 \\
\text { Personen-Jahren Follow- } \\
\text { up } \\
\text { RR: } 0,79 \text { ( } 95 \% \text { Cl } 0,73 \text { - } \\
0,87 \text { ), P<0,001 }\end{array}$ & $\begin{array}{l}\text { Risiko für Bias, } \\
\text { keine Sonogra- } \\
\text { fie zur Baseline } \\
\text { durchgeführt }\end{array}$ & III \\
\hline $\begin{array}{l}\text { Norden- } \\
\text { vall } 2016 \\
{[46]}\end{array}$ & $\begin{array}{l}\text { prospektive } \\
\text { Kohortenstudie }\end{array}$ & & $\begin{array}{l}\mathrm{N}=74554 \\
\text { (Frauen } \\
40-75 \text { Jahre, } \\
\text { Männer } \\
45-79 \text { Jahre) }\end{array}$ & $\begin{array}{l}\text { HR für höchste } \\
\text { Quartile des Ver- } \\
\text { zehrs von Obst } \\
\text { und Gemüse im } \\
\text { Vergleich zur nied- } \\
\text { rigsten Quartile } \\
\text { (geschlechtsspezi- } \\
\text { fisch) mit multiva- } \\
\text { riater Analyse für } \\
\text { Störeinflüsse } \\
\text { (Alter, Geschlecht, } \\
\text { Bildungsniveau, } \\
\text { Rauchen, Alkohol- } \\
\text { konsum, körperli- } \\
\text { che Aktivität, ASS, } \\
\text { Kaffee, Gesamt- } \\
\text { energieaufnahme) }\end{array}$ & $\begin{array}{l}\mathrm{N}=2120 \text { Cholezystekto- } \\
\text { mien während } 939715 \\
\text { Personen-Jahren Follow-up } \\
\text { HR: } 0,95 \text { ( } 95 \% \text { Cl 0,83 - } \\
1,08) \\
\text { höherer Verzehr von Obst } \\
\text { und Gemüse korrelierte } \\
\text { mit einer verminderten } \\
\text { HR für Cholezystektomie } \\
\text { bei Frauen bis zu einem } \\
\text { Alter von } 60 \text { Jahren }\end{array}$ & $\begin{array}{l}\text { Risiko für Bias, } \\
\text { keine Sonogra- } \\
\text { fie zur Baseline } \\
\text { durchgeführt }\end{array}$ & III \\
\hline
\end{tabular}




\begin{tabular}{|c|c|c|c|c|c|c|c|}
\hline Referenz & Studientyp & Intervention & Teilnehmer & $\begin{array}{l}\text { Index- und } \\
\text { Referenztest }\end{array}$ & Zielgröße und Ergebnis & Bemerkungen & Evidenzgrad \\
\hline \multicolumn{8}{|c|}{ Vegetarische Ernährung } \\
\hline $\begin{array}{l}\text { Pixley } \\
1985 \text { [47] }\end{array}$ & $\begin{array}{l}\text { prospektive } \\
\text { Kohortenstudie }\end{array}$ & & $\begin{array}{l}\mathrm{N}=632 \\
\text { Nicht-Vege- } \\
\text { tarierinnen } \\
\text { und } 130 \text { Ve- } \\
\text { getarierinnen } \\
\text { (40-69 Jahre) }\end{array}$ & $\begin{array}{l}\text { OR für Vegetarier } \\
\text { vs. Nicht-Vegetarier }\end{array}$ & $\begin{array}{l}\text { asymptomatische Gallen- } \\
\text { steine bzw. Cholezystek- } \\
\text { tomie bei } N=156 \text { bzw. } 43 \\
\text { Nicht-Vegetarierinnen } \\
\text { und } N=13 \text { bzw. } 2 \text { Vege- } \\
\text { tarierinnen } \\
\text { OR für Gallensteinen bei } \\
\text { Nicht-Vegetarierinnen im } \\
\text { Vergleich zu Vegetarierin- } \\
\text { nen } 2,5 \text { ( } 9 \text { nach Anpas- } \\
\text { sung für Alter und BMI) }\end{array}$ & & III \\
\hline $\begin{array}{l}\text { Pixley } \\
1988 \text { [48] }\end{array}$ & $\begin{array}{l}\text { prospektive } \\
\text { Kohortenstudie }\end{array}$ & & $\begin{array}{l}\mathrm{N}=652 \\
\text { Nicht-Vege- } \\
\text { tarierinnen } \\
\text { und } 130 \text { Ve- } \\
\text { getarier } \\
\text { (40 - } 70 \text { Jahre) }\end{array}$ & $\begin{array}{l}109 \text { Nicht-Vegeta- } \\
\text { rier und } 12 \text { Vege- } \\
\text { tarier mit Gallen- } \\
\text { steinen wurden } \\
\text { mit gesunden Kon- } \\
\text { trollen gematcht }\end{array}$ & $\begin{array}{l}\text { Patienten mit Gallenstei- } \\
\text { nen waren adipöser im } \\
\text { Vergleich zu Kontrollen ( } P \\
<0,001 \text { ) }\end{array}$ & & \\
\hline $\begin{array}{l}\text { Walcher } \\
2010 \text { [49] }\end{array}$ & $\begin{array}{l}\text { prospektive } \\
\text { Kohortenstudie }\end{array}$ & & $\begin{array}{l}N=2130 \\
(18-65 \text { Jahre })\end{array}$ & $\begin{array}{l}N=67 \text { Vegetarier } \\
\text { vs. } N=2063 \text { Nicht- } \\
\text { Vegetarier }\end{array}$ & $\begin{array}{l}\mathrm{N}=87 \text { Gallensteine; } \mathrm{N}=2 \\
\text { Sludge; } \mathrm{N}=84 \text { Cholezyst- } \\
\text { ektomie } \\
\text { Gallensteine: } \mathrm{N}=4(6,0 \%) \\
\text { vs. } \mathrm{N}=166(8,1 \%)\end{array}$ & $\begin{array}{l}\text { kleine Anzahl } \\
\text { von Vegetariern }\end{array}$ & III \\
\hline $\begin{array}{l}\text { Lander } \\
2016[50]\end{array}$ & $\begin{array}{l}\text { Kohorte von } 3 \\
\text { klinischen Stu- } \\
\text { dien und einer } \\
\text { Beobachtungs- } \\
\text { studie }\end{array}$ & & $\begin{array}{l}\mathrm{N}=130859 \\
\text { postmenopa- } \\
\text { usale Frauen } \\
\text { ( } 50-79 \text { jahre) }\end{array}$ & $\begin{array}{l}\text { HR für höchste } \\
\text { Quintile des Ver- } \\
\text { zehrs von tieri- } \\
\text { schem und pflanz- } \\
\text { lichem Protein im } \\
\text { Vergleich zu ande- } \\
\text { ren Quintilen mit } \\
\text { multivariater Ana- } \\
\text { lyse für Störeinflüs- } \\
\text { se (Alter, Gesamt- } \\
\text { energieaufnahme, } \\
\text { BMI, körperliche } \\
\text { Aktivität, Ethnizi- } \\
\text { tät, Hormonthera- } \\
\text { pie, Thiaziddiure- } \\
\text { tika, Statine, } \\
\text { Leberkrankheiten, } \\
\text { Alkohol) }\end{array}$ & $\begin{array}{l}\mathrm{N}=10615 \text { selbst berichte- } \\
\text { te Gallenblasenerkrankun- } \\
\text { gen nach } 7,5 \pm 1,9 \text { Jahren } \\
\text { Follow-up } \\
\text { HR für pflanzliches Pro- } \\
\text { tein: } 0,87 \text { ( } 95 \% \mathrm{Cl} 0,81 \text { - } \\
0,93 \text { ) } \\
\text { Aufnahme von tierischem } \\
\text { Protein nicht mit einem } \\
\text { Risiko für Gallenblasener- } \\
\text { krankungen assoziiert }\end{array}$ & $\begin{array}{l}\text { alle Gallenbla- } \\
\text { senerkrankun- } \\
\text { gen, nicht nur } \\
\text { steinbedingte }\end{array}$ & III \\
\hline $\begin{array}{l}\text { Barre } \\
2017 \text { [51] }\end{array}$ & $\begin{array}{l}\text { prospektive } \\
\text { Kohortenstudie }\end{array}$ & & $\begin{array}{l}\mathrm{N}=64052 \\
\text { Frauen }\end{array}$ & $\begin{array}{l}\text { Vergleich der höch- } \\
\text { sten und niedrigs- } \\
\text { ten Kategorien von } \\
\text { Lebensmittelgrup- } \\
\text { pen } \\
\text { HR mit Adjustie- } \\
\text { rung für Störein- } \\
\text { flüsse (Alter, sozio- } \\
\text { ökonomischer } \\
\text { Status, BMI, } \\
\text { Lebendgeburten, } \\
\text { hormonelle Ersatz- } \\
\text { therapie, körper- } \\
\text { liche Aktivität, } \\
\text { Rauchen, Gesamt- } \\
\text { energieaufnahme, } \\
\text { Alkohol, Diabetes, } \\
\text { Cholesterinsenker) }\end{array}$ & 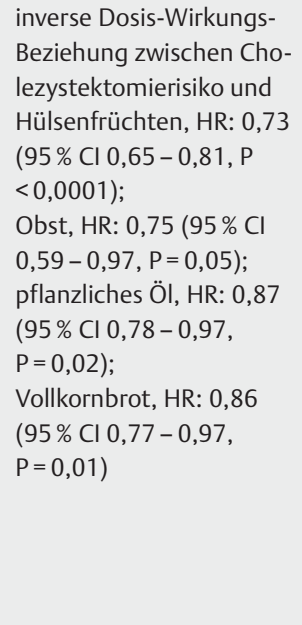 & & III \\
\hline
\end{tabular}




\begin{tabular}{|c|c|c|c|c|c|c|c|}
\hline Referenz & Studientyp & Intervention & Teilnehmer & $\begin{array}{l}\text { Index- und } \\
\text { Referenztest }\end{array}$ & Zielgröße und Ergebnis & Bemerkungen & Evidenzgrad \\
\hline $\begin{array}{l}\text { McCon- } \\
\text { nell } 2017 \\
{[52]}\end{array}$ & $\begin{array}{l}\text { prospektive } \\
\text { Kohortenstudie }\end{array}$ & & $\begin{array}{l}N=49652 \\
(20-90 \text { Jahre) }\end{array}$ & $\begin{array}{l}\mathrm{N}=16176 \text { Vegeta- } \\
\text { rier vs. N= } 33476 \\
\text { Nicht-Vegetarier } \\
\text { HR mit Adjustie- } \\
\text { rung für Störein- } \\
\text { flüsse (Rauchen, } \\
\text { Alkohol, sozioöko- } \\
\text { nomischer Status, } \\
\text { hormonelle Ersatz- } \\
\text { therapie, langfris- } \\
\text { tige medizinische } \\
\text { Behandlung, } \\
\text { Geschlecht, Wohn- } \\
\text { ort, Rekrutierungs- } \\
\text { methode, BMI) }\end{array}$ & $\begin{array}{l}\text { symptomatische Gallen- } \\
\text { steine: } 317(2,0 \%) \text { vs. } 865 \\
(2,6 \%) \\
\text { BMI-adjustierte HR für } \\
\text { Gallensteine bei Vegeta- } \\
\text { riern } 1,22(95 \% \text { Cl 1,06- } \\
1,41, P=0,006)\end{array}$ & & III \\
\hline \multicolumn{8}{|l|}{ Fette } \\
\hline $\begin{array}{l}\text { Tsai } 2004 \\
\text { [53] }\end{array}$ & $\begin{array}{l}\text { prospektive } \\
\text { Kohortenstudie }\end{array}$ & & $\begin{array}{l}\mathrm{N}=80718 \\
\text { Frauen } \\
(30-55 \text { Jahre) }\end{array}$ & $\begin{array}{l}\text { RR für Cholezyst- } \\
\text { ektomie bei hoh- } \\
\text { em Verzehr von } \\
\text { Nüssen } \\
\text { ( } 29 \mathrm{~g} \text { pro Tag) vs. } \\
\text { seltenem Konsum }\end{array}$ & $\begin{array}{l}\mathrm{N}=7831 \text { Cholezystekto- } \\
\text { mien während } 1393256 \\
\text { Personen-Jahren Follow- } \\
\text { up } \\
\text { Risikoreduktion durch } \\
\text { Nüsse: RR } 0,75(95 \% \mathrm{Cl} \\
0,66-0,85, \mathrm{P}<0,0001)\end{array}$ & $\begin{array}{l}\text { Risiko für Bias, } \\
\text { keine Sonogra- } \\
\text { fie zur Baseline } \\
\text { durchgeführt }\end{array}$ & III \\
\hline $\begin{array}{l}\text { Tsai } 2004 \\
\text { [54] }\end{array}$ & $\begin{array}{l}\text { prospektive } \\
\text { Kohortenstudie }\end{array}$ & & $\begin{array}{l}N=45756 \\
\text { Männer } \\
\text { (40 - } 75 \text { Jahre) }\end{array}$ & $\begin{array}{l}\text { RR auch mit multi- } \\
\text { variater Analyse } \\
\text { für Störeinflüsse } \\
\text { für höchstes Quin- } \\
\text { til im Vergleich zu } \\
\text { denen im unters- } \\
\text { ten Quintil für: } \\
\text { 1) Verzehr von } \\
\text { mehrfach ungesät- } \\
\text { tigten Fettsäuren } \\
\text { 2) Verzehr von } \\
\text { einfach ungesät- } \\
\text { tigten Fettsäuren } \\
\text { 3) Verzehr von } \\
\text { cis-ungesättigten } \\
\text { Fettsäuren }\end{array}$ & $\begin{array}{l}\mathrm{N}=2323 \text { Fälle mit Gallen- } \\
\text { steine } \mathrm{n} \text { (davon } 1.279 \\
\text { Cholezystektomien) wäh- } \\
\text { rend } 561938 \text { Personen- } \\
\text { Jahren Follow-up } \\
\text { 1) RR } 0,84(95 \% \mathrm{Cl} 0,74 \text { - } \\
0,96, \mathrm{P}=0,02) \\
\text { 2) RR } 0,83(95 \% \mathrm{Cl} 0,70 \text { - } \\
\text { 1,00, } \mathrm{P}=0,01) \\
\text { 3) RR } 0,82(95 \% \mathrm{Cl} 0,69 \text { - } \\
\text { 0,96, } \mathrm{P}=0,01)\end{array}$ & $\begin{array}{l}\text { Risiko für Bias, } \\
\text { keine Sonogra- } \\
\text { fie zur Baseline } \\
\text { durchgeführt }\end{array}$ & III \\
\hline $\begin{array}{l}\text { Tsai } 2005 \\
\text { [55] }\end{array}$ & $\begin{array}{l}\text { prospektive } \\
\text { Kohortenstudie }\end{array}$ & & $\begin{array}{l}\mathrm{N}=45912 \\
\text { Männer (40- } \\
75 \text { Jahre) }\end{array}$ & $\begin{array}{l}\text { RR für höchste } \\
\text { Quintile des Ver- } \\
\text { zehrs von Transfet- } \\
\text { ten im Vergleich } \\
\text { zur niedrigsten } \\
\text { Quintile sowie mit } \\
\text { multivariater Ana- } \\
\text { lyse für Störeinflüs- } \\
\text { se (Alter, Gesamt- } \\
\text { energieaufnahme, } \\
\text { BMI, Gewichts-än- } \\
\text { derungen in den } \\
\text { letzten } 2 \text { Jahren, } \\
\text { Rauchen, Diabetes, } \\
\text { Koffein- und/oder } \\
\text { Alkohol, körperli- } \\
\text { che Aktivität, Thia- } \\
\text { zid- diuretika, } \\
\text { NSAID, Ballaststof- } \\
\text { fe, Eiweiß, gesät- } \\
\text { tigte und ungesät- } \\
\text { tigte Fettsäuren) }\end{array}$ & $\begin{array}{l}\mathrm{N}=2356 \text { Fälle symptoma- } \\
\text { tischer Gallensteine (da- } \\
\text { von } 1294 \text { Cholezystekto- } \\
\text { mien) während } 546112 \\
\text { Personen-Jahren Follow- } \\
\text { up } \\
\text { RR: } 1,29 \text { ( } 95 \% \text { Cl } 1,13 \text { - } \\
1,47), P<0,001 \\
\text { RR: } 1,23(95 \% \text { Cl } 1,04 \text { - } \\
1,44), P=0,03\end{array}$ & $\begin{array}{l}\text { Risiko für Bias, } \\
\text { keine Sonogra- } \\
\text { fie zur Baseline } \\
\text { durchgeführt }\end{array}$ & IIII \\
\hline
\end{tabular}




\begin{tabular}{|c|c|c|c|c|c|c|c|}
\hline Referenz & Studientyp & Intervention & Teilnehmer & $\begin{array}{l}\text { Index- und } \\
\text { Referenztest }\end{array}$ & Zielgröße und Ergebnis & Bemerkungen & Evidenzgrad \\
\hline $\begin{array}{l}\text { Tsai } 2008 \\
\text { [56] }\end{array}$ & $\begin{array}{l}\text { prospektive } \\
\text { Kohortenstudie }\end{array}$ & & $\begin{array}{l}\mathrm{N}=44524 \\
\text { Männer } \\
\text { (40-75 Jahre) }\end{array}$ & $\begin{array}{l}\text { RR für höchste } \\
\text { Quintile des Ver- } \\
\text { zehrs von langket- } \\
\text { tigen gesättigten } \\
\text { Fetten im Vergleich } \\
\text { zur niedrigsten } \\
\text { Quintile sowie mit } \\
\text { multivariater Ana- } \\
\text { lyse für Störein- } \\
\text { flüsse (Alter, Ge- } \\
\text { samtenergieauf- } \\
\text { nahme, BMI, } \\
\text { Gewichtsänderun- } \\
\text { gen in den letzten } \\
2 \text { Jahren, Rauchen, } \\
\text { Koffein- und/oder } \\
\text { Alkohol, körperli- } \\
\text { che Aktivität, } \\
\text { Thiaziddiuretika, } \\
\text { NSAID, Ballaststof- } \\
\text { fe, Eiweiß, Trans- } \\
\text { fette und ungesät- } \\
\text { tigte Fettsäuren) }\end{array}$ & $\begin{array}{l}\mathrm{N}=2350 \text { Fälle symptoma- } \\
\text { tischer Gallensteine (da- } \\
\text { von } 1.387 \text { Cholezystekto- } \\
\text { mien) während } 584679 \\
\text { Personen-Jahren Follow-up } \\
\text { RR: } 1,34 \text { ( } 95 \% \text { CI } 1,17 \text { - } \\
\text { 1,52), } \mathrm{P}<0,0001 \\
\text { RR: } 1,24 \text { ( } 95 \% \text { Cl } 1,02 \text { - } \\
\text { 1,50), } P=0,03\end{array}$ & $\begin{array}{l}\text { Risiko für Bias, } \\
\text { keine Sonogra- } \\
\text { fie zur Baseline } \\
\text { durchgeführt }\end{array}$ & III \\
\hline \multicolumn{8}{|l|}{ Vitamin C } \\
\hline $\begin{array}{l}\text { Simon } \\
1998 \text { [57] }\end{array}$ & $\begin{array}{l}\text { Querschnitts- } \\
\text { studie }\end{array}$ & & $\begin{array}{l}\mathrm{N}=9110 \\
(20-74 \text { Jahre })\end{array}$ & $\begin{array}{l}\text { Relation zwischen } \\
\text { Serum-Ascorbin- } \\
\text { säure und Gallen- } \\
\text { blasenerkrankung } \\
\text { (Gallensteine bzw. } \\
\text { Cholezystektomie) } \\
\text { mit Adjustierung } \\
\text { für Störeinflüsse } \\
\text { (Alter, Ethnizität, } \\
\text { Bildungsniveau, } \\
\text { körperliche Aktivi- } \\
\text { tät, BMI, Gesamt- } \\
\text { energie- und Fett- } \\
\text { aufnahme, Diabe- } \\
\text { tes, Diuretika, } \\
\text { Lipidsenker, Rau- } \\
\text { chen, Alkohol, } \\
\text { Gesamtcholesterin } \\
\text { und HDL-Choleste- } \\
\text { rin, Vitamin E-Sup- } \\
\text { plementation; zu- } \\
\text { sätzlich für Frauen: } \\
\text { hormonelle Ersatz- } \\
\text { therapie, Schwan- } \\
\text { gerschaften, } \\
\text { Lebendgeburten, } \\
\text { Menopause) }\end{array}$ & $\begin{array}{l}\text { keine Assoziation bei } \\
\text { Männern } \\
\text { Frauen: } \\
\text { OR 2,34 ( } 95 \% \text { Cl 1,00 - } \\
5,51) \\
\text { bzw. } \\
\text { OR 3,51 (95\% Cl 1,17 - } \\
\text { 10,50) } \\
\text { U-förmige Assoziation bei } \\
\text { Frauen }\end{array}$ & $\begin{array}{l}\text { Risiko für Bias, } \\
\text { keine Sonogra- } \\
\text { fie zur Baseline } \\
\text { durchgeführt }\end{array}$ & III \\
\hline $\begin{array}{l}\text { Simon } \\
1998 \text { [58] }\end{array}$ & $\begin{array}{l}\text { prospektive } \\
\text { Kohortenstu- } \\
\text { die }\end{array}$ & & $\begin{array}{l}\mathrm{N}=2763 \\
\text { postmeno- } \\
\text { pausale Frau- } \\
\text { en ( } 44-79 \\
\text { Jahre) }\end{array}$ & $\begin{array}{l}\text { Vitamin C-Supple- } \\
\text { mentation und Ri- } \\
\text { siko von Gallenbla- } \\
\text { senerkrankungen } \\
\text { bzw. Cholezystek- } \\
\text { tomie bei hohem } \\
\text { Alkoholkonsum }\end{array}$ & $\begin{array}{l}\text { OR } 0,50(95 \% \mathrm{Cl} 0,31 \text { - } \\
0,81) \\
\text { OR } 0,38(95 \% \mathrm{Cl} 0,21 \text { - } \\
1,67)\end{array}$ & $\begin{array}{l}\text { Risiko für Bias, } \\
\text { keine Sonogra- } \\
\text { fie zur Baseline } \\
\text { durchgeführt }\end{array}$ & III \\
\hline
\end{tabular}




\begin{tabular}{|c|c|c|c|c|c|c|c|}
\hline Referenz & Studientyp & Intervention & Teilnehmer & $\begin{array}{l}\text { Index- und } \\
\text { Referenztest }\end{array}$ & Zielgröße und Ergebnis & Bemerkungen & Evidenzgrad \\
\hline $\begin{array}{l}\text { Simon } \\
2000 \text { [59] }\end{array}$ & $\begin{array}{l}\text { prospektive } \\
\text { Kohortenstudie }\end{array}$ & & $\begin{array}{l}N=9650 \\
(20-90 \text { Jahre })\end{array}$ & $\begin{array}{l}\text { Relation zwischen } \\
\text { Serum-Ascorbin- } \\
\text { säure und Gallen- } \\
\text { blasenerkranung } \\
\text { mit Adjustierung } \\
\text { für Störeinflüsse } \\
\text { (Alter, Ethnizität, } \\
\text { Bildungsniveau, } \\
\text { körperliche Aktivi- } \\
\text { tät, BMI, Diabetes, } \\
\text { Diuretika, Lipidsen- } \\
\text { ker, Rauchen, Alko- } \\
\text { hol, Gesamtcholes- } \\
\text { terin und } \\
\text { HDL-Cholesterin, } \\
\text { Serum-Vitamin E; } \\
\text { zusätzlich für Frau- } \\
\text { en: hormonelle } \\
\text { Ersatztherapie, } \\
\text { Schwangerschaf- } \\
\text { ten, Lebendgebur- } \\
\text { ten, Menopause) }\end{array}$ & $\begin{array}{l}\text { inverse Assoziation bei } \\
\text { Frauen } \\
\text { jeder Anstieg der Ascor- } \\
\text { binsäure um } 27 \mu \mathrm{mol} / \mathrm{l} \\
\text { war mit einer } 22 \% \text { niedri- } \\
\text { geren Prävalenz von } \\
\text { asymptomatischen } \\
\text { Gallensteinen assoziiert } \\
\text { (13\% nach Adjustierung } \\
\text { für die Störeinflüsse) }\end{array}$ & & III \\
\hline $\begin{array}{l}\text { Walcher } \\
2009[60]\end{array}$ & $\begin{array}{l}\text { prospektive } \\
\text { Kohortenstudie }\end{array}$ & & $\begin{array}{l}N=2129 \\
(18-65 \text { Jahre })\end{array}$ & $\begin{array}{l}\text { Prävalenz von Gal- } \\
\text { lensteinen bei Vi- } \\
\text { tamin C-Supple- } \\
\text { mentation } \\
(\mathrm{N}=232) \text { vs. keine } \\
\text { Supplementation } \\
(\mathrm{N}=1897)\end{array}$ & $11(4,7 \%)$ vs. $156(8,2 \%)$ & & III \\
\hline \multicolumn{8}{|l|}{ Magnesium } \\
\hline $\begin{array}{l}\text { Tsai } 2008 \\
{[61]}\end{array}$ & $\begin{array}{l}\text { prospektive } \\
\text { Kohortenstudie }\end{array}$ & & $\begin{array}{l}\mathrm{N}=42705 \\
\text { Männer } \\
\text { (40-75 Jahre) }\end{array}$ & $\begin{array}{l}\text { RR für höchste } \\
\text { Quintile der Mag- } \\
\text { nesiumaufnahme } \\
\text { im Vergleich zur } \\
\text { niedrigsten Quin- } \\
\text { tile sowie mit mul- } \\
\text { tivariater Analyse } \\
\text { für Störeinflüsse } \\
\text { (Alter, Gesamt- } \\
\text { energieaufnahme, } \\
\text { BMI, Gewichtsän- } \\
\text { derungen in den } \\
\text { letzten } 2 \text { Jahren, } \\
\text { Rauchen, körperli- } \\
\text { che Aktivität, } \\
\text { Thiaziddiuretika, } \\
\text { NSAID, Koffein- } \\
\text { und/oder Alkohol, } \\
\text { Ballaststoffe, Ei- } \\
\text { weiß, Kohlenhy- } \\
\text { drate, gesättigte } \\
\text { und ungesättigte } \\
\text { Fettsäuren) }\end{array}$ & $\begin{array}{l}\mathrm{N}=2.195 \text { Fälle sympto- } \\
\text { matischer Gallensteine } \\
\text { (davon } 1,297 \text { Cholecyst- } \\
\text { ektomien) während } \\
560.810 \text { Personen-Jahren } \\
\text { Follow-up } \\
\text { RR: } 0,67 \text { ( } 95 \% \mathrm{Cl} 0,59 \text { - } \\
0,77), \mathrm{P}<0,0001 \\
\text { RR: } 0,72 \text { ( } 95 \% \mathrm{Cl} 0,61 \text { - } \\
0,86), \mathrm{P}=0,006\end{array}$ & $\begin{array}{l}\text { Risiko für Bias, } \\
\text { keine Sonogra- } \\
\text { fie zur Baseline } \\
\text { durchgeführt }\end{array}$ & III \\
\hline \multicolumn{8}{|l|}{ Kaffee } \\
\hline $\begin{array}{l}\text { Jørgensen } \\
1989 \text { [62] }\end{array}$ & $\begin{array}{l}\text { Querschnitts- } \\
\text { studie }\end{array}$ & & $\begin{array}{l}N=4608 \\
(30-60 \text { Jahre) }\end{array}$ & $\begin{array}{l}\text { Kaffeekonsum und } \\
\text { Risiko von Gallen- } \\
\text { steinen }\end{array}$ & $\begin{array}{l}\text { keine signifikante } \\
\text { Assoziation }\end{array}$ & & \\
\hline $\begin{array}{l}\text { Misciagna } \\
1996 \text { [63] }\end{array}$ & $\begin{array}{l}\text { prospektive } \\
\text { Kohortenstudie }\end{array}$ & & $N=1962$ & $\begin{array}{l}\text { OR für Gallenstei- } \\
\text { ne Risiko mit Kaf- }\end{array}$ & $0,75(95 \%$ Cl 0,47 - 1,19) & & III \\
\hline
\end{tabular}




\begin{tabular}{|c|c|c|c|c|c|c|c|}
\hline Referenz & Studientyp & Intervention & Teilnehmer & $\begin{array}{l}\text { Index- und } \\
\text { Referenztest }\end{array}$ & Zielgröße und Ergebnis & Bemerkungen & Evidenzgrad \\
\hline & & & & $\begin{array}{l}\text { feekonsum vs. } \\
\text { ohne Kaffeekon- } \\
\text { sum }\end{array}$ & & & \\
\hline $\begin{array}{l}\text { Leitzmann } \\
1999 \text { [64] }\end{array}$ & $\begin{array}{l}\text { prospektive } \\
\text { Kohortenstudie }\end{array}$ & & $\begin{array}{l}N=46008 \\
\text { Männer } \\
\text { (40 - } 75 \text { Jahre) }\end{array}$ & $\begin{array}{l}\text { RR für verschiede- } \\
\text { ne Mengen des } \\
\text { Kaffeekonsums vs. } \\
\text { kein Kaffeekonsum } \\
\text { mit multivariater } \\
\text { Analyse für Stör- } \\
\text { einflüsse (Alter, } \\
\text { BMI, Gewichts- } \\
\text { änderungen in den } \\
\text { letzten } 2 \text { Jahren, } \\
\text { Diabetes, Rauchen, } \\
\text { körperliche Aktivi- } \\
\text { tät, Thiaziddiureti- } \\
\text { ka, NSAID, Choles- } \\
\text { terinsenker, } \\
\text { Alkohol, Ballast- } \\
\text { stoffe, Kohlenhy- } \\
\text { drate, Fette, } \\
\text { Gesamtenergieauf- } \\
\text { nahme) }\end{array}$ & $\begin{array}{l}\mathrm{N}=1081 \text { Fälle symptoma- } \\
\text { tischer Gallensteine (da- } \\
\text { von } 885 \text { Cholezystekto- } \\
\text { mien) während } 404166 \\
\text { Personen-Jahren Follow-up } \\
\text { RR für höchste ( }>800 \mathrm{mg} \\
\text { Koffein/Tag) vs. niedrigs- } \\
\text { te Kategorie ( } \leq 25 \mathrm{mg} \text { pro } \\
\text { Tag) } 0,55 \text { ( } 95 \% \text { Cl } 0,35 \text { - } \\
0,87) \\
\text { RR bei } 2-3 \text { Tassen Kaffee } \\
\text { pro Tag: } \\
0,60(0,42-0,86) \\
\text { RR bei } \geq 4 \text { Tassen Kaffee } \\
\text { pro Tag: } \\
0,55(0,33-0,92)\end{array}$ & $\begin{array}{l}\text { Risiko für Bias, } \\
\text { keine Sonogra- } \\
\text { fie zur Baseline } \\
\text { durchgeführt }\end{array}$ & III \\
\hline $\begin{array}{l}\text { Ruhl \& } \\
\text { Everhart } \\
2000 \text { [65] }\end{array}$ & $\begin{array}{l}\text { Nationale } \\
\text { Verzehrsstudie }\end{array}$ & & $\begin{array}{l}N=13938 \\
\text { (20-74 Jahre) }\end{array}$ & $\begin{array}{l}\text { Assoziationen zwi- } \\
\text { schen Erkrankung } \\
\text { der Gallenblase } \\
\text { und Kaffekonsum }\end{array}$ & $\begin{array}{l}\text { Erkrankung der Gallen- } \\
\text { blase: N = } 1415 \text { (19,5\%) } \\
\text { Frauen und } 578 \text { (8,7\% } \\
\text { Männer } \\
\text { keine Assoziation zwi- } \\
\text { schen Erkrankung der } \\
\text { Gallenblasse und Kaffee- } \\
\text { konsum }\end{array}$ & $\begin{array}{l}\text { keine Daten für } \\
\text { koffeinfreien } \\
\text { Kaffee }\end{array}$ & III \\
\hline $\begin{array}{l}\text { Leitz- } \\
\text { mann } \\
2002 \text { [66] }\end{array}$ & $\begin{array}{l}\text { prospektive } \\
\text { Kohortenstudie }\end{array}$ & & $\begin{array}{l}\mathrm{N}=80898 \\
\text { Frauen } \\
\text { (34-59 Jahre) }\end{array}$ & $\begin{array}{l}\text { RR für symptoma- } \\
\text { tische Gallensteine } \\
\text { bei verschiedenen } \\
\text { Mengen des Kaffe- } \\
\text { konsums vs. kein } \\
\text { Kaffeekonsum }\end{array}$ & $\begin{array}{l}\mathrm{N}=7811 \text { Cholezstekto- } \\
\text { mien nach } 20 \text { Jahren } \\
\text { Follow-up } \\
\text { RR bei } 2 \text { - } 3 \text { Tassen Kaffee } \\
\text { pro Tag: } \\
\text { RR 0,78 (95\% Cl } 0,71 \text { - } \\
0,86) \\
\text { RR bei } \geq 4 \text { Tassen Kaffee } \\
\text { pro Tag: } \\
0,72(0,62-0,84)\end{array}$ & $\begin{array}{l}\text { Risiko für Bias, } \\
\text { keine Sonogra- } \\
\text { fie zur Baseline } \\
\text { durchgeführt }\end{array}$ & III \\
\hline $\begin{array}{l}\text { Ishizuk } \\
2003 \text { [67] }\end{array}$ & $\begin{array}{l}\text { prospektive } \\
\text { Kohortenstudie }\end{array}$ & & $\begin{array}{l}\mathrm{N}=6889 \\
\text { Kontrollen } \\
\mathrm{N}=174 \\
\text { Patienten mit } \\
\text { Gallensteinen } \\
\mathrm{N}=104 \text { Post- } \\
\text { cholezystek- } \\
\text { tomie }\end{array}$ & $\begin{array}{l}\text { OR für Gallenstei- } \\
\text { ne mit multivaria- } \\
\text { ter Analyse für } \\
\text { Störeinflüsse (BMI, } \\
\text { Rauchen, Alkohol, } \\
\text { Glukosetoleranz, } \\
\text { Krankenhaus, } \\
\text { Dienstgrad) }\end{array}$ & $\begin{array}{l}\text { OR bei } 1-2 \text { Tassen Kaffee } \\
\text { pro Tag: } \\
\text { 1,0 ( } 95 \% \text { Cl 0,6 - 1,5) } \\
\text { OR bei } 3-4 \text { Tassen Kaffee } \\
\text { pro Tag: } \\
0,9(95 \% \text { Cl 0,6-1,4) } \\
\text { OR bei } \geq 5 \text { Tassen Kaffee } \\
\text { pro Tag } \\
1,4(95 \% \text { Cl 0,9-2,2) }\end{array}$ & & III \\
\hline $\begin{array}{l}\text { Walcher } \\
2010 \text { [49] }\end{array}$ & $\begin{array}{l}\text { prospektive } \\
\text { Kohortenstudie }\end{array}$ & & $\begin{array}{l}N=2139 \\
(18-65 \text { Jahre) }\end{array}$ & $\begin{array}{l}\text { Prävalenz von } \\
\text { Gallensteinen bei } \\
N=1966 \text { mit Kof- } \\
\text { feinkonsum vs. } \\
N=173 \text { ohne } \\
\text { Koffeinkonsum } \\
\text { OR mit multivaria- } \\
\text { ter Analyse für } \\
\text { Störeinflüsse } \\
\text { (Alter, Geschlecht, }\end{array}$ & $\begin{array}{l}156(7,9 \%) \text { vs. } 173(8,1 \%) \\
\text { OR nicht signifkant: } 0,77 \\
(95 \% \text { CI } 0,42-1,42) \\
P=0,40\end{array}$ & & III \\
\hline
\end{tabular}




\begin{tabular}{|c|c|c|c|c|c|c|c|}
\hline \multirow[t]{2}{*}{ Referenz } & Studientyp & Intervention & Teilnehmer & $\begin{array}{l}\text { Index- und } \\
\text { Referenztest }\end{array}$ & Zielgröße und Ergebnis & Bemerkungen & Evidenzgrad \\
\hline & & & & $\begin{array}{l}\text { BMI, positive Fa- } \\
\text { milienanamnese } \\
\text { für Gallensteine) }\end{array}$ & & & \\
\hline $\begin{array}{l}\text { Norden- } \\
\text { vall } 2015 \\
{[68]}\end{array}$ & $\begin{array}{l}2 \text { prospektive } \\
\text { Kohortenstu- } \\
\text { dien }\end{array}$ & & $\begin{array}{l}\mathrm{N}=71925 \\
\text { (Frauen } 40 \text { - } \\
75 \text { Jahre) } \\
\text { Männer } 45 \text { - } \\
79 \text { Jahre) }\end{array}$ & $\begin{array}{l}\text { HR für ge- } \\
\text { schlechtsspezifi- } \\
\text { sche Quintile des } \\
\text { Kaffeekonsums } \\
\text { mit multivariater } \\
\text { Analyse von Stör- } \\
\text { einflüsse (Bil- } \\
\text { dungsniveau, BMI, } \\
\text { Rauchen, Alkohol, } \\
\text { Tee, körperliche } \\
\text { Aktivität, ASS, Hy- } \\
\text { perlipidämie, Dia- } \\
\text { betes, Gesamt- } \\
\text { energieaufnahme, } \\
\text { orale Kontrazepti- } \\
\text { va, Geburtenzahl, } \\
\text { hormonelle Ersatz- } \\
\text { therapie, Meno- } \\
\text { pause) }\end{array}$ & $\begin{array}{l}\text { N= } 2019 \text { Cholezystekto- } \\
\text { mien während } 905933 \\
\text { Personen-Jahren Follow-up } \\
\text { HR für } \geq 6 \text { Tassen vs. <2 } \\
\text { Tassen pro Tag bei Frau- } \\
\text { en: 0,58 ( } 95 \% \text { Cl 0,44- } \\
0,78 \text { ) } \\
\text { HR für Männer: 0,96 ( } 95 \% \\
\text { Cl 0,75-1,24) }\end{array}$ & $\begin{array}{l}\text { Risiko für Bias, } \\
\text { keine Sonogra- } \\
\text { fie zur Baseline } \\
\text { durchgeführt }\end{array}$ & III \\
\hline $\begin{array}{l}\text { Zhang } \\
2015 \text { [69] }\end{array}$ & Metaanalyse & & $\begin{array}{l}\mathrm{N}=6 \text { Studien } \\
\text { (1 Fall-Kon- } \\
\text { troll-Studie, } 5 \\
\text { prospektive } \\
\text { Kohortenstu- } \\
\text { dien) mit ins- } \\
\text { gesamt } \\
227749 \text { Teil- } \\
\text { nehmern }\end{array}$ & $\begin{array}{l}\text { Kaffeekonsum und } \\
\text { Gallensteinrisiko } \\
\text { (RR) }\end{array}$ & $\begin{array}{l}0,83(95 \% \mathrm{Cl} 0,76-0,89) \\
\text { Dosis-Wirkungs-Analyse } \\
\text { pro Tasse Kaffee: } \\
0,95(95 \% \mathrm{Cl} 0,91-1,00)\end{array}$ & & II \\
\hline \multicolumn{8}{|c|}{ Gewichtsreduktion } \\
\hline $\begin{array}{l}\text { Gebhard } \\
1996 \text { [70] }\end{array}$ & $\begin{array}{l}\text { randomisierte } \\
\text { Studie }\end{array}$ & $\begin{array}{l}\text { kalorienarme } \\
\text { fettangerei- } \\
\text { cherte Diät } \\
\text { (900 kcal, } \\
30 \mathrm{~g} \text { Fett) für } \\
12 \text { Wo. vs. } \\
\text { sehr kalorien- } \\
\text { arme fettar- } \\
\text { me Diät } \\
\text { ( } 520 \text { kcal, } 2 \mathrm{~g} \\
\text { Fett) für } 12 \\
\text { Wo. } \\
\text { in beiden Ar- } \\
\text { men gefolgt } \\
\text { von kontinu- } \\
\text { ierlich wieder } \\
\text { gesteigerter } \\
\text { Nahrungszu- } \\
\text { fuhr für } 12 \\
\text { Wo. }\end{array}$ & $\begin{array}{l}\mathrm{N}=13(\mathrm{~N}=7 \\
\text { vs. } \mathrm{N}=6) \text { adi- } \\
\text { pöse Perso- } \\
\text { nen }\end{array}$ & $\begin{array}{l}\text { 1. Gallensteine } \\
\text { 2. Gallenblasen- } \\
\text { motilität } \\
\text { 3. Cholesterinsät- } \\
\text { tigungsindex (CSI) } \\
\text { 4. Blutlipide } \\
\text { 5. Gewichtsreduk- } \\
\text { tion }\end{array}$ & $\begin{array}{l}\text { 1. } 4 \text { Patienten in der fett- } \\
\text { armen Gruppe haben } \\
\text { Gallenstein entwickelt vs. } \\
0 \text { Patienten unter fettrei- } \\
\text { cher Diät } \\
\text { 2. geringere Gallenbla- } \\
\text { senentleerung bei }<1 \mathrm{~g} \\
\text { Fett-Mahlzeit vs. } 10 \mathrm{~g} \\
\text { Fett- Mahlzeit } \\
3 . \text { Steigerung des CSI nach } \\
8 \text { Wo. ( } 26 \pm 11 \% \text {, P } \\
<0,05) \text { und Verringerung } \\
\text { nach } 24 \text { Wo. ( }-15 \pm 6 \%, \mathrm{P} \\
<0,05) \text { in beiden Gruppen } \\
4 \text {. Abnahme des LDL- } \\
\text { Cholesterins bei allen Pa- } \\
\text { tienten ( } 136 \pm 7 \text { vs. } 93 \\
\pm 7 \text { mg/dl), Anstieg des } \\
\text { Gesamtcholesterins ( } 213 \\
\pm 8 \text { vs. } 159 \pm 8 \text { mg/dl) } \\
\text { nach } 8 \text { Wo. (beide P } \\
<0,05 \text { ) } \\
5 \text {. Gewichtsreduktion in } \\
\text { beiden Gruppen identisch }\end{array}$ & $\begin{array}{l}\text { kleine Stich- } \\
\text { probengröße } \\
\text { und Studie vor- } \\
\text { zeitig beendet } \\
\text { wegen symp- } \\
\text { tomatischer } \\
\text { Gallensteine } \\
(\mathrm{N}=2)\end{array}$ & III \\
\hline
\end{tabular}




\begin{tabular}{|c|c|c|c|c|c|c|c|}
\hline Referenz & Studientyp & Intervention & Teilnehmer & $\begin{array}{l}\text { Index- und } \\
\text { Referenztest }\end{array}$ & Zielgröße und Ergebnis & Bemerkungen & Evidenzgrad \\
\hline $\begin{array}{l}\text { Festi } \\
1998 \text { [71] }\end{array}$ & $\begin{array}{l}\text { randomisierte } \\
\text { Studie }\end{array}$ & $\begin{array}{l}\text { kalorienarme } \\
\text { fettangerei- } \\
\text { cherte Diät } \\
\text { ( } 577 \text { kcal, } \\
12,2 \mathrm{~g} \text { Fett) } \\
\text { für } 12 \text { Wo. vs. } \\
\text { sehr kalorien- } \\
\text { arme Diät } \\
\text { ( } 532 \mathrm{kcal}, 3 \mathrm{~g} \\
\text { Fett) für } 12 \\
\text { Wo. } \\
\text { in beiden Ar- } \\
\text { men gefolgt } \\
\text { von einer ka- } \\
\text { lorienreichen } \\
\text { Diät } \\
\text { (1000 kcal, } \\
30 \mathrm{~g} \text { Fett) für } \\
12 \text { Wo. }\end{array}$ & $\begin{array}{l}\mathrm{N}=32 \\
(\mathrm{~N}=11 \text { vs. } \\
\mathrm{N}=11) \\
\text { adipöse } \\
\text { Personen }\end{array}$ & $\begin{array}{l}\text { 1. Gallensteine } \\
\text { 2. Gallenblasen- } \\
\text { motilität } \\
\text { 3. biliäre Lipid-Zu- } \\
\text { sammensetzung } \\
\text { 4. Gewichtsreduk- } \\
\text { tion }\end{array}$ & $\begin{array}{l}\text { 1. } 6 \text { Patienten in der fett- } \\
\text { armen Gruppe haben } \\
\text { Gallensteineentwickelt } \\
\text { vs. } 0 \text { Patienten unter fett- } \\
\text { reicher Diät } \\
\text { 2. bessere Gallenblasen- } \\
\text { entleerung in den ersten } \\
3 \text { Mo. unter fettreicher } \\
\text { Diät } \\
\text { 3. Anstieg des CSI in bei- } \\
\text { den Gruppen nach } 45 \text { Ta- } \\
\text { gen, gefolgt von einem } \\
\text { Abfall nach } 90 \text { Tagen im } \\
\text { Vergleich zum Studienbe- } \\
\text { ginn } \\
\text { 4. Gewichtsreduktion } \\
\text { identisch in beiden } \\
\text { Gruppen }\end{array}$ & $\begin{array}{l}\text { kleine Stich- } \\
\text { probengröße }\end{array}$ & ॥ \\
\hline $\begin{array}{l}\text { Mendez- } \\
\text { Sanchez } \\
2001[72]\end{array}$ & $\begin{array}{l}\text { randomisierte } \\
\text { kontrollierte } \\
\text { Studie }\end{array}$ & $\begin{array}{l}\text { kalorienarme } \\
\text { Diät } \\
\text { (1200 kcal) } \\
\text { für } 6 \text { Wo. mit } \\
11,3 \mathrm{~g} \omega-3 \\
\text { mehrfach } \\
\text { ungesättig- } \\
\text { ten Fettsäu- } \\
\text { ren pro Tag } \\
\text { vs. } 1200 \text { mg } \\
\text { UDCA pro } \\
\text { Tag } \\
\text { vs. Placebo }\end{array}$ & $\begin{array}{l}N=35 \\
(N=12 \text { vs. } \\
N=12 \text { vs. } \\
N=11) \\
\text { adipöse } \\
\text { Frauen }\end{array}$ & $\begin{array}{l}\text { 1. Gallensteine } \\
\text { 2. CSI und Nuklea- } \\
\text { tionszeit } \\
\text { 3. Gewichtsreduk- } \\
\text { tion }\end{array}$ & $\begin{array}{l}\text { 1. niemand entwickelte } \\
\text { Gallensteine } \\
\text { 2. keine Änderung des } \\
\text { CSI, Abnahme der } \\
\text { Nukleationszeit in den } \\
\text { Vergleichsgruppen } \\
(P<0,05) \text {, aber nicht in } \\
\text { der } \omega \text {-3-Gruppe } \\
\text { 3. Gewichtsreduktion } \\
\text { identisch in allen Gruppen }\end{array}$ & $\begin{array}{l}\text { kurze Interven- } \\
\text { tionszeit }\end{array}$ & II \\
\hline $\begin{array}{l}\text { Moran } \\
1998 \text { [73] }\end{array}$ & $\begin{array}{l}\text { randomisierte } \\
\text { Studie }\end{array}$ & $\begin{array}{l}500 \text { kcal-Re- } \\
\text { duktionsdiät } \\
\text { mit } 15 \mathrm{~g} \text { Bal- } \\
\text { laststoffzu- } \\
\text { satz pro Tag } \\
\text { vs. } 750 \mathrm{mg} \\
\text { UDCA pro } \\
\text { Tag }\end{array}$ & $\begin{array}{l}\mathrm{N}=36 \\
(\mathrm{~N}=18 \text { vs. } \\
\mathrm{N}=18) \\
\text { adipöse } \\
\text { Personen }\end{array}$ & $\begin{array}{l}\text { 1. Gallensteine } \\
\text { 2. Gewichtsreduk- } \\
\text { tion }\end{array}$ & $\begin{array}{l}\text { 1. } 2 \text { Patienten in der Bal- } \\
\text { laststoff-Gruppe haben } \\
\text { nach } 8 \text { Wo. Gallensteine } \\
\text { entwickelt vs. } 1 \text { Patient in } \\
\text { der UDCA-Gruppe } \\
\text { 2. Gewichtsreduktion } \\
\text { identisch in beiden Grup- } \\
\text { pen }\end{array}$ & $\begin{array}{l}\text { kurze Interven- } \\
\text { tionszeit }\end{array}$ & III \\
\hline \multicolumn{8}{|c|}{ Körperliche Aktivität } \\
\hline $\begin{array}{l}\text { Utter } \\
2000 \text { [74] }\end{array}$ & $\begin{array}{l}\text { randomisierte } \\
\text { Studie }\end{array}$ & $\begin{array}{l}45 \text { min Trai- } \\
\text { ningseinhei- } \\
\text { ten (5-mal } \\
\text { pro Wo. bei } \\
60-80 \% \text { der } \\
\text { maximalen } \\
\text { Herzfre- } \\
\text { quenz) über } \\
12 \text { Wo. vs. } \\
\text { keine Inter- } \\
\text { vention }\end{array}$ & $\begin{array}{l}N=27 \\
(N=16 \text { vs. } \\
N=11) \text { adi- } \\
\text { pöse Frauen }\end{array}$ & $\begin{array}{l}\text { 1. Gallenblasen- } \\
\text { funktion (Chole- } \\
\text { zintigrafie) } \\
\text { 2. Körperzusam- } \\
\text { mensetzung }\end{array}$ & $\begin{array}{l}\text { 1. Steigerung der Gallen- } \\
\text { blasenentleerung in der } \\
\text { Interventionsgruppe (von } \\
36 \pm 5 \% \text { auf } 55 \pm 7 \% \text {, P } \\
<0,05 \text { ), aber diese Stei- } \\
\text { gerung war nicht höher } \\
\text { als in der Kontrollgruppe } \\
\text { 2. keine Änderung des } \\
\text { BMI }\end{array}$ & & III \\
\hline
\end{tabular}


Empfehlung II.2

\begin{tabular}{|c|c|c|c|c|c|c|c|}
\hline Referenz & Studientyp & Intervention & Teilnehmer & $\begin{array}{l}\text { Index- und Re- } \\
\text { ferenztest }\end{array}$ & $\begin{array}{l}\text { Zielgröße und } \\
\text { Ergebnis }\end{array}$ & Bemerkungen & Evidenzgrad \\
\hline $\begin{array}{l}\text { Ahmed } 2011 \\
\text { [76] }\end{array}$ & $\begin{array}{l}\text { prospektive } \\
\text { Kohorte }\end{array}$ & $N=1869$ & $\begin{array}{l}\text { Patienten zur } \\
\text { LC wegen biliä- } \\
\text { rer Symptome }\end{array}$ & $\begin{array}{l}\text { prä-OP Sono- } \\
\text { grafie vs. Histo- } \\
\text { pathologie }\end{array}$ & $\begin{array}{l}\text { Sensitivität } \\
1,00, \text { Spezifität } \\
0,14(0,10- \\
0,18)\end{array}$ & $\begin{array}{l}\text { Risiko für Bias, } \\
\text { sehr niedrige } \\
\text { Qualität, nicht } \\
\text { für erhöhten } \\
\text { BMI korrigiert }\end{array}$ & III \\
\hline
\end{tabular}

Empfehlung II.4

\begin{tabular}{|c|c|c|c|c|c|c|c|}
\hline Referenz & Studientyp & Intervention & Teilnehmer & $\begin{array}{l}\text { Index- und } \\
\text { Referenztest }\end{array}$ & $\begin{array}{l}\text { Zielgröße und } \\
\text { Ergebnis }\end{array}$ & Bemerkungen & Evidenzgrad \\
\hline $\begin{array}{l}\text { Ahvenjari } \\
2011 \text { [77] }\end{array}$ & $\begin{array}{l}\text { retrospektiv, } \\
\text { Fall-Kontroll- } \\
\text { Studie }\end{array}$ & $N=127$ & $\begin{array}{l}\text { V.a. akute akal- } \\
\text { kulöse Chole- } \\
\text { zystitis }\end{array}$ & $\begin{array}{l}\text { CT vs. offene } \\
\text { Cholezystekto- } \\
\text { mie bei } \\
43 \text { Patienten, } \\
84 \text { Kontrollen }\end{array}$ & $\begin{array}{l}\text { Dichte der Gal- } \\
\text { le und subse- } \\
\text { rosales Ödem: } \\
\text { Sensitivität } \\
23 \% \text {, Spezifität } \\
94 \% \\
\text { Gas in Gallen- } \\
\text { blasenwand } \\
\text { oder -lumen: } \\
\text { Sensitivität } \\
11 \%, \text { Spezifität } \\
99 \% \\
\text { Dicke der Gal- } \\
\text { lenblasen- } \\
\text { wand: } \\
\text { Sensitivät } 38 \%, \\
\text { Spezifität 95\% } \\
\text { Ödem um die } \\
\text { Gallenblase: } \\
\text { Sensitivität } \\
22 \%, \text { Spezifität } \\
92 \%\end{array}$ & & III \\
\hline $\begin{array}{l}\text { Altun } 2007 \\
{[78]}\end{array}$ & $\begin{array}{l}\text { prospektive } \\
\text { Kohorte }\end{array}$ & $N=32$ & $\begin{array}{l}\text { histopatholo- } \\
\text { gisch gesicherte } \\
\text { akute oder } \\
\text { chronische Cho- } \\
\text { lezystitis }\end{array}$ & $\begin{array}{l}\text { MRT }(1,5 \mathrm{~T}) \text { vs. } \\
\text { Cholezystekto- } \\
\text { mie }\end{array}$ & $\begin{array}{l}\text { Sensitivität } \\
0,95(95 \% \text { Cl } \\
0,71-0,99) \text {, } \\
\text { Spezifität 0,69 } \\
(95 \% \text { Cl 0,41 - } \\
0,88)\end{array}$ & $\begin{array}{l}\text { Selektionsbias } \\
\text { möglich, } \\
\text { Abstand von } \\
\text { Index- und } \\
\text { Refenztest mit } \\
\text { einem Monat } \\
\text { lang }\end{array}$ & III \\
\hline $\begin{array}{l}\text { Kiewiet } 2012 \\
\text { [79] }\end{array}$ & $\begin{array}{l}\text { systematisches } \\
\text { Review und } \\
\text { Metaanalyse }\end{array}$ & $\begin{array}{l}\mathrm{N}=5859 \text { in } 57 \\
\text { Studien }\end{array}$ & $\begin{array}{l}\text { Medline, Emba- } \\
\text { se, Cochrane } \\
\text { und CINAHL bis } \\
2011 \\
\text { Arbeiten, die UI- } \\
\text { traschall, Szinti- } \\
\text { grafie, CT und } \\
\text { MRT bei er- } \\
\text { wachsenen Pa- } \\
\text { tienten mit V.a. } \\
\text { akute Cholezys- } \\
\text { titis verglichen } \\
\text { haben }\end{array}$ & $\begin{array}{l}\text { Sonografie, } \\
\text { Szintigrafie, CT, } \\
\text { MRT vs. Chole- } \\
\text { zystektomie }\end{array}$ & $\begin{array}{l}\text { Sonografie: } \\
\text { Sensitivität } \\
81 \%(95 \% \text { Cl } \\
75-87 \%), \\
\text { Spezifität } 83 \% \\
\text { (95\% Cl } 74 \text { - } \\
89 \%) \\
\text { Szintigrafie: } \\
\text { Sensitivität } \\
96 \% \text { (95\% Cl } \\
94 \text { - } 97 \%), \\
\text { Spezifität } 90 \% \\
(95 \% \text { Cl } 86- \\
93 \%)\end{array}$ & $\begin{array}{l}\text { keine Studien } \\
\text { mit direktem } \\
\text { Vergleich in der- } \\
\text { selben Patien- } \\
\text { ten-gruppe, } \\
\text { daher Confoun- } \\
\text { ding und Selek- } \\
\text { tionsbias mög- } \\
\text { lich, mäßige bis } \\
\text { schlechte Quali- } \\
\text { tät der Studien }\end{array}$ & I \\
\hline
\end{tabular}




\begin{tabular}{|c|c|c|c|c|c|c|c|}
\hline Referenz & Studientyp & Intervention & Teilnehmer & $\begin{array}{l}\text { Index- und } \\
\text { Referenztest }\end{array}$ & $\begin{array}{l}\text { Zielgröße und } \\
\text { Ergebnis }\end{array}$ & Bemerkungen & Evidenzgrad \\
\hline & & & & & $\begin{array}{l}\text { CT (nur } 1 \text { Stu- } \\
\text { die): Sensitivi- } \\
\text { tät } 94 \% \text { (95\% } \\
\text { Cl } 73 \text { - } 99 \% \text { ), } \\
\text { Spezifität 59\% } \\
\text { (95\% Cl } 42 \text { - } \\
74 \%) \\
\text { MRT: Sensitivi- } \\
\text { tät } 85 \% \text { (95\% } \\
\text { Cl } 66 \text { - 95\%), } \\
\text { Spezifität } 81 \% \\
\text { (95\% CI } 69 \text { - } \\
90 \%)\end{array}$ & & \\
\hline $\begin{array}{l}\text { Gurusamy } \\
2015 \text { [80] }\end{array}$ & $\begin{array}{l}\text { systematisches } \\
\text { Review und } \\
\text { Metaanalyse }\end{array}$ & $\begin{array}{l}\mathrm{N}=523 \text { in } 5 \\
\text { Studien zur } \\
\text { Bewertung der } \\
\text { diagnostischen } \\
\text { Genauigkeit } \\
\text { des abdomi- } \\
\text { nellen Ultra- } \\
\text { schalls für die } \\
\text { Diagnostik der } \\
\text { Choledocholi- } \\
\text { thiasis } \\
\mathrm{N}=262 \text { in einer } \\
\text { Studie, die } \\
\text { Leberfunkti- } \\
\text { onstests mit } \\
\text { Ultraschall } \\
\text { verglich }\end{array}$ & $\begin{array}{l}\text { Medline, Emba- } \\
\text { se, SCI expan- } \\
\text { ded, BIOSIS und } \\
\text { Clinicaltrials.gov } \\
\text { bis September } \\
2012\end{array}$ & $\begin{array}{l}\text { Sonografie } \\
\text { und Leberfunkti- } \\
\text { onstests zur } \\
\text { Diagnose einer } \\
\text { Choledocholit- } \\
\text { hiasis }\end{array}$ & $\begin{array}{l}\text { Sonografie: } \\
\text { Sensitivität } \\
32 \% \text { - } 100 \% \text {, } \\
\text { gepoolt } 73 \% \\
\text { (95\% Cl } 44 \text { - } \\
90 \% \text { ) Spezifi- } \\
\text { tät } 77 \text { - } 97 \% \text {, } \\
\text { gepoolt } 91 \% \\
\text { (95\% Cl } 84 \text { - } \\
95 \% \text { ). } \\
\text { Bei der media- } \\
\text { nen Prätest- } \\
\text { Wahrschein- } \\
\text { lichkeit für } \\
\text { Choledocholi- } \\
\text { thiasis von } \\
40,8 \% \text { war die } \\
\text { Posttestwahr- } \\
\text { scheinlichkeit } \\
\text { bei positiver } \\
\text { Sonografie bei } \\
85 \% \text { (95\% Cl } \\
75 \%-91 \%) \\
\text { und bei nega- } \\
\text { tiver Sonogra- } \\
\text { fie bei } 17 \% \\
\text { (95\% Cl } 8 \% \text { - } \\
33 \% \text { ). } \\
\text { Die einzelne } \\
\text { Studie zum } \\
\text { Vergleich } \\
\text { Leber-Bioche- } \\
\text { mie zu Sono- } \\
\text { grafie wurde } \\
\text { für die Evi- } \\
\text { denzanalyse } \\
\text { nicht berück- } \\
\text { sichtigt. }\end{array}$ & $\begin{array}{l}\text { starke Studien- } \\
\text { heterogenität, } \\
\text { methodisch } \\
\text { geringe Studi- } \\
\text { enqualität, kei- } \\
\text { ne prospektiv- } \\
\text { vergleichenden } \\
\text { Studien }\end{array}$ & III \\
\hline
\end{tabular}




\begin{tabular}{|c|c|c|c|c|c|c|c|}
\hline Referenz & Studientyp & Intervention & Teilnehmer & $\begin{array}{l}\text { Index- und } \\
\text { Referenztest }\end{array}$ & $\begin{array}{l}\text { Zielgröße und } \\
\text { Ergebnis }\end{array}$ & Bemerkungen & Evidenzgrad \\
\hline $\begin{array}{l}\text { Garrow } 2007 \\
\text { [81] }\end{array}$ & $\begin{array}{l}\text { systematisches } \\
\text { Review mit } \\
\text { Metaanalyse }\end{array}$ & $\begin{array}{l}\mathrm{N}=3532 \text { in } 36 \\
\text { Studien }\end{array}$ & $\begin{array}{l}\text { Medline } 1987 \text { - } \\
\text { 2006: Vergleich } \\
\text { von EUS und } \\
\text { Goldstandard, } \\
\text { ausreichende } \\
\text { Informationen } \\
\text { für Kontingenz- } \\
\text { tafeln }\end{array}$ & $\begin{array}{l}\text { EUS vs. ERC, } \\
\text { IOC, PTCD, chi- } \\
\text { rurgische Explo- } \\
\text { ration, Histopa- } \\
\text { thologie, CT mit } \\
\text { Follow-up } \geq 6 \\
\text { Monate }\end{array}$ & $\begin{array}{l}\text { EUS: Sensitivi- } \\
\text { tät } 88 \% \text { ( } 95 \% \\
\text { Cl } 85-91 \%) \\
\text { Spezifität } 90 \% \\
\text { (95\% Cl } 87 \text { - } \\
93 \%) \text { für biliä- } \\
\text { re Obstruktion } \\
\text { Sensensitivtät } \\
89 \% \text { (95\% Cl } \\
87-91 \%) \\
\text { Spezifität } 94 \% \\
\text { (95\% Cl } 91 \text { - } \\
\text { 96\%) für Cho- } \\
\text { ledocholithiasis }\end{array}$ & $\begin{array}{l}\text { fehlerhafte Klas- } \\
\text { sifikation von } \\
\text { Patienten auf- } \\
\text { grund unvoll- } \\
\text { ständiger Krite- } \\
\text { rien führt } \\
\text { möglicherweise } \\
\text { zur Unterschät- } \\
\text { zung der Ge- } \\
\text { nauigkeit des } \\
\text { EUS }\end{array}$ & II \\
\hline $\begin{array}{l}\text { Jovanovic } \\
2011 \text { [82] }\end{array}$ & $\begin{array}{l}\text { prospektive } \\
\text { Kohorte }\end{array}$ & $N=203$ & $\begin{array}{l}\text { ERC wegen V.a. } \\
\text { Choledocholithi- } \\
\text { asis, sonografi- } \\
\text { sche Kriterien: } \\
\text { CBD > } 7 \text { mm } \\
\text { oder CBD-Steine }\end{array}$ & $\begin{array}{l}\text { Sonografie vs. } \\
\text { ERC }\end{array}$ & $\begin{array}{l}\text { Sensitivität } \\
0,91(95 \% \mathrm{Cl} \\
0,85-0,97), \\
\text { Spezifität } 0,34 \\
(95 \% \text { Cl } 0,25- \\
0,44)\end{array}$ & monozentrisch & III \\
\hline $\begin{array}{l}\text { Karki } 2013 \\
{[83]}\end{array}$ & $\begin{array}{l}\text { prospektive } \\
\text { Kohorte }\end{array}$ & $\mathrm{N}=88$, Indien & $\begin{array}{l}\text { V.a. Verschluss- } \\
\text { ikterus und ab- } \\
\text { norme Choles- } \\
\text { taseparameter } \\
\text { (Bilirubin, AP) }\end{array}$ & $\begin{array}{l}\text { Sonografie vs. } \\
\text { ERC }\end{array}$ & $\begin{array}{l}\text { Sensitivität } 1 \text {, } \\
\text { Spezifität } 0,89\end{array}$ & $\begin{array}{l}\text { Selektionsbias } \\
\text { möglich, sehr } \\
\text { niedrige Quali- } \\
\text { tät, keine Cl } \\
\text { angegeben }\end{array}$ & III \\
\hline $\begin{array}{l}\text { Tse } 2008 \\
{[84]}\end{array}$ & $\begin{array}{l}\text { systematisches } \\
\text { Review mit } \\
\text { Metaanalyse } \\
\text { prospektiverer } \\
\text { Kohortenstu- } \\
\text { dien }\end{array}$ & $\begin{array}{l}\mathrm{N}=2673 \text { in } 27 \\
\text { Studien }\end{array}$ & $\begin{array}{l}\text { Medline } 1996 \text { - } \\
2006 \text { und Em- } \\
\text { base } 1980 \text { - } \\
2006 \text { : EUS mit } \\
7,5 \text { oder } \\
12 \mathrm{MHz} \text {, akzep- } \\
\text { table Kriterien- } \\
\text { standards, Pa- } \\
\text { tienten mit V. a. } \\
\text { Gallengang- } \\
\text { steine, detallier- } \\
\text { te Ergebnisse für } \\
\text { Kontingenzta- } \\
\text { feln }\end{array}$ & $\begin{array}{l}\text { EUS vs. ERC, } \\
\text { IOC, chirurgi- } \\
\text { sche Explorati- } \\
\text { on, klinisches } \\
\text { Follow-up mind. } \\
3 \text { Monate }\end{array}$ & $\begin{array}{l}\text { EUS: Sensitvi- } \\
\text { tät } 94 \%(95 \% \\
\text { Cl } 93-95 \%) \\
\text { Spezifität } 95 \% \\
\text { (95\% Cl } 94- \\
96 \%) \text { für Cho- } \\
\text { ledocholithiasis }\end{array}$ & $\begin{array}{l}\text { fehlerhafte Klas- } \\
\text { sifikation von } \\
\text { Patienten } \\
\text { aufgrund unvoll- } \\
\text { ständiger Krite- } \\
\text { rien, möglicher- } \\
\text { weise zur } \\
\text { Unterschätzung } \\
\text { der Genauigkeit } \\
\text { des EUS }\end{array}$ & 1 \\
\hline $\begin{array}{l}\text { Tseng } 2008 \\
{[85]}\end{array}$ & $\begin{array}{l}\text { prospektive } \\
\text { Kohorte }\end{array}$ & $N=266$ & $\begin{array}{l}\text { ERC wegen V.a. } \\
\text { Choledocholithi- } \\
\text { asis, CT inner- } \\
\text { halb von } 5 \text { Ta- } \\
\text { gen vor ERC }\end{array}$ & CT vs. ERC & $\begin{array}{l}\text { Sensitivität } \\
0,77(95 \% \mathrm{Cl} \\
0,71-0,84), \\
\text { Spezifität } 0,73 \\
(0,64-0,82)\end{array}$ & $\begin{array}{l}3 \text { verschiedene } \\
\text { CT-Sequenzen }\end{array}$ & III \\
\hline $\begin{array}{l}\text { Patel } 2017 . \\
{[86]}\end{array}$ & $\begin{array}{l}\text { prospektive } \\
\text { Kohorte }\end{array}$ & $N=78$ & $\begin{array}{l}\text { Patienten mit } \\
\text { hoher Wahr- } \\
\text { scheinlichkeit } \\
\text { für Choledocho- } \\
\text { lithiasis } \\
\text { alle Patienten } \\
\text { erhielten EUS } \\
\text { vor eventueller } \\
\text { ERC: } 41 \text { \% Präva- } \\
\text { lenz von Chole- } \\
\text { docholithiasis/ } \\
\text { Sludge im Gal- } \\
\text { lengang }\end{array}$ & $\begin{array}{l}\text { Vermeidung von } \\
\text { ERC durch EUS- } \\
\text { first-Strategie } \\
\text { bei Hochrisiko- } \\
\text { Patienten }\end{array}$ & $\begin{array}{l}\text { Sensitivität, } \\
\text { Spezifität, PPV } \\
\text { und NPV des } \\
\text { EUS für die Di- } \\
\text { agnose einer } \\
\text { Choledocholit- } \\
\text { hiasis: 93,9\%, } \\
\text { 97,3\%, 96,9\% } \\
\text { bzw. 94,7\% } \\
\text { Vermeidung } \\
\text { einer unnöti- } \\
\text { gen ERC bei } \\
\text { 58\% der Pa- }\end{array}$ & $\begin{array}{l}\text { keine Kontroll- } \\
\text { gruppe, ERC-Un- } \\
\text { tersucher nicht } \\
\text { verblindet ge- } \\
\text { gen EUS-Ergeb- } \\
\text { nis, nur } 3 \text { Mona- } \\
\text { te Follow-up }\end{array}$ & II \\
\hline
\end{tabular}




\begin{tabular}{|c|c|c|c|c|c|c|c|}
\hline Referenz & Studientyp & Intervention & Teilnehmer & $\begin{array}{l}\text { Index- und } \\
\text { Referenztest }\end{array}$ & $\begin{array}{l}\text { Zielgröße und } \\
\text { Ergebnis }\end{array}$ & Bemerkungen & Evidenzgrad \\
\hline & & & & & $\begin{array}{l}\text { tienten mit } \\
\text { hoher Wahr- } \\
\text { scheinlichkeit } \\
\text { für Choledo- } \\
\text { cholithiasis } \\
\text { durch EUS- } \\
\text { first-Strategie }\end{array}$ & & \\
\hline $\begin{array}{l}\text { Narvaez } \\
2016 \text { [87] }\end{array}$ & $\begin{array}{l}\text { prospektive } \\
\text { Kohorte }\end{array}$ & $N=256$ & $\begin{array}{l}208 \text { Patienten } \\
\text { mit hoher Wahr- } \\
\text { scheinlichkeit } \\
\text { und } 48 \text { Patien- } \\
\text { ten mit inter- } \\
\text { mediärer Wahr- } \\
\text { scheinlichkeit } \\
\text { einer Choledo- } \\
\text { cholithiasis nach } \\
\text { den ASGE-Krite- } \\
\text { rien }\end{array}$ & $\begin{array}{l}\text { Untersuchung } \\
\text { der Validität der } \\
\text { ASGE-Kriterien } \\
\text { für hohe und in- } \\
\text { termediäre } \\
\text { Wahrscheinlich- } \\
\text { keit einer Chole- } \\
\text { docholithiasis } \\
\text { Goldstandard } \\
\text { ERC }\end{array}$ & $\begin{array}{l}\text { ASGE Kriterien } \\
\text { für hohe und } \\
\text { intermediäre } \\
\text { Wahrschein- } \\
\text { lichkeit hatten } \\
\text { eine Genauig- } \\
\text { keit von } 59 \% \\
\text { ( } 86 \% \text { Sensitivi- } \\
\text { tät, } 24 \% \text { Spe- } \\
\text { zifität) bzw. } \\
41 \% \text { ( } 14 \% \\
\text { Sensitivität, } \\
76 \% \text { Spezifi- } \\
\text { tät), sodass die } \\
\text { Anwendung } \\
\text { dieser Krite- } \\
\text { rien in nahezu } \\
\text { der Hälfte der } \\
\text { Fälle eine un- } \\
\text { nötige ERC } \\
\text { nach sich zog }\end{array}$ & $\begin{array}{l}\text { lange Zeitspan- } \\
\text { ne von 6,1 bzw. } \\
6,4 \text { Tagen zwi- } \\
\text { schen Indexun- } \\
\text { tersuchungen } \\
\text { und ERC, kein } \\
\text { EUS oder MRCP }\end{array}$ & II \\
\hline $\begin{array}{l}\text { Sharma } \\
2015 \text { [88] }\end{array}$ & $\begin{array}{l}\text { RCT, prospektive } \\
\text { Kohorten }\end{array}$ & $N=100$ & $\begin{array}{l}\text { prospektiv-ran- } \\
\text { domisierte Stu- } \\
\text { die }\end{array}$ & $\begin{array}{l}\text { EUS + unselekti- } \\
\text { ve ERC bei allen } \\
\text { Patienten } \\
\text { (Gruppe A) vs. } \\
\text { EUS + selektive } \\
\text { ERC bei positi- } \\
\text { vem EUS-Ergeb- } \\
\text { nis (Gruppe B) }\end{array}$ & $\begin{array}{l}\text { Vermeidung } \\
\text { von } 44 \% \text { der } \\
\text { ERC in Gruppe } \\
\text { B }\end{array}$ & & 1 \\
\hline $\begin{array}{l}\text { Giljaca } 2015 \\
\text { [89] }\end{array}$ & $\begin{array}{l}\text { systematisches } \\
\text { Review und } \\
\text { Metaanalyse }\end{array}$ & $\begin{array}{l}\mathrm{N}=2366 \text { aus } \\
18 \text { Studien (11 } \\
\text { nur EUS, } 5 \text { nur } \\
\text { MRCP, zwei } \\
\text { vergleichend) }\end{array}$ & $\begin{array}{l}\text { Medline, Emba- } \\
\text { se, SCl expan- } \\
\text { ded, BIOSIS und } \\
\text { Clinicaltrials.gov } \\
\text { bis September } \\
2012\end{array}$ & $\begin{array}{l}\text { MRCP vs. EUS } \\
\text { für Diagnose der } \\
\text { Choledocholi- } \\
\text { thiasis }\end{array}$ & $\begin{array}{l}\text { EUS: Sensitivi- } \\
\text { tät } 75-100 \% \text {, } \\
\text { gepoolt } 95 \% \\
\text { (95\% CI } 91 \text { - } \\
97 \%), \text { Spezifi- } \\
\text { tät } 85-100 \% \text {, } \\
\text { gepoolt } 97 \% \\
\text { (95\% CI } 94- \\
99 \%) \\
\text { MRCP: Sensiti- } \\
\text { vität } 77 \text { - } \\
100 \% \text {, gepoolt } \\
93 \% \text { (95\% Cl } \\
87-96 \%), \\
\text { Spezifität } 73- \\
99 \% \text {, gepoolt } \\
96 \% \text { (95\% CI } \\
90-98 \%) \\
\text { bei der media- } \\
\text { nen Prätest- } \\
\text { Wahrschein- } \\
\text { lichkeit für } \\
\text { Choledocholi- } \\
\text { thiasis von } \\
41 \% \text { war die }\end{array}$ & $\begin{array}{l}\text { eingeschränkte } \\
\text { methodische } \\
\text { Qualität der } \\
\text { Studien, nur } \\
\text { zwei verglei- } \\
\text { chende Studien } \\
\text { eingeschlossen }\end{array}$ & III \\
\hline
\end{tabular}




\begin{tabular}{|c|c|c|c|c|c|c|c|}
\hline Referenz & Studientyp & Intervention & Teilnehmer & $\begin{array}{l}\text { Index- und } \\
\text { Referenztest }\end{array}$ & $\begin{array}{l}\text { Zielgröße und } \\
\text { Ergebnis }\end{array}$ & Bemerkungen & Evidenzgrad \\
\hline & & & & & $\begin{array}{l}\text { Posttest- } \\
\text { Wahrschein- } \\
\text { lichkeit bei po- } \\
\text { sitivem EUS } \\
\text { bei } 96 \% \text { ( } 95 \% \\
\text { Cl } 92 \text { - } 98 \% \text { ) } \\
\text { und bei nega- } \\
\text { tivem EUS bei } \\
3 \% \text { (95\% Cl } \\
2 \text {-6\%) } \\
\text { bei der glei- } \\
\text { chen media- } \\
\text { nen Prätest- } \\
\text { Wahrschein- } \\
\text { lichkeit für } \\
\text { Choledocholi- } \\
\text { thiasis von } \\
41 \% \text { war die } \\
\text { Posttest- } \\
\text { Wahrschein- } \\
\text { lichkeit bei po- } \\
\text { sitiver MRCP } \\
\text { bei } 94 \% \text { (95\% } \\
\text { Cl } 87 \text { - 97\%) } \\
\text { und bei nega- } \\
\text { tiver MRCP bei } \\
5 \% \text { (95\% Cl } \\
3 \text { - } 9 \% \text { ) } \\
\text { Sensitivität } \\
\text { und Spezifität } \\
\text { von EUS und } \\
\text { MRCP unter- } \\
\text { schieden sich } \\
\text { nicht }\end{array}$ & & \\
\hline $\begin{array}{l}\text { De Castro } \\
2016[90]\end{array}$ & $\begin{array}{l}\text { systematisches } \\
\text { Review }\end{array}$ & $\begin{array}{l}\mathrm{N}=538 \text { aus } 8 \\
\text { prospektiv- } \\
\text { vergleichen- } \\
\text { den Kohorten- } \\
\text { studien }\end{array}$ & $\begin{array}{l}\text { MedLine, Emba- } \\
\text { se, Cochrane, } \\
\text { LILACS und } \\
\text { Scopus bis Mai } \\
2015\end{array}$ & $\begin{array}{l}\text { MRCP vs. EUS } \\
\text { für Diagnose der } \\
\text { Choledocholi- } \\
\text { thiasis }\end{array}$ & $\begin{array}{l}\text { EUS: Sensitivi- } \\
\text { tät gepoolt } \\
94 \% \text { ( } 87 \text { - } \\
100 \%), \text { Spezi- } \\
\text { fität gepoolt } \\
89 \% \text { ( } 72 \text { - } \\
100 \%) \\
\text { MRCP: Sensiti- } \\
\text { vität gepoolt } \\
84 \% \text { (65 - } \\
100 \%), \text { Spezi- } \\
\text { fität gepoolt } \\
92 \% \text { ( } 81 \text { - } \\
100 \%) \\
\text { bei der media- } \\
\text { nen Prätest- } \\
\text { Wahrschein- } \\
\text { lichkeit für } \\
\text { Choledocholi- } \\
\text { thiasis waren } \\
\text { PPV und NPV } \\
\text { für EUS höher } \\
\text { als für MRCP }\end{array}$ & $\begin{array}{l}\text { methodisch } \\
\text { geringe Qualität } \\
\text { von einge- } \\
\text { schlossenen } \\
\text { Studien } \\
\text { Verzicht auf eine } \\
\text { Metaanalyse }\end{array}$ & II \\
\hline $\begin{array}{l}\text { Chen } 2015 \\
\text { [91] }\end{array}$ & $\begin{array}{l}\text { systematisches } \\
\text { Review }\end{array}$ & $\begin{array}{l}\mathrm{N}=3048 \text { in } 25 \\
\text { Studien, } \\
\text { darunter } 10 \\
\text { prospektiv- }\end{array}$ & $\begin{array}{l}\text { Medline und } \\
\text { Embase (1980 - } \\
\text { 2014), Web of } \\
\text { Science (1990 - }\end{array}$ & $\begin{array}{l}\text { diagnostische } \\
\text { Genauigkeit der } \\
\text { MRCP für Chole- } \\
\text { docholithiasis }\end{array}$ & $\begin{array}{l}\text { Sensitivität } \\
38-100 \% \text {, } \\
\text { gepoolt } 90 \%\end{array}$ & $\begin{array}{l}\text { überwiegend } \\
\text { hohe Qualität } \\
\text { der Studien, }\end{array}$ & II \\
\hline
\end{tabular}




\begin{tabular}{|c|c|c|c|c|c|c|c|}
\hline Referenz & Studientyp & Intervention & Teilnehmer & $\begin{array}{l}\text { Index- und } \\
\text { Referenztest }\end{array}$ & $\begin{array}{l}\text { Zielgröße und } \\
\text { Ergebnis }\end{array}$ & Bemerkungen & Evidenzgrad \\
\hline & & $\begin{array}{l}\text { kontrollierte } \\
\text { Vergleichsstu- } \\
\text { dien }\end{array}$ & $\begin{array}{l}\text { 2014) und } \\
\text { Cochrane }\end{array}$ & & $\begin{array}{l}(95 \% \text { Cl } 88- \\
92 \%) \\
\text { Spezifität } 19- \\
100 \%, \text { gepoolt } \\
95 \%(95 \% \text { Cl } \\
93-100 \%)\end{array}$ & $\begin{array}{l}\text { keine Heteroge- } \\
\text { nität }\end{array}$ & \\
\hline $\begin{array}{l}\text { Meeralam } \\
2017 \text { [92] }\end{array}$ & $\begin{array}{l}\text { systematisches } \\
\text { Review und } \\
\text { Metaanalyse der } \\
\text { diagnostischen } \\
\text { Testgenauigkeit }\end{array}$ & $\begin{array}{l}\mathrm{N}=272 \text { aus } 5 \\
\text { prospektiv- } \\
\text { vergleichen- } \\
\text { den Kohorten- } \\
\text { studien }\end{array}$ & $\begin{array}{l}\text { Medline (1946 } \\
\text { bis Januar } \\
2017), \text { Embase } \\
\text { (1980 bis Januar } \\
2017), \text { Coch- } \\
\text { rane, Clinicaltri- } \\
\text { als.gov und Web } \\
\text { of Science } 1980 \\
\text { bis Januar } 2017\end{array}$ & $\begin{array}{l}\text { Diagnostische } \\
\text { Genauigkeit der } \\
\text { MRCP für Chole- } \\
\text { docholithiasis }\end{array}$ & $\begin{array}{l}\text { EUS: Sensitivi- } \\
\text { tät gepoolt } \\
97 \%(91- \\
99 \%), \text { Spezifi- } \\
\text { tät gepoolt } \\
90 \% \text { ( } 83 \text { - } \\
94 \%) \\
\text { MRCP: Sensiti- } \\
\text { vität gepoolt } \\
87 \% \text { ( } 80 \text { - } \\
93 \% \text { ), Spezifi- } \\
\text { tät gepoolt } \\
92 \%(87- \\
96 \%) \\
\text { höhere Sensi- } \\
\text { tivität } \\
(\mathrm{P}=0,006) \\
\text { und diagnosti- } \\
\text { sche OR } \\
(\mathrm{P}=0,008) \text { von } \\
\text { EUS vs. MRCP }\end{array}$ & $\begin{array}{l}\text { teilweise sehr } \\
\text { geringe Fallzahl, } \\
\text { nur vergleichen- } \\
\text { de prospektive } \\
\text { Studien }\end{array}$ & 1 \\
\hline
\end{tabular}

Empfehlung II.12

\begin{tabular}{|c|c|c|c|c|c|c|c|}
\hline Referenz & Studientyp & Intervention & Teilnehmer & $\begin{array}{l}\text { Index- und } \\
\text { Referenztest }\end{array}$ & $\begin{array}{l}\text { Zielgröße und } \\
\text { Ergebnis }\end{array}$ & Bemerkungen & Evidenzgrad \\
\hline $\begin{array}{l}\text { Smith } 2015 \\
\text { [93] }\end{array}$ & $\begin{array}{l}\text { systematisches } \\
\text { Review }\end{array}$ & 13 Studien & $\begin{array}{l}\text { PubMed Januar } \\
2000 \text { - November } \\
2014\end{array}$ & $\begin{array}{l}\text { diagnostischer } \\
\text { Ertrag des EUS } \\
\text { bei Patienten mit } \\
\text { idiopathischer } \\
\text { Pankreatitis }\end{array}$ & $\begin{array}{l}\text { in } 61 \% \text { der Fälle } \\
\text { diagnostische } \\
\text { Information } \\
\text { durch EUS, } \\
\text { insbesondere } \\
\text { ( } 41 \%) \text { biliäre } \\
\text { Ursache } \\
\text { in der Detektion } \\
\text { biliärer } \\
\text { Ursachen Über- } \\
\text { legenheit EUS } \\
\text { vs. MRCP, die } \\
\text { wiederum häu- } \\
\text { figer Gangano- } \\
\text { malien diagnos- } \\
\text { tizierte }\end{array}$ & & III \\
\hline
\end{tabular}




\begin{tabular}{|c|c|c|c|c|c|c|c|}
\hline Referenz & Studientyp & Intervention & Teilnehmer & $\begin{array}{l}\text { Index- und } \\
\text { Referenztest }\end{array}$ & $\begin{array}{l}\text { Zielgröße und } \\
\text { Ergebnis }\end{array}$ & Bemerkungen & Evidenzgrad \\
\hline $\begin{array}{l}\text { Wilcox } 2016 \\
{[94]}\end{array}$ & $\begin{array}{l}\text { prospektive } \\
\text { Kohortenstudie }\end{array}$ & $N=101$ & $\begin{array}{l}\text { EUS bei allen } \\
\text { konsekutiven } \\
\text { Patienten mit } \\
\text { idiopathischer } \\
\text { akuter Pankrea- } \\
\text { titis in einer } \\
\text { 10-Jahres-Periode }\end{array}$ & $\begin{array}{l}\text { ERC und/oder } \\
\text { Cholezystekto- } \\
\text { mie bei biliärer } \\
\text { Ursache im EUS } \\
\text { Follow-up bei } \\
\text { allen Patienten } \\
\text { mit einzelner At- } \\
\text { tacke, negativem } \\
\text { EUS, chronischer } \\
\text { Pankreatitis oder } \\
\text { Pancreas divisum } \\
\text { Endpunkt: Pan- } \\
\text { kreatitisrezidiv }\end{array}$ & $\begin{array}{l}\text { Rezidivrate } \\
\text { nach einzelner } \\
\text { Pankreatitis: } \\
54 \% \\
\text { nach EUS = } \\
\text { „idiopathisch“: } \\
15 \%\end{array}$ & & II \\
\hline
\end{tabular}

Empfehlungen IIIA.4

\begin{tabular}{|c|c|c|c|c|c|c|c|}
\hline Referenz & Studientyp & Intervention & Teilnehmer & $\begin{array}{l}\text { Index- und } \\
\text { Referenztest }\end{array}$ & $\begin{array}{l}\text { Zielgröße und } \\
\text { Ergebnis }\end{array}$ & Bemerkungen & Evidenzgrad \\
\hline $\begin{array}{l}\text { Mazeh } 2012 \\
\text { [95] }\end{array}$ & RCT & $\begin{array}{l}\mathrm{N}=84,42 \text { in } \\
\text { jeder Gruppe }\end{array}$ & $\begin{array}{l}\text { Patienten im } \\
\text { Alter von 18-70 } \\
\text { Jahren mit akuter } \\
\text { kalkulöser Chole- } \\
\text { zystitis }\end{array}$ & $\begin{array}{l}\text { Antibiotika i. v. } \\
\text { vs. Standardthe- } \\
\text { rapie }\end{array}$ & $\begin{array}{l}\text { kein Unter- } \\
\text { schied bei pe- } \\
\text { rioperativem } \\
\text { Verlauf oder } \\
\text { Krankenhaus- } \\
\text { verweildauer }\end{array}$ & $\begin{array}{l}\text { keine Verblin- } \\
\text { dung oder Place- } \\
\text { bo, Behandlung } \\
\text { von verschiede- } \\
\text { nen Ärzten, } 23 \\
\text { Patienten wur- } \\
\text { den nicht einge- } \\
\text { schlossen }\end{array}$ & II \\
\hline
\end{tabular}

Empfehlung IIIB.1

\begin{tabular}{|c|c|c|c|c|c|c|c|}
\hline Referenz & Studientyp & Intervention & Teilnehmer & $\begin{array}{l}\text { Index- und } \\
\text { Referenztest }\end{array}$ & $\begin{array}{l}\text { Zielgröße und } \\
\text { Ergebnis }\end{array}$ & Bemerkungen & Evidenzgrad \\
\hline $\begin{array}{l}\text { Schmidt } \\
2011 \text { [96] }\end{array}$ & $\mathrm{RCT}$ & $\begin{array}{l}\mathrm{N}=137 \mathrm{~Pa}- \\
\text { tienten mit } \\
\text { unkomplizier- } \\
\text { ten und } \mathrm{N}=64 \\
\text { Patienten mit } \\
\text { komplizierten } \\
\text { Gallenblasen- } \\
\text { steinen }\end{array}$ & $\begin{array}{l}18 \text { - } 80 \text { Jahre, } \\
1991 \text { - } 1994\end{array}$ & $\begin{array}{l}\text { Cholezystek- } \\
\text { tomie (LC bei } \\
\text { unkomplzierter } \\
\text { Cholezystolithia- } \\
\text { sis) vs. konserva- } \\
\text { tive Behandlung }\end{array}$ & $\begin{array}{l}\text { Cholezystekto- } \\
\text { mie bei } 44 \% \\
\text { der konservativ } \\
\text { behandelten } \\
\text { Patienten, häu- } \\
\text { figer Krank- } \\
\text { heitsprogressi- } \\
\text { on (12,7\% vs. } \\
4,0 \% \text {, RR 0,32, } \\
95 \% \text { Cl } 0,11 \text { - } \\
0,93) \\
\text { Wiederaufnah- } \\
\text { me wegen bi- } \\
\text { liärer Schmer- } \\
\text { zen (5,1\% vs. } \\
18,6 \%, \text { RR } \\
0,33,95 \% \text { Cl } \\
0,06 \text { - 1,97) } \\
\text { und Mortalität } \\
(8,1 \% \text { vs. } \\
3,9 \% \text {, RR 2,20, } \\
95 \% \text { Cl } 0,25 \text { - } \\
19,39) \text { idem }\end{array}$ & $\begin{array}{l}\text { Studie wurde in } \\
\text { mindestens } 7 \\
\text { getrennten } \\
\text { Publikationen } \\
2002-2011 \text { ver- } \\
\text { öffentlicht, teil- } \\
\text { weise inkonsis- } \\
\text { tente Daten, } \\
\text { Krankenhausver- } \\
\text { weildauer nicht } \\
\text { angegeben }\end{array}$ & 1 \\
\hline
\end{tabular}


Empfehlung IIIB.3

\begin{tabular}{|c|c|c|c|c|c|c|c|}
\hline Referenz & Studientyp & Intervention & Teilnehmer & $\begin{array}{l}\text { Index- und } \\
\text { Referenztest }\end{array}$ & $\begin{array}{l}\text { Zielgröße und } \\
\text { Ergebnis }\end{array}$ & Bemerkungen & Evidenzgrad \\
\hline $\begin{array}{l}\text { Festi } 2008 \\
\text { [97] }\end{array}$ & $\begin{array}{l}\text { Fallserie, } \\
\text { prospektiv }\end{array}$ & $\begin{array}{l}\mathrm{N}=9611 \text { (4134 } \\
\text { Frauen, } 30-79 \\
\text { Jahre), italieni- } \\
\text { sche Population } \\
\text { multizentrisch, } \\
9517 \text { in der } \\
\text { Analyse }\end{array}$ & $\begin{array}{l}\text { keine Gallensteine } \\
\text { in der Sonografie }\end{array}$ & & $\begin{array}{l}\text { kumulative } \\
\text { Steininzidenz } \\
0,67 \% / J a h r \\
(0,66 \% \text { bei } \\
\text { Frauen, } 0,81 \% \\
\text { bei Frauen })\end{array}$ & 10 Jahre Follow-up & III \\
\hline $\begin{array}{l}\text { Festi } 2010 \\
{[98]}\end{array}$ & Fallserie & $\begin{array}{l}\mathrm{N}=11229 \text {, ita- } \\
\text { lienische Popu- } \\
\text { lation, } 856 \text { ein- } \\
\text { geschlossen, } \\
793 \text { mit abge- } \\
\text { schlossenem } \\
\text { Follow-up }\end{array}$ & $\begin{array}{l}\text { asymptomatische } \\
\text { Cholezystolithiasis }\end{array}$ & & $\begin{array}{l}856 \text { Gallenstein- } \\
\text { träger }(7,1 \%) \text {, } \\
\text { zum Einschluss } \\
580 \text { (73\%) } \\
\text { asymptoma- } \\
\text { tisch } \\
\text { am Ende des } \\
\text { Follow-ups } 453 \\
\text { (78\%) weiterhin } \\
\text { asymptoma- } \\
\text { tisch, } 61 \\
\text { (10,5\%) milde } \\
\text { Symptome, 66 } \\
\text { (11,4\%) schwe- } \\
\text { re Symptome } \\
\text { von initial } 94 \\
\text { Patienten (12\%) } \\
\text { mit milden } \\
\text { Symptomen } \\
\text { dann } 55 \text { (59\%) } \\
\text { asymptoma- } \\
\text { tisch, } 16 \text { (17\%) } \\
\text { stabil und } 23 \\
\text { (25\%) mit } \\
\text { schweren } \\
\text { Symptomen } \\
\text { von initial } 119 \\
\text { Patienten ( } 15 \%) \\
\text { mit schweren } \\
\text { Symptomen } \\
\text { dann } 62 \text { (52\%) } \\
\text { asymptoma- } \\
\text { tisch, } 20 \text { ( } 17 \%) \\
\text { mit milden } \\
\text { Symptomen } \\
\text { und } 37 \text { (31\%) } \\
\text { idem }\end{array}$ & $\begin{array}{l}\text { Follow-up im Mittel } \\
8,7 \text { Jahre } \\
\text { Cholezystektomie } \\
\text { kurz nach der Diag- } \\
\text { nose auch bei } \\
\text { asymptomatischen } \\
\text { Steinträgern }\end{array}$ & III \\
\hline
\end{tabular}


Empfehlung IIIB.4

\begin{tabular}{|c|c|c|c|c|c|c|c|}
\hline Referenz & Studientyp & Intervention & Teilnehmer & $\begin{array}{l}\text { Indextest und } \\
\text { Referenztest }\end{array}$ & $\begin{array}{l}\text { Zielgröße und } \\
\text { Ergebnis }\end{array}$ & Bemerkungen & Evidenzgrad \\
\hline $\begin{array}{l}\text { Khan } 2011 \\
\text { [99] }\end{array}$ & $\begin{array}{l}\text { retrospektive } \\
\text { Fallserie }\end{array}$ & $\begin{array}{l}\mathrm{N}=13 \text { aus } 1200 \\
\text { Cholezystekto- } \\
\text { mien }\end{array}$ & $\begin{array}{l}\text { Porzellangallen- } \\
\text { blase }\end{array}$ & - & $\begin{array}{l}\text { Karzinomrisiko } \\
\text { etwa 3\% }\end{array}$ & $\begin{array}{l}\text { wenige Patienten } \\
\text { mit Karzinom }\end{array}$ & III \\
\hline
\end{tabular}

Empfehlung IIIB.6

\begin{tabular}{|c|c|c|c|c|c|c|c|}
\hline Referenz & Studientyp & Intervention & Teilnehmer & $\begin{array}{l}\text { Indextest und } \\
\text { Referenztest }\end{array}$ & $\begin{array}{l}\text { Zielgröße und } \\
\text { Ergebnis }\end{array}$ & Bemerkungen & Evidenzgrad \\
\hline $\begin{array}{l}\text { Cha } 2011 \\
{[100]}\end{array}$ & $\begin{array}{l}\text { retrospektive } \\
\text { Fallserie }\end{array}$ & $\begin{array}{l}\mathrm{N}=210 \text { konse- } \\
\text { kutive asiati- } \\
\text { sche Patienten }\end{array}$ & $\mathrm{GBP} \geq 10 \mathrm{~mm}$ & - & $\begin{array}{l}64(30,5 \%) \\
\text { Neoplasie } \\
\text { Risikofaktoren: } \\
\geq 64 \text { Jahre (OR } \\
2,27), \text { Diabetes } \\
\text { (OR 2,64), GBP } \\
\geq 15 \text { mm (OR } \\
4,94)\end{array}$ & retrospektiv & III \\
\hline $\begin{array}{l}\text { Colecchia } \\
2009 \\
{[101]}\end{array}$ & $\begin{array}{l}\text { prospektiv, Fall- } \\
\text { Kontroll-Studie }\end{array}$ & $\begin{array}{l}\mathrm{N}=56 \mathrm{GBP} \\
\leq 10 \mathrm{~mm}, \mathrm{~N}=30 \\
\text { gematchte Gal- } \\
\text { lensteinträger, } \\
\mathrm{N}=30 \text { Kontrol- } \\
\text { len }\end{array}$ & $\mathrm{GBD} \leq 10 \mathrm{~mm}$ & $\begin{array}{l}\text { GPP } \leq 10 \mathrm{~mm} \\
\text { vs. Gallenstein }\end{array}$ & $\begin{array}{l}91 \% \text { keine } \\
\text { Veränderung } \\
\text { während } \\
\text { Follow-up }\end{array}$ & $\begin{array}{l}\text { Follow-up nur } 5 \\
\text { Jahre, größter } \\
\text { GBP } 8 \text { mm in } 2 \\
\text { Patienten }\end{array}$ & II \\
\hline $\begin{array}{l}\text { French } \\
2013 \\
{[102]}\end{array}$ & $\begin{array}{l}\text { retrospektiv, Fall- } \\
\text { Kontroll-Studie }\end{array}$ & $\begin{array}{l}\mathrm{N}=102740 \text { So- } \\
\text { nografiebefun- } \\
\text { de, } N=6.612 \\
\text { GBP } \\
\mathrm{N}=13278 \mathrm{~Pa}- \\
\text { thologiebefun- } \\
\text { de, } N=159 \mathrm{GBP}\end{array}$ & $\begin{array}{l}\text { Sonografie- und } \\
\text { Pathologiebefun- } \\
\text { de der } \\
\text { Gallenblase }\end{array}$ & $\begin{array}{l}\text { transkutane } \\
\text { Sonografie vs. } \\
\text { Histopathologie }\end{array}$ & $\begin{array}{l}\text { Sensitivität } \\
50 \%, \text { Spezifität } \\
98 \% \text {, PPV 10, } \\
\text { NPV } 100\end{array}$ & retrospektiv & III \\
\hline $\begin{array}{l}\text { Ito } 2009 \\
\text { [103] }\end{array}$ & $\begin{array}{l}\text { retrospektive Fall- } \\
\text { serie }\end{array}$ & $\begin{array}{l}\mathrm{N}=417 \mathrm{GBP}, \\
\mathrm{N}=94 \text { mit } \\
\text { abdominellen } \\
\text { Beschwerden, } \\
94 \% \mathrm{GBP} \\
\leq 10 \mathrm{~mm}, 7 \% \\
\mathrm{GBP}>10 \mathrm{~mm}\end{array}$ & $\begin{array}{l}\text { Patienten mit } \\
\text { sonografisch } \\
\text { detektierten GBP }\end{array}$ & - & $\begin{array}{l}\text { sonografisches } \\
\text { Polypenwachs- } \\
\text { tum bei } 8 / 143 \\
\text { Patienten (6\%) } \\
\text { Cholezystekto- } \\
\text { mie bei 80/143 } \\
\text { Patienten } \\
\text { (56\%): } 58 \% \\
\text { Pseudopolypen, } \\
32 \% \text { kein GBP, } \\
10 \% \text { neoplas- } \\
\text { tisch (Adenom), } \\
\text { nur } 1 \text { Patient } \\
\text { mit Tis }\end{array}$ & retrospektiv & III \\
\hline $\begin{array}{l}\text { Elmasry } \\
2016 \\
{[104]}\end{array}$ & $\begin{array}{l}\text { systematisches } \\
\text { Review }\end{array}$ & $\begin{array}{l}\mathrm{N}=5482 \text { Pati- } \\
\text { enten mit } \\
\text { sonografisch de- } \\
\text { tektierten GBP } \\
\text { in } 12 \text { Studien }\end{array}$ & & $\begin{array}{l}\text { Inzidenz und } \\
\text { Risikofaktoren } \\
\text { neoplastischer } \\
\text { und maligner GBP }\end{array}$ & $\begin{array}{l}\text { Inzidenz mali- } \\
\text { gner GBP 0,57\% } \\
\text { Risikofaktoren } \\
\text { für maligne } \\
\text { GBP: Größe } \\
\text { >6 mm, solitäre } \\
\text { GBP, sympto- } \\
\text { matische GBP, } \\
\text { Alter > } 60 \text { Jahre, } \\
\text { indianische Her- } \\
\text { kunft, Gallen- } \\
\text { steine, Chole- } \\
\text { zystitis }\end{array}$ & $\begin{array}{l}\text { Heterogenität } \\
\text { der Studien, un- } \\
\text { terschiedliche } \\
\text { Referenzstan- } \\
\text { dards }\end{array}$ & III \\
\hline
\end{tabular}




\begin{tabular}{|c|c|c|c|c|c|c|c|}
\hline Referenz & Studientyp & Intervention & Teilnehmer & $\begin{array}{l}\text { Indextest und } \\
\text { Referenztest }\end{array}$ & $\begin{array}{l}\text { Zielgröße und } \\
\text { Ergebnis }\end{array}$ & Bemerkungen & Evidenzgrad \\
\hline $\begin{array}{l}\text { Bhatt } \\
2016 \\
{[105]}\end{array}$ & $\begin{array}{l}\text { systematisches } \\
\text { Review }\end{array}$ & $\begin{array}{l}53 \text { Studien, da- } \\
\text { von Daten aus } \\
21 \text { Studien } \\
\text { gepoolt }\end{array}$ & & $\begin{array}{l}\text { Inzidenz und Risi- } \\
\text { kofaktoren neo- } \\
\text { plastischer und } \\
\text { maligner GBP } \\
\text { Algorithmus für } \\
\text { Management }\end{array}$ & $\begin{array}{l}\text { optimaler } \\
\text { Grenzwert für } \\
\text { Entfernung von } \\
\text { GBP } 10 \mathrm{~mm} \\
\text { Malignitätsrisi- } \\
\text { ko } 0 \text { bei Durch- } \\
\text { messer } \\
<4,15 \text { mm } \\
\text { unabhängige } \\
\text { Risikofaktoren } \\
\text { für Malignität: } \\
\text { Alter > } 50 \text { Jahre, } \\
\text { sessile und soli- } \\
\text { täre GBP }\end{array}$ & $\begin{array}{l}\text { Heterogenität } \\
\text { der Studien, un- } \\
\text { terschiedliche } \\
\text { Referenzstan- } \\
\text { dards }\end{array}$ & III \\
\hline $\begin{array}{l}\text { Wiles } \\
2014 \\
{[106]}\end{array}$ & $\begin{array}{l}\text { systematisches } \\
\text { Review }\end{array}$ & $\begin{array}{l}\mathrm{N}=1958 \text { aus } 10 \\
\text { Studien }\end{array}$ & $\begin{array}{l}\text { Medline und Em- } \\
\text { base Januar } 1976 \\
\text { - Januar } 2012\end{array}$ & $\begin{array}{l}\text { Wachstum von } \\
\text { GBP (Ultraschall- } \\
\text { kontrollen), Cho- } \\
\text { lezystektomie/ } \\
\text { Histologie }\end{array}$ & $\begin{array}{l}1 \text { - } 23 \% \text { der GBP } \\
\text { mit Wachstum } \\
\text { im Follow-up } \\
43 \text { neoplasti- } \\
\text { sche GBP, davon } \\
20 \text { maligne, da- } \\
\text { von mindestens } \\
7>10 \text { mm } \\
\text { mindestens } 7 \\
\text { maligne GBP } \\
<10 \text { mm, aber } \\
\text { keine Daten } \\
\text { zum Wachstum } \\
\text { im Follow-up }\end{array}$ & $\begin{array}{l}\text { unterschiedliche } \\
\text { Follow-up-Inter- } \\
\text { valle, unter- } \\
\text { schiedliche } \\
\text { Nachsorgezei- } \\
\text { ten, nur teilwei- } \\
\text { se Follow-up- } \\
\text { Daten für } \\
\text { maligne GBP }\end{array}$ & III \\
\hline
\end{tabular}

Empfehlungen I.2a und IIIB.7

\begin{tabular}{|c|c|c|c|c|c|c|c|}
\hline Referenz & Studientyp & Intervention & Teilnehmer & $\begin{array}{l}\text { Indextest und } \\
\text { Referenztest }\end{array}$ & $\begin{array}{l}\text { Zielgröße und } \\
\text { Ergebnis }\end{array}$ & Bemerkungen & Evidenzgrad \\
\hline Li 2009 [107] & $\begin{array}{l}\text { Fall-Kontroll-Stu- } \\
\text { die, retrospektiv }\end{array}$ & $\begin{array}{l}\text { Patienten, die } \\
\text { einen lap. } \\
\text { Roux-en-Y-By- } \\
\text { pass oder eine } \\
\text { Sleeve-Gast- } \\
\text { rektomie } \\
\text { erhielten }\end{array}$ & $\begin{array}{l}\mathrm{N}=496 \text { von } 670 \\
\text { Patienten By- } \\
\text { pass, } \mathrm{N}=52 \text { von } \\
79 \text { Patienten } \\
\text { Sleeve }\end{array}$ & $\begin{array}{l}\text { Sonografie, } \\
\text { MRT, CT }\end{array}$ & $\begin{array}{l}\text { höherer BMI in } \\
\text { der Sleeve- } \\
\text { Gruppe, kein } \\
\text { Unterschied } \\
\text { bei symptoma- } \\
\text { tischen Gallen- } \\
\text { steinen ( } 8,7 \text { vs. } \\
3,8 \% \text { und } \\
\text { komplizierten } \\
\text { Steinen ( } 1,8 \text { vs. } \\
1,9 \%)\end{array}$ & $\begin{array}{l}\text { retrospektiv, } \\
\text { Sonografie kann } \\
\text { bei adipösen } \\
\text { Patienten falsch- } \\
\text { negative Befun- } \\
\text { de ergeben, } \\
\text { unterschiedlich } \\
\text { langes Follow-up }\end{array}$ & III \\
\hline $\begin{array}{l}\text { Moon } 2014 \\
{[108]}\end{array}$ & $\begin{array}{l}\text { retrospektive } \\
\text { Kohorte }\end{array}$ & $\begin{array}{l}\mathrm{N}=937 \text { Patien- } \\
\text { ten, die bari- } \\
\text { atrisch operiert } \\
\text { wurden }\end{array}$ & $\begin{array}{l}\mathrm{N}=598 \text { lap. } \\
\text { Roux-en-Y- } \\
\text { Bypass, } \mathrm{N}=197 \\
\text { lap. Sleeve-Gast- } \\
\text { rektomie, } \\
\mathrm{N}=142 \text { lap. - } \\
\text { Magenband }\end{array}$ & & $\begin{array}{l}\text { symptomati- } \\
\text { sche Gallen- } \\
\text { steine bei 5,7, } \\
6,1 \text { und } 0 \% \text {, } \\
\text { kein Unter- } \\
\text { schied zwi- } \\
\text { schen Roux-en- } \\
\text { Y und Sleeve, } \\
\text { signifkante Un- } \\
\text { terschiede zwi- } \\
\text { schen Roux-en- } \\
\text { Y und Banding } \\
\text { sowie Sleeve } \\
\text { und Banding }\end{array}$ & $\begin{array}{l}\text { möglicherweise } \\
\text { weniger Gallen- } \\
\text { steine nach Ma- } \\
\text { genband wegen } \\
\text { geringerer Ge- } \\
\text { wichtsreduktion, } \\
\text { BMI prä OP } \\
\text { höher in Magen- } \\
\text { band-Gruppe, } \\
\text { mittleres Follow- } \\
\text { up zwischen } 11,6 \\
\text { und } 18,0 \text { Mona- } \\
\text { ten }\end{array}$ & III \\
\hline
\end{tabular}




\begin{tabular}{|c|c|c|c|c|c|c|c|}
\hline Referenz & Studientyp & Intervention & Teilnehmer & $\begin{array}{l}\text { Indextest und } \\
\text { Referenztest }\end{array}$ & $\begin{array}{l}\text { Zielgröße und } \\
\text { Ergebnis }\end{array}$ & Bemerkungen & Evidenzgrad \\
\hline $\begin{array}{l}\text { Plecka } \\
\text { Östlund } 2012 \\
\text { [109] }\end{array}$ & $\begin{array}{l}\text { Populationsko- } \\
\text { horte }\end{array}$ & $\begin{array}{l}\text { nationale } \\
\text { Datenbank } \\
1987-2008, \\
\mathrm{~N}=13443 \\
\text { Patienten mit } \\
\text { Adipositaschi- } \\
\text { rurgie }\end{array}$ & $\begin{array}{l}\text { Patienten mit } \\
\text { Adipositaschirur- } \\
\text { gie, bei denen } \\
\text { eine Cholezyst- } \\
\text { ektomie durch- } \\
\text { geführt wurde, } \\
\text { im Vergleich zu } \\
\text { Normalbevölke- } \\
\text { rung, Antireflux- } \\
\text { chirurgie und } \\
\text { Appendektomie }\end{array}$ & & $\begin{array}{l}\text { standardisierte } \\
\text { Inzidenzrate } \\
\text { für Cholezyst- } \\
\text { ektomie } \\
\text { SIR = 5,5 ( } 95 \% \\
\mathrm{CI}=5,1 \text { - } 5,8) \text {, } \\
\text { SIR für kompli- } \\
\text { zierte Gallen- } \\
\text { steine } 5,2 \text { (05\% } \\
\text { CI 4,7 - 5,7), } \\
\text { Cholezystekto- } \\
\text { mie bei Antire- } \\
\text { fluxchirurgie } \\
\text { 2,3 und bei } \\
\text { Appendekto- } \\
\text { mie 1,7 }\end{array}$ & $\begin{array}{l}\text { möglicherweise } \\
\text { Detektionsbias }\end{array}$ & II \\
\hline $\begin{array}{l}\text { Stokes } 2014 \\
\text { [110] }\end{array}$ & $\begin{array}{l}\text { systematisches } \\
\text { Review (Coch- } \\
\text { rane), Metaana- } \\
\text { lyse }\end{array}$ & $\begin{array}{l}13 \text { Studien, } \\
\text { nicht-chirurgi- } \\
\text { sche Interven- } \\
\text { tionen zur } \\
\text { Steinpräven- } \\
\text { tion unter } \\
\text { Gewichtsreduk- } \\
\text { tion, } 1836 \\
\text { Patienten }\end{array}$ & $\begin{array}{l}\geq 18 \text { Jahre, keine } \\
\text { Gallensteine zur } \\
\text { Baseline }\end{array}$ & $\begin{array}{l}\text { UDCA vs. } \\
\text { Plazebo }\end{array}$ & $\begin{array}{l}\text { UDC vermin- } \\
\text { dertes Steinri- } \\
\text { siko auf } 0,33 \\
\text { ( } 95 \% \text { CI } 0,18 \text { - } \\
0,60, \text { NNT 9), } \\
\text { bei Redukti- } \\
\text { onsdiät stärke- } \\
\text { rer Effekt } \\
(0,17,0,11 \text { - } \\
0,25) \text { als bei } \\
\text { Adipositaschi- } \\
\text { rurgie }(0,42 \text {, } \\
0,21-0,83) \text {, } \\
\text { auch Diät mit } \\
\text { hohem Fettge- } \\
\text { halt protektiv } \\
(0,09,0,01 \text { - } \\
0,61)\end{array}$ & & I \\
\hline $\begin{array}{l}\text { Tsirline } 2014 \\
\text { [111] }\end{array}$ & $\begin{array}{l}\text { retrospektive } \\
\text { Kohorte }\end{array}$ & $\begin{array}{l}\mathrm{N}=1.398 \\
\text { Patienten mit } \\
\text { Adipositas- } \\
\text { chirurgie }\end{array}$ & $\begin{array}{l}\mathrm{N}=879 \text { Roux-en- } \\
\text { Y-Bypass, } \\
\mathrm{N}=349 \text { Magen- } \\
\text { band, } \mathrm{N}=170 \\
\text { Sleeve }\end{array}$ & & $\begin{array}{l}\text { weniger Chole- } \\
\text { zystektomien } \\
\text { nach Roux-en-Y } \\
\text { als nach Sleeve } \\
\text { oder Banding }\end{array}$ & $\begin{array}{l}\text { medianes Follow- } \\
\text { up } 49 \text { Monate }\end{array}$ & III \\
\hline $\begin{array}{l}\text { Warschkow } \\
2013 \text { [112] }\end{array}$ & $\begin{array}{l}\text { systematisches } \\
\text { Review, Meta- } \\
\text { analyse }\end{array}$ & $\begin{array}{l}13 \text { Studien, } \\
6.048 \text { adipöse } \\
\text { Patienten mit } \\
\text { lap. Roux-en-Y- } \\
\text { Magen-Bypass } \\
\text { ohne Chole- } \\
\text { zystektomie }\end{array}$ & $\begin{array}{l}\text { lap. Roux-en-Y- } \\
\text { Magen-Bypass, } \\
\text { bei dem die Gal- } \\
\text { lenblase wäh- } \\
\text { rend der Adipo- } \\
\text { sitaschirurgie in } \\
\text { situ verbleibt }\end{array}$ & $\begin{array}{l}\text { lap. Roux-en-Y- } \\
\text { Magen-Bypass } \\
\text { ohne Chole- } \\
\text { zystektomie }\end{array}$ & $\begin{array}{l}6,8 \% \text { der Pa- } \\
\text { tienten }(95 \% \mathrm{Cl} \\
5,0-8,7) \text { wur- } \\
\text { den cholezyst- } \\
\text { ektomiert, } \\
5,3 \% \text { wegen } \\
\text { Koliken }\end{array}$ & $\begin{array}{l}\text { unterschiedli- } \\
\text { ches Studiende- } \\
\text { sign, variables } \\
\text { Follow-up }\end{array}$ & II \\
\hline
\end{tabular}


Empfehlungen IIIB.8

\begin{tabular}{|c|c|c|c|c|c|c|c|}
\hline Referenz & Studientyp & Intervention & Teilnehmer & $\begin{array}{l}\text { Index- und } \\
\text { Referenztest }\end{array}$ & $\begin{array}{l}\text { Zielgröße und } \\
\text { Ergebnis }\end{array}$ & Bemerkungen & $\begin{array}{l}\text { Evidenz- } \\
\text { grad }\end{array}$ \\
\hline $\begin{array}{l}\text { Gelbard } \\
2014 \text { [113] }\end{array}$ & $\begin{array}{l}\text { retrospektiv, Fall- } \\
\text { Kontroll-Studie }\end{array}$ & $\begin{array}{l}\mathrm{N}=144 \text { Pati- } \\
\text { enten mit } \\
\text { Diabetes, } 432 \\
\text { ohne Diabe- } \\
\text { tes (aus einer } \\
\text { Population } \\
\text { von } \mathrm{N}=2892 \\
\text { Patienten) }\end{array}$ & $\begin{array}{l}\text { LC wegen akuter } \\
\text { Cholezystitis }\end{array}$ & frühe vs. späte LC & $\begin{array}{l}\text { höheres Risiko } \\
\text { für Wundinfek- } \\
\text { tionen und län- } \\
\text { gere Kranken- } \\
\text { hausverweil- } \\
\text { dauer bei } \\
\text { später LC bei } \\
\text { Patienten mit } \\
\text { Diabetes }\end{array}$ & retrospektiv & III \\
\hline $\begin{array}{l}\text { Gul } 2013 \\
{[114]}\end{array}$ & $\mathrm{RCT}$ & $N=60$ & $\begin{array}{l}\text { akute Cholezysti- } \\
\text { tis (Symptome } \\
<72 \text { h) }\end{array}$ & $\begin{array}{l}\text { frühe vs. späte LC } \\
\text { (nach } 6-12 \text { Wo- } \\
\text { chen) }\end{array}$ & $\begin{array}{l}\text { Krankenhaus- } \\
\text { verweildauer } \\
4,8 \text { vs. } 10,1 \\
\text { Tage } \\
\text { Schmerzen } \\
\text { post-OP nach } 1 \\
\text { und } 12 \text { h bei } \\
\text { früher LC stär- } \\
\text { ker, nach } 24 \\
\text { und } 48 \text { h kein } \\
\text { Unterschied }\end{array}$ & $\begin{array}{l}\text { kleine Fallzahl, } \\
\text { keine } \mathrm{Cl}\end{array}$ & 1 \\
\hline $\begin{array}{l}\text { Gurusamy } \\
2013 \text { [115] }\end{array}$ & $\begin{array}{l}\text { systematisches } \\
\text { Review mit Meta- } \\
\text { analyse }\end{array}$ & $\begin{array}{l}\mathrm{N}=488 \text { in } 7 \\
\mathrm{RCT}\end{array}$ & $\begin{array}{l}\text { akute Cholezysti- } \\
\text { tis }\end{array}$ & $\begin{array}{l}\text { frühe LC (<7 Ta- } \\
\text { ge) vs. späte LC } \\
\text { (>6 Wo.) }\end{array}$ & $\begin{array}{l}\text { keine Unter- } \\
\text { schiede bei } \\
\text { Konversionsrate } \\
\text { und ernsten } \\
\text { Komplikationen } \\
\text { kürzere Auf- } \\
\text { nahmedauer } \\
\text { bei früher LC }\end{array}$ & $\begin{array}{l}\text { keine Verblin- } \\
\text { dung } \\
3 \text { Trials mit } \\
\text { hohem Risiko für } \\
\text { Bias } \\
\text { Power der RCT zu } \\
\text { niedrig }\end{array}$ & 1 \\
\hline $\begin{array}{l}\text { Gutt } 2013 \\
{[116]}\end{array}$ & $\mathrm{RCT}$ & $N=618$ & $\begin{array}{l}\text { akute Cholezysti- } \\
\text { tis }\end{array}$ & $\begin{array}{l}\text { frühe LC }(<24 \mathrm{~h} \\
\text { nach Aufnahme) } \\
(\mathrm{N}=304) \text { vs. An- } \\
\text { tibiotika (Moxi- } \\
\text { floxacin) + späte } \\
\text { LC ( } 7-45 \text { Tage) } \\
(\mathrm{N}=314)\end{array}$ & $\begin{array}{l}\text { in später Grup- } \\
\text { pe Morbidität } \\
(11,8 \text { vs. } \\
34,4 \%) \text {, Auf- } \\
\text { nahmedauer } \\
\text { und Kosten } \\
\text { höher } \\
\text { Konversionsra- } \\
\text { te und Mortali- } \\
\text { tät nicht unter- } \\
\text { schiedlich }\end{array}$ & multizentrisch & 1 \\
\hline $\begin{array}{l}\text { De Mestral } \\
2013 \text { [117] }\end{array}$ & $\begin{array}{l}\text { retrospektive } \\
\text { Kohortenstudie }\end{array}$ & $N=10034$ & $\begin{array}{l}\text { akute Cholezysti- } \\
\text { tis }\end{array}$ & $\begin{array}{l}\text { Gallenstein-asso- } \\
\text { ziierte Ereignisse }\end{array}$ & $\begin{array}{l}6 \text { Wochen: } 14 \% \\
12 \text { Wochen: } \\
19 \% \\
1 \text { Jahr: } 29 \%\end{array}$ & retrospektiv & III \\
\hline $\begin{array}{l}\text { Macafee } \\
2009[118]\end{array}$ & RCT & $N=72$ & $\begin{array}{l}\text { Patienten mit } \\
\text { akuter Cholezys- } \\
\text { titis oder biliärer } \\
\text { Kolik, die als Not- } \\
\text { fall aufgenom- } \\
\text { men wurden }\end{array}$ & $\begin{array}{l}\text { frühe LC ( }<72 \mathrm{~h} \\
\text { nach Aufnahme) } \\
\text { vs. späte LC (nach } \\
3 \text { Monaten) }\end{array}$ & $\begin{array}{l}\text { Wiederaufnah- } \\
\text { me bei } 3 / 36 \\
\text { ( } 8,3 \%) \text { Patien- } \\
\text { ten während } \\
\text { der Wartezeit } \\
\text { auf die späte LC } \\
\text { Krankenhaus- } \\
\text { verweildauer } \\
\text { 7,1 } \pm 4,5 \text { vs. } 7,1 \\
\pm 3,8 \text { Tage } \\
\text { QoL idem }\end{array}$ & $\begin{array}{l}\text { Anteil der Patien- } \\
\text { ten mit biliärer } \\
\text { Kolik unklar }\end{array}$ & 1 \\
\hline $\begin{array}{l}\text { Regimbeau } \\
2014 \text { [119] }\end{array}$ & $\mathrm{RCT}$ & $N=64$ & $\begin{array}{l}\text { akute Cholezysti- } \\
\text { tis }\end{array}$ & $\begin{array}{l}\text { späte Cholezyst- } \\
\text { ektomie }(\mathrm{N}=31) \\
\text { vs. Beobachtung } \\
(\mathrm{N}=33)\end{array}$ & $\begin{array}{l}\text { Cholezystekto- } \\
\text { mie: } 27 / 31 \text { in } \\
\text { der OP-Gruppe } \\
\text { vs. } 11 / 33 \text { in der }\end{array}$ & & I \\
\hline
\end{tabular}




\begin{tabular}{|c|c|c|c|c|c|c|c|}
\hline Referenz & Studientyp & Intervention & Teilnehmer & $\begin{array}{l}\text { Index- und } \\
\text { Referenztest }\end{array}$ & $\begin{array}{l}\text { Zielgröße und } \\
\text { Ergebnis }\end{array}$ & Bemerkungen & $\begin{array}{l}\text { Evidenz- } \\
\text { grad }\end{array}$ \\
\hline & & & & & $\begin{array}{l}\text { Watch-and- } \\
\text { wait-Gruppe } \\
\text { nach } 5 \text { Jahren } \\
\text { kein Unter- } \\
\text { schied bei } \\
\text { Komplikationen } \\
(P=0,565)\end{array}$ & & \\
\hline $\begin{array}{l}\text { Roulin } 2016 \\
{[120]}\end{array}$ & $\mathrm{RCT}$ & $N=86$ & $\begin{array}{l}\text { akute Cholezysti- } \\
\text { tis }\end{array}$ & $\begin{array}{l}\text { frühe }(<72 \text { h) vs. } \\
\text { späte Cholezyst- } \\
\text { ektomie }(>6 \\
\text { Wo.) }(\mathrm{N}=42)+ \\
\text { Antibiotika } \\
\text { (Amoxicillin + } \\
\text { Clavulansäure) } \\
(\mathrm{N}=44)\end{array}$ & $\begin{array}{l}\text { Morbidität } \\
\text { 14,3\% bei frü- } \\
\text { her und 38,6\% } \\
\text { bei später LC } \\
\text { ungeplante } \\
\text { Wiederaufnah- } \\
\text { men/Notauf- } \\
\text { nahmen 22,7\% } \\
\text { bei später } \\
\text { Gruppe } \\
\text { Komplikationen } \\
\text { post OP idem }\end{array}$ & $\begin{array}{l}213 \text { Patienten } \\
\text { ausgeschlossen, } \\
\text { davon } 127 \text { we- } \\
\text { gen Symptomen } \\
\text { > } 72 \text { h }\end{array}$ & I \\
\hline $\begin{array}{l}\text { Schmidt } \\
2011 \text { [121] }\end{array}$ & RCT & $N=64$ & $\begin{array}{l}\text { akute Cholezysti- } \\
\text { tis }\end{array}$ & $\begin{array}{l}\text { späte Cholezyst- } \\
\text { ektomie }(\mathrm{N}=31) \\
\text { vs. Beobachtung } \\
(\mathrm{N}=33)\end{array}$ & $\begin{array}{l}\text { Cholezystekto- } \\
\text { mie: } 27 / 31 \text { in } \\
\text { der OP-Gruppe } \\
\text { vs. } 10 / 33 \text { in der } \\
\text { Watch-and- } \\
\text { wait-Gruppe } \\
\text { ( } P<0,0001) \\
\text { kein Unter- } \\
\text { schied bei } \\
\text { Komplikationen } \\
\text { (10 vs. } 30 \% \text { ) }\end{array}$ & & I \\
\hline $\begin{array}{l}\text { Yadav } 2009 \\
\text { [122] }\end{array}$ & RCT & $N=50$ & $\begin{array}{l}\text { akute Cholezysti- } \\
\text { tis (Symptome } \\
<7 \text { Tage) }\end{array}$ & $\begin{array}{l}\text { frühe vs. späte LC } \\
\text { (nach 6-8 Wo- } \\
\text { chen) }\end{array}$ & $\begin{array}{l}\text { Krankenhaus- } \\
\text { verweildauer } \\
\text { kürzer: } 4,3 \pm 1,5 \\
\text { vs. 7,2 } \pm 1,6 \\
\text { Tage }\end{array}$ & $\begin{array}{l}\text { ein einziger } \\
\text { Chirurg für alle } \\
\text { Patienten }\end{array}$ & I \\
\hline
\end{tabular}

Empfehlung IIIB.9

\begin{tabular}{|c|c|c|c|c|c|c|c|}
\hline Referenz & Studientyp & Intervention & Teilnehmer & $\begin{array}{l}\text { Indextest und } \\
\text { Referenztest }\end{array}$ & $\begin{array}{l}\text { Zielgröße und } \\
\text { Ergebnis }\end{array}$ & Bemerkungen & Evidenzgrad \\
\hline $\begin{array}{l}\text { Deng } 2015 \\
{[123]}\end{array}$ & $\begin{array}{l}\text { retrospektive } \\
\text { Fallserie }\end{array}$ & $\begin{array}{l}\mathrm{N}=14369 \text { cho- } \\
\text { lezystektomier- } \\
\text { te asiatische } \\
\text { Patienten }\end{array}$ & $\begin{array}{l}\text { Gallenblasenprä- } \\
\text { parate } 2008 \text { - } \\
2013 \text { nach elekti- } \\
\text { ver Cholezystek- } \\
\text { tomie }\end{array}$ & - & $\begin{array}{l}\text { Prävalenz Gal- } \\
\text { lenblasenkarzi- } \\
\text { nom } 0,32 \%, \\
61 \% \text { Tis/T1a/ } \\
\text { T1b, ansonsten } \\
\text { bereits prä-OP } \\
\text { Verdacht }\end{array}$ & retrospektiv & III \\
\hline $\begin{array}{l}\text { Glauser } \\
2010[124]\end{array}$ & $\begin{array}{l}\text { retrospektive } \\
\text { Fallserie }\end{array}$ & $\begin{array}{l}\text { Schweizer Re- } \\
\text { gister: } \mathrm{N}=69 \\
\text { von } \mathrm{N}=89 \mathrm{~Pa}- \\
\text { tienten mit } \\
\text { Gallenblasen- } \\
\text { karzinom aus } \\
\mathrm{N}=30960\end{array}$ & $\begin{array}{l}\text { okkulte Gallen- } \\
\text { blasenkarzinome }\end{array}$ & $\begin{array}{l}\text { Re-Resektion mit } \\
\text { Gallenblasenbett } \\
\text { und Lymphaden- } \\
\text { ektomie vs. ein- } \\
\text { fache Cholezyst- } \\
\text { ektomie }\end{array}$ & $\begin{array}{l}\text { Inzidenz Gal- } \\
\text { lenblasenkarzi- } \\
\text { nom } 0,28 \% \\
\text { Re-Resektion } \\
\text { verbessert das } \\
\text { Überleben bei } \\
\text { T2/T3, jedoch } \\
\text { nicht bei T1b }\end{array}$ & & III \\
\hline
\end{tabular}




\begin{tabular}{|c|c|c|c|c|c|c|c|}
\hline Referenz & Studientyp & Intervention & Teilnehmer & $\begin{array}{l}\text { Indextest und } \\
\text { Referenztest }\end{array}$ & $\begin{array}{l}\text { Zielgröße und } \\
\text { Ergebnis }\end{array}$ & Bemerkungen & Evidenzgrad \\
\hline $\begin{array}{l}\text { Götze } 2008 \\
\text { [125] }\end{array}$ & $\begin{array}{l}\text { retrospektive } \\
\text { Fall-Kontroll-Stu- } \\
\text { die }\end{array}$ & $\begin{array}{l}\text { prospektives } \\
\text { Register okkul- } \\
\text { ter Gallenbla- } \\
\text { senkarzinome } \\
\mathrm{N}=83 \text { von } 502\end{array}$ & $\begin{array}{l}\text { Patienten mit } \\
\text { T1a/T1b-Karzi- } \\
\text { nomen }\end{array}$ & $\begin{array}{l}\text { sofortige Re-Re- } \\
\text { sektion vs. keine } \\
\text { Re-Resektion }\end{array}$ & $\begin{array}{l}\text { kein Vorteil bei } \\
5 \text { Patienten mit } \\
\text { T1a-Karzino- } \\
\text { men, die } \\
\text { re-reseziert } \\
\text { wurden, jedoch } \\
\text { bei } 23 \text { Patien- } \\
\text { ten mit T1b- } \\
\text { Karzinomen } \\
\text { Rezidiv danach } \\
\text { 3-mal seltener }\end{array}$ & & III \\
\hline $\begin{array}{l}\text { Hari } 2013 \\
{[126]}\end{array}$ & $\begin{array}{l}\text { retrospektive } \\
\text { Fallserie }\end{array}$ & $\begin{array}{l}\text { nationale Da- } \\
\text { tenbank USA } \\
\mathrm{N}=1115 \mathrm{~T} 1- \\
\text { Karzinome aus } \\
\mathrm{N}=2788 \mathrm{Gal}- \\
\text { lenblasenkarzi- } \\
\text { nomen }\end{array}$ & $\begin{array}{l}\text { Patienten mit } \\
\text { T1-Karzinomen }\end{array}$ & $\begin{array}{l}\text { Cholezystekto- } \\
\text { mie vs. Chole- } \\
\text { zystektomie + } \\
\text { Lymphadenekto- } \\
\text { mie/radikale Cho- } \\
\text { lezystektomie }\end{array}$ & $\begin{array}{l}25,8 \% \text { der Pa- } \\
\text { tienten nach } \\
\text { im Median } 22 \\
\text { Monaten ver- } \\
\text { storben } \\
\text { 5-Jahres-Über- } \\
\text { leben nach } \\
\text { Cholezystekto- } \\
\text { mie } 50 \%,+ \\
\text { Lymphadenek- } \\
\text { tomie } 70 \% \text { und } \\
\text { nach radikaler } \\
\text { OP } 79 \%\end{array}$ & $\begin{array}{l}\text { retrospektiv, } \\
44,2 \% \text { unbe- } \\
\text { kannte Todesur- } \\
\text { sachen, Komor- } \\
\text { biditäten unbe- } \\
\text { rücksichtigt }\end{array}$ & III \\
\hline $\begin{array}{l}\text { Lee } 2011 \\
{[127]}\end{array}$ & $\begin{array}{l}\text { systematisches } \\
\text { Review von } \\
\text { retrospektiven } \\
\text { Studien }\end{array}$ & $\begin{array}{l}29 \text { Studien } \\
\text { (Englisch) aus } \\
2312 \text { potenzi- } \\
\text { ellen Artikeln } \\
\mathrm{N}=1266 \text { mit } \\
\text { Gallenblasen- } \\
\text { karzinom, } \\
\text { davon } \mathrm{N}=706 \\
\mathrm{~T} 1 \text { a und } \\
\mathrm{N}=560 \mathrm{~T} 1 \mathrm{~b}\end{array}$ & $\begin{array}{l}\text { histopatholo- } \\
\text { gisch gesicherte } \\
\text { T1a/T1b-Karzi- } \\
\text { nome, chirurgi- } \\
\text { sche Interventio- } \\
\text { nen beschrieben }\end{array}$ & - & $\begin{array}{l}\text { einfache Cho- } \\
\text { lezystektomie } \\
\text { bei } N=590 \text { T1a } \\
\text { und } N=375 \\
\text { T1b } \\
\text { 5-Jahres-Über- } \\
\text { leben bei T1a } \\
100 \% \\
\text { Lymphknoten- } \\
\text { metatstasen: } \\
\text { T1a 1,8\%, T1b } \\
10,9 \% \\
1,1 \% \text { der Pa- } \\
\text { tienten mit } \\
\text { T1a-Karzinom } \\
\text { und 9,3\% der } \\
\text { Patienten mit } \\
\text { T1b-Karzinom } \\
\text { verstorben }\end{array}$ & $\begin{array}{l}\text { OP bei T1b noch } \\
\text { unklar }\end{array}$ & III \\
\hline $\begin{array}{l}\text { Swank } 2013 \\
{[128]}\end{array}$ & $\begin{array}{l}\text { systematisches } \\
\text { Review und } \\
\text { Metaanalyse }\end{array}$ & $\begin{array}{l}\mathrm{N}=30 \text { Artikel, } \\
\text { davon } 20 \text { euro- } \\
\text { päische und } 10 \\
\text { asiatische Ko- } \\
\text { horten }\end{array}$ & $\begin{array}{l}\text { Auswertung der } \\
\text { Ergebnisse von } \\
\text { Routine- Histo- } \\
\text { pathologie-Be- } \\
\text { funden }\end{array}$ & - & $\begin{array}{l}\text { mediane Präva- } \\
\text { lenz Gallenbla- } \\
\text { senkarzinome } \\
\text { Europa } 0,4 \% \text {, } \\
65 \% \text { Verdacht } \\
\text { prä- oder post- } \\
\text { OP, } 72 \% \text { der } \\
\text { Patienten } \\
\text { erhielten keine } \\
\text { weitere Be- } \\
\text { handlung }\end{array}$ & $\begin{array}{l}\text { retrospektive } \\
\text { Studien einge- } \\
\text { schlossen, oft } \\
\text { unvollständige } \\
\text { Daten und unzu- } \\
\text { reichende Be- } \\
\text { schreibung der } \\
\text { Methoden }\end{array}$ & II \\
\hline $\begin{array}{l}\text { Tantia } 2009 \\
\text { [129] }\end{array}$ & $\begin{array}{l}\text { retrospektive } \\
\text { Fallserie }\end{array}$ & $\begin{array}{l}\mathrm{N}=3205 \\
\text { konsekutive } \\
\text { Patienten }\end{array}$ & $\begin{array}{l}\text { Patienten, die } \\
\text { eine } L C \text { erhielten }\end{array}$ & - & $\begin{array}{l}\text { Inzidenz Gal- } \\
\text { lenblasenkarzi- } \\
\text { nom 19/ } \\
3205=0,59 \% \text {, } \\
\text { Durchschnitts- } \\
\text { alter } 56 \text { Jahre } \\
\text { alle T1/T2 }\end{array}$ & $\begin{array}{l}2 \text { Patienten Loss } \\
\text { to follow-up }\end{array}$ & III \\
\hline
\end{tabular}




\begin{tabular}{|c|c|c|c|c|c|c|c|}
\hline Referenz & Studientyp & Intervention & Teilnehmer & $\begin{array}{l}\text { Indextest und } \\
\text { Referenztest }\end{array}$ & $\begin{array}{l}\text { Zielgröße und } \\
\text { Ergebnis }\end{array}$ & Bemerkungen & Evidenzgrad \\
\hline $\begin{array}{l}\text { van Vliet } \\
2013 \text { [130] }\end{array}$ & $\begin{array}{l}\text { retrospektive } \\
\text { Fallserie }\end{array}$ & $N=1375$ & $\begin{array}{l}\text { Patienten, die } \\
\text { eine Cholezyst- } \\
\text { ektomie erhiel- } \\
\text { ten }\end{array}$ & - & $\begin{array}{l}0,4 \% \text { Gallen- } \\
\text { blasenkarzino- } \\
\text { me, alle mit } \\
\text { makroskopi- } \\
\text { schen Befun- } \\
\text { den }\end{array}$ & $\begin{array}{l}\text { retrospektiv, } \\
\text { monozentrisch }\end{array}$ & III \\
\hline $\begin{array}{l}\text { Yoon } 2014 \\
{[131]}\end{array}$ & $\begin{array}{l}\text { retrospektiv, Fall- } \\
\text { Kontroll-Studie }\end{array}$ & $\begin{array}{l}\text { N= } 54 \text { T1b aus } \\
895 \text { Patienten } \\
\text { mit Gallenbla- } \\
\text { senkarzinomen }\end{array}$ & T1b-Karzinome & $\begin{array}{l}\text { einfache Chole- } \\
\text { zystektomie } \\
(\mathrm{N}=36) \text { vs. } \\
\text { erweiterte Cho- } \\
\text { lezystektomie } \\
(\mathrm{N}=36)\end{array}$ & $\begin{array}{l}\text { 5-Jahres-Über- } \\
\text { leben idem, } \\
\text { jedoch } \\
\text { Lymphknoten- } \\
\text { metastasen } \\
\text { nach einfacher } \\
\text { Cholezystekto- } \\
\text { mie }\end{array}$ & asiatische Studie & III \\
\hline $\begin{array}{l}\text { You } 2008 \\
{[132]}\end{array}$ & $\begin{array}{l}\text { retrospektiv, Fall- } \\
\text { Kontroll-Studie }\end{array}$ & $\begin{array}{l}\mathrm{N}=52 \text { aus } 290 \\
\text { Patienten mit } \\
\text { Gallenblasen- } \\
\text { karzinomen }\end{array}$ & $\begin{array}{l}\text { Patienten mit } \\
\text { T1a }(\mathrm{N}=27) \text { und } \\
\text { T1b-Karzinomen } \\
(\mathrm{N}=25)\end{array}$ & - & $\begin{array}{l}\text { kein Unter- } \\
\text { schied bei lo- } \\
\text { koregionärem } \\
\text { Rezidiv, Metas- } \\
\text { tasen oder } \\
\text { Überleben mit } \\
\text { oder ohne Le- } \\
\text { berresektion }\end{array}$ & $\begin{array}{l}\text { retrospektiv, } \\
\text { kleine Fallzahl, } \\
\text { Follow-up 3- } \\
145 \text { Monate } \\
\text { (Median 37,5) }\end{array}$ & III \\
\hline $\begin{array}{l}\text { Zhang } 2009 \\
\text { [133] }\end{array}$ & $\begin{array}{l}\text { retrospektive } \\
\text { Fallserie }\end{array}$ & $\begin{array}{l}\text { unter } \\
\mathrm{N}=10466 \mathrm{~Pa}- \\
\text { tienten mit LC } \\
20 \text { Gallenbla- } \\
\text { senkarzinomen }\end{array}$ & $\begin{array}{l}\text { Patienten mit } \\
\text { Gallenblasenkar- } \\
\text { zinomen }\end{array}$ & - & $\begin{array}{l}\text { Inzidenz okkul- } \\
\text { ter Karzinome } \\
0,19 \% \\
\text { Überleben } \\
\text { idem zwischen } \\
\text { intra- und } \\
\text { postoperativ } \\
\text { entdeckten } \\
\text { Karzinomen }\end{array}$ & kleine Fallzahl & III \\
\hline
\end{tabular}

Empfehlung IIIB.10

\begin{tabular}{|c|c|c|c|c|c|c|c|}
\hline Referenz & Studientyp & Intervention & Teilnehmer & $\begin{array}{l}\text { Indextest und } \\
\text { Referenztest }\end{array}$ & $\begin{array}{l}\text { Zielgröße und } \\
\text { Ergebnis }\end{array}$ & Bemerkungen & Evidenzgrad \\
\hline $\begin{array}{l}\text { Fuks } 2011 \\
{[134]}\end{array}$ & $\begin{array}{l}\text { retrospektive } \\
\text { Fallserie }\end{array}$ & $\begin{array}{l}\text { französisches } \\
\text { Register: } \\
\mathrm{N}=218 \mathrm{~Pa}- \\
\text { tienten mit } \\
\text { Gallenblasen- } \\
\text { karzinom }\end{array}$ & $\begin{array}{l}\text { Patienten mit } \\
\text { okkulten Gallen- } \\
\text { blasenkarzino- } \\
\text { men }\end{array}$ & - & $\begin{array}{l}\text { Resektion ver- } \\
\text { bessert das } \\
\text { Überleben bei } \\
\text { T2/T3 } \\
\text { CBD-Resektion } \\
\text { verbessert das } \\
\text { Überleben } \\
\text { nicht, erhöht } \\
\text { jedoch die } \\
\text { postoperati- } \\
\text { ven Komplika- } \\
\text { tionen }\end{array}$ & retrospektiv & III \\
\hline $\begin{array}{l}\text { Fuks } 2013 \\
{[135]}\end{array}$ & $\begin{array}{l}\text { retrospektive } \\
\text { Fall-Kontroll- } \\
\text { Studie }\end{array}$ & $\begin{array}{l}\text { französisches } \\
\text { Register: } \\
\mathrm{N}=218 \mathrm{~Pa}- \\
\text { tienten mit } \\
\text { Gallenblasen- } \\
\text { karzinom, } \\
\mathrm{N}=148 \mathrm{Re}-\mathrm{Re}- \\
\text { sektionen }\end{array}$ & $\begin{array}{l}\text { okkulte Gallen- } \\
\text { blasenkarzino- } \\
\text { me, die einer } \\
\text { kurativen Re-Re- } \\
\text { sektion unterzo- } \\
\text { gen wurden }\end{array}$ & $\begin{array}{l}\text { Trokarsite-Re- } \\
\text { sektion }(\mathrm{N}=54) \\
\text { vs. ohne }(\mathrm{N}=94)\end{array}$ & $\begin{array}{l}\mathrm{N}=54 \text { mit Re- } \\
\text { sektion der } \\
\text { Trokarsite, } \\
\mathrm{N}=94 \text { keine } \\
\text { Metastasen } \\
\text { nur bei } 1 \mathrm{~Pa}- \\
\text { tient mit T3- } \\
\text { Tumor }\end{array}$ & $\begin{array}{l}\text { retrospektiv, } \\
\text { kleine Fallzahl }\end{array}$ & III \\
\hline
\end{tabular}




\begin{tabular}{|c|c|c|c|c|c|c|c|}
\hline Referenz & Studientyp & Intervention & Teilnehmer & $\begin{array}{l}\text { Indextest und } \\
\text { Referenztest }\end{array}$ & $\begin{array}{l}\text { Zielgröße und } \\
\text { Ergebnis }\end{array}$ & Bemerkungen & Evidenzgrad \\
\hline & & & & & $\begin{array}{l}\text { keine Verbes- } \\
\text { serung des } \\
\text { Überlebens } \\
8 \% \text { Hernie }\end{array}$ & & \\
\hline $\begin{array}{l}\text { Glauser } \\
2010 \text { [124] }\end{array}$ & $\begin{array}{l}\text { retrospektive } \\
\text { Fallserie }\end{array}$ & $\begin{array}{l}\text { Schweizer } \\
\text { Register: } \\
\mathrm{N}=69 \text { von } \\
\mathrm{N}=89 \text { Patien- } \\
\text { ten mit Gallen- } \\
\text { blasenkarzi- } \\
\text { nom aus } \\
\mathrm{N}=30960\end{array}$ & $\begin{array}{l}\text { okkulte Gallen- } \\
\text { blasenkarzinome }\end{array}$ & $\begin{array}{l}\text { Re-Resektion } \\
\text { mit Gallenbla- } \\
\text { senbett und } \\
\text { Lymphadenek- } \\
\text { tomie vs. einfa- } \\
\text { che Cholezyst- } \\
\text { ektomie }\end{array}$ & $\begin{array}{l}\text { Inzidenz Gal- } \\
\text { lenblasenkarzi- } \\
\text { nom } 0,28 \% \\
\text { Re-Resektion } \\
\text { verbessert das } \\
\text { Überleben bei } \\
\text { T2/T3, jedoch } \\
\text { nicht bei T1b }\end{array}$ & & III \\
\hline $\begin{array}{l}\text { Götze } 2008 \\
\text { [136] }\end{array}$ & $\begin{array}{l}\text { retrospektive } \\
\text { Fall-Kontroll- } \\
\text { Studie }\end{array}$ & $\begin{array}{l}\text { prospektives } \\
\text { Register okkul- } \\
\text { ter Gallenbla- } \\
\text { senkarzinome } \\
\mathrm{N}=439\end{array}$ & $\begin{array}{l}\text { Patienten mit } \geq \\
\text { T2-Karzinomen } \\
\text { Re-Resektionen } \\
\text { bei } 85 \text { von } 200 \\
\text { T2-Karzinomen, } \\
32 \text { von } 85 \text { T3- } \\
\text { Karzinomen und } \\
6 \text { von } 33 \text { T4- } \\
\text { Karzinomen }\end{array}$ & $\begin{array}{l}\text { sofortige Re-Re- } \\
\text { sektion vs. keine } \\
\text { Re-Resektion }\end{array}$ & $\begin{array}{l}\text { Anstieg des 5- } \\
\text { Jahres-Überle- } \\
\text { bens für T2- } \\
\text { Karzinome bei } \\
\text { Re-Resektion } \\
\text { von } 35 \% \text { auf } \\
55 \% \text {, nicht } \\
\text { weiter für T3/ } \\
\text { T4-Karzinome }\end{array}$ & & III \\
\hline $\begin{array}{l}\text { Maker } 2012 \\
\text { [137] }\end{array}$ & $\begin{array}{l}\text { retrospektive } \\
\text { Fall-Kontroll- } \\
\text { Studie }\end{array}$ & $\begin{array}{l}\mathrm{N}=113 \mathrm{~Pa}- \\
\text { tienten } 1992- \\
2009\end{array}$ & $\begin{array}{l}\text { okkulte Gallen- } \\
\text { blasenkarzino- } \\
\text { me nach LC, die } \\
\text { einer chirurgi- } \\
\text { schen Re-Resek- } \\
\text { tion unterzogen } \\
\text { wurden }\end{array}$ & $\begin{array}{l}\text { Trokarsite-Re- } \\
\text { sektion }(\mathrm{N}=44) \\
\text { vs. ohne }(\mathrm{N}=44)\end{array}$ & $\begin{array}{l}\text { Trokarsite-Me- } \\
\text { tastasen (Inzi- } \\
\text { denz 19\%) nur } \\
\text { bei T2/T3 mit } \\
\text { peritonealen } \\
\text { Metastasen } \\
\text { korreliert } \\
\text { Überleben bei } \\
\text { Tumorrezidiv } \\
\text { idem }\end{array}$ & & III \\
\hline
\end{tabular}

Empfehlung IIIB.11 und I.1

\begin{tabular}{|c|c|c|c|c|c|c|c|}
\hline Referenz & Studientyp & Intervention & Teilnehmer & $\begin{array}{l}\text { Index- und } \\
\text { Referenztest }\end{array}$ & $\begin{array}{l}\text { Zielgröße und } \\
\text { Ergebnis }\end{array}$ & Bemerkungen & Evidenzgrad \\
\hline Ко 2014 [75] & $\begin{array}{l}\text { randomisierte } \\
\text { Studie }\end{array}$ & $\begin{array}{l}45-60 \text { Minuten } \\
\text { Trainingseinhei- } \\
\text { ten }(4-5 x / \text { Wo. }) \\
\text { vs. keine Inter- } \\
\text { vention }\end{array}$ & $\begin{array}{l}\mathrm{N}=1196(\mathrm{~N}=605 \\
\text { vs. } \mathrm{N}=591) \\
\text { schwangeren } \\
\text { Frauen } \\
\text { (<SSW 20, 18-45 } \\
\text { Jahre) }\end{array}$ & $\begin{array}{l}\text { 1. Sludge und } \\
\text { Gallensteine } \\
\text { (Sonografie) } \\
\text { 2. Serumlipide, } \\
\text { Insulin, Leptin- } \\
\text { und Adiponek- } \\
\text { tin- Konzentra- } \\
\text { tionen im Blut }\end{array}$ & $\begin{array}{l}\text { 1. kein Unter- } \\
\text { schied zwischen } \\
\text { den Gruppen be- } \\
\text { züglich Sludge } \\
\text { oder Gallenstei- } \\
\text { nen ( } 7,8 \text { vs. } \\
8,2 \%) \\
2 . \text { ähnliche Kon- } \\
\text { zentrationen von } \\
\text { Insulin, Leptin } \\
\text { und Adiponek- } \\
\text { tin, Gesamtcho- } \\
\text { lesterin niedriger } \\
\text { und LDL-Choles- } \\
\text { terin höher in } \\
\text { der Interventi- } \\
\text { onsgruppe }\end{array}$ & & 1 \\
\hline
\end{tabular}


Empfehlung IIIB.12

\begin{tabular}{|c|c|c|c|c|c|c|c|}
\hline Referenz & Studientyp & Intervention & Teilnehmer & $\begin{array}{l}\text { Index- und } \\
\text { Referenztest }\end{array}$ & $\begin{array}{l}\text { Zielgröße und } \\
\text { Ergebnis }\end{array}$ & Bemerkungen & Evidenzgrad \\
\hline $\begin{array}{l}\text { Gurusamy } \\
2013 \text { [138] }\end{array}$ & $\begin{array}{l}\text { systemati- } \\
\text { sches Review } \\
\text { (Cochrane) }\end{array}$ & $\begin{array}{l}12 \text { RCT mit } 380 \\
\text { und } 351 \text { Patien- } \\
\text { ten }\end{array}$ & $\begin{array}{l}\text { symptomatische } \\
\text { Cholezystolithiasis }\end{array}$ & LC vs. Mini-LC & $\begin{array}{l}\text { kein Unterschied } \\
\text { bei Mortalität, } \\
\text { Morbidität, Kran- } \\
\text { kenhausaufenthalt, } \\
\text { Wiederaufnahme } \\
\text { der Arbeit oder } \\
\text { kosmetischen Er- } \\
\text { gebnissen } \\
\text { moderater } \\
\text { Anstieg der OP- } \\
\text { Zeiten bei Mini- } \\
\text { ports, weitere Da- } \\
\text { ten zur Sicherheit } \\
\text { notwendig }\end{array}$ & $\begin{array}{l}\text { nur RCT mit } \\
\text { niedrigem } \\
\text { Risiko für Bias }\end{array}$ & II \\
\hline $\begin{array}{l}\text { Milas } 2014 \\
\text { [139] }\end{array}$ & $\begin{array}{l}\text { systematisches } \\
\text { Review mit } \\
\text { Metaanalyse }\end{array}$ & $\begin{array}{l}\mathrm{N}=30 \text { RCT mit } \\
2411 \text { Patienten }\end{array}$ & $\begin{array}{l}\text { Patienten mit } \\
\text { unkomplizierter } \\
\text { symptomatischer } \\
\text { Cholelithiasis }\end{array}$ & $\begin{array}{l}\operatorname{SILC}(N=1209) \\
\text { vs. LC }(N=1202)\end{array}$ & $\begin{array}{l}\text { längere OP-Dauer, } \\
\text { aber mit zuneh- } \\
\text { mender Erfahrung } \\
\text { sinkend, größerer } \\
\text { Blutverlust, aber } \\
\text { praktisch irrelevant } \\
\text { kein Unterschied } \\
\text { bei Schmerzen } \\
\text { post OP, Kranken- } \\
\text { hausdauer und } \\
\text { Komplikationen } \\
\text { bei unverblindeten } \\
\text { Patienten bessere } \\
\text { kosmetische Erge- } \\
\text { bisse, bei Verblin- } \\
\text { dung kein Unter- } \\
\text { schied }\end{array}$ & $\begin{array}{l}\text { die meisten Stu- } \\
\text { dien von niedri- } \\
\text { ger bis mittlerer } \\
\text { Qualität }\end{array}$ & II \\
\hline
\end{tabular}

Empfehlung IIIB.14

\begin{tabular}{|c|c|c|c|c|c|c|c|}
\hline Referenz & Studientyp & Intervention & Teilnehmer & $\begin{array}{l}\text { Indextest und } \\
\text { Referenztest }\end{array}$ & $\begin{array}{l}\text { Zielgröße und } \\
\text { Ergebnis }\end{array}$ & Bemerkungen & Evidenzgrad \\
\hline $\begin{array}{l}\text { Keizman } \\
2007 \text { [140] }\end{array}$ & $\begin{array}{l}\text { retrospektive } \\
\text { Fall-Kontroll-Studie }\end{array}$ & $N=228$ & $\begin{array}{l}\text { ERC wegen V.a. } \\
\text { Choledocholithiasis }\end{array}$ & ERC & $\begin{array}{l}\text { Sludge in den } \\
\text { Gallengängen } \\
\text { bei } 14 \% \text {, v. a. bei } \\
\text { Frauen } \\
\text { Rezidivsteine bei } \\
17 \% \text { der Patien- } \\
\text { ten mit CBD- } \\
\text { Steinen und bei } \\
16 \% \text { der } \\
\text { Patienten mit } \\
\text { Sludge } \\
\text { keine anderen } \\
\text { Risikofaktoren }\end{array}$ & $\begin{array}{l}\text { Follow-up } 36 \\
\pm 19 \text { Monate }\end{array}$ & III \\
\hline $\begin{array}{l}\text { Lee } 2015 \\
{[141]}\end{array}$ & $\begin{array}{l}\text { retrospektiv, } \\
\text { Fallserie }\end{array}$ & $N=58$ & $\begin{array}{l}\text { Patienten mit } \\
\text { Bauchschmerzen } \\
\text { und Sludge in der } \\
\text { Sonografie }\end{array}$ & - & $\begin{array}{l}16 \% \text { akute Cho- } \\
\text { lezystitis } \\
16 \% \text { akute Cho- } \\
\text { langitis } \\
18 \% \text { Pankreatitis }\end{array}$ & kleine Fallzahl & III \\
\hline
\end{tabular}


Empfehlung IIIB.15

\begin{tabular}{|c|c|c|c|c|c|c|c|}
\hline Referenz & Studientyp & Intervention & Teilnehmer & $\begin{array}{l}\text { Indextest und } \\
\text { Referenztest }\end{array}$ & $\begin{array}{l}\text { Zielgröße und } \\
\text { Ergebnis }\end{array}$ & Bemerkungen & Evidenzgrad \\
\hline $\begin{array}{l}\text { Alvarez } 2014 \\
{[142]}\end{array}$ & $\begin{array}{l}\text { retrospektive } \\
\text { Fallserie }\end{array}$ & $\begin{array}{l}\mathrm{N}=11423 \mathrm{~Pa}- \\
\text { tienten mit } \mathrm{LC} \\
+\mathrm{IOC}\end{array}$ & $\begin{array}{l}\text { alle Patienten } \\
\text { mit Gallengang- } \\
\text { verletzung }\end{array}$ & $\begin{array}{l}\text { IOC vs. ERC oder } \\
\text { MRCP }\end{array}$ & $\begin{array}{l}\text { Sensitivität } \\
79 \% \text {, Spezifität } \\
100 \%\end{array}$ & $\begin{array}{l}\text { Strassberg-Klas- } \\
\text { sifikation }\end{array}$ & III \\
\hline $\begin{array}{l}\text { De Reuver } \\
2007 \text { [143] }\end{array}$ & $\begin{array}{l}\text { prospektive } \\
\text { Kohortenstudie }\end{array}$ & $N=500$ & $\begin{array}{l}\text { Patienten mit } \\
\text { Gallengangver- } \\
\text { letzung }\end{array}$ & $\begin{array}{l}\text { multidisziplinäre } \\
\text { Behandlung }\end{array}$ & $\begin{array}{l}\text { 10-Jahres- } \\
\text { Überleben un- } \\
\text { terscheidet sich } \\
\text { nicht von der } \\
\text { gesunden } \\
\text { Bevölkerung } \\
\text { Gallengangver- } \\
\text { letzungen sind } \\
\text { mit schwerer } \\
\text { Morbidität und } \\
\text { hohem Scha- } \\
\text { densersatz ver- } \\
\text { bunden } \\
\text { positive Effekte } \\
\text { bei Behandlung } \\
\text { durch multidis- } \\
\text { ziplinäres Team }\end{array}$ & $\begin{array}{l}\text { ausschließlich } \\
\text { universitäres } \\
\text { Zentrum }\end{array}$ & III \\
\hline $\begin{array}{l}\text { De Reuver } \\
2007 \text { [144] }\end{array}$ & $\begin{array}{l}\text { retrospektive } \\
\text { Fallserie }\end{array}$ & $\begin{array}{l}\mathrm{N}=151 \text { von } \\
500 \text { Patienten }\end{array}$ & $\begin{array}{l}\text { Patienten mit } \\
\text { Gallengangver- } \\
\text { letzungen, die } \\
\text { chirurgisch } \\
\text { rekonstruiert } \\
\text { wurden }\end{array}$ & $\begin{array}{l}\text { Roux-en-Y-jeju- } \\
\text { nostomie }\end{array}$ & $\begin{array}{l}\text { ausgedehnte } \\
\text { Gallengangver- } \\
\text { letzung (OR } \\
3,70,95 \% \mathrm{Cl} \\
1,32-10,34) \text {, } \\
\text { sekundäre Zu- } \\
\text { weisung (OR } \\
4,35,95 \% \mathrm{Cl} \\
1,12-16,76) \\
\text { und Revision in } \\
\text { der akuten } \\
\text { Phase nach } \\
\text { Gallengangver- } \\
\text { letzung (OR } \\
\text { 5,44, 95\% Cl } \\
\text { 1.20 - } 24,43 \text { ) } \\
\text { unabhängige } \\
\text { negative Prä- } \\
\text { diktoren für } \\
\text { das Ergebnis } \\
\text { nach rekons- } \\
\text { truktiven Ein- } \\
\text { griffen }\end{array}$ & $\begin{array}{l}\text { universitäres } \\
\text { Zentrum }\end{array}$ & III \\
\hline $\begin{array}{l}\text { Ejaz } 2014 \\
{[145]}\end{array}$ & Kohortenstudie & $N=167$ & $\begin{array}{l}\text { Behandlung } \\
\text { schwerer Gallen- } \\
\text { gangverletzun- } \\
\text { gen (Lazeratio- } \\
\text { nen und } \\
\text { Transektionen) }\end{array}$ & $\begin{array}{l}\text { kombinierte Fra- } \\
\text { gebögen SF-36 } \\
\text { und GIQLI }\end{array}$ & $\begin{array}{l}\text { Rücklaufquote } \\
37 \% \\
\text { depressive Ver- } \\
\text { stimmung bei } \\
49 \% \text { und Kraft- } \\
\text { losigkeit bei } \\
40 \%\end{array}$ & $\begin{array}{l}\text { medianes Fol- } \\
\text { low-up } 169 \text { Mo- } \\
\text { nate, niedrige } \\
\text { Rücklaufquote }\end{array}$ & ॥ \\
\hline $\begin{array}{l}\text { Eikermann } \\
2012 \text { [146] }\end{array}$ & $\begin{array}{l}\text { systematisches } \\
\text { Review in Richt- } \\
\text { linie }\end{array}$ & $\begin{array}{l}671 \text { Studien, } \\
\text { davon } 18 \text { RCT }\end{array}$ & $\begin{array}{l}\text { erwachsene Pa- } \\
\text { tienten mit einer } \\
\text { Gallengangver- } \\
\text { letzung während } \\
\text { der LC } \\
<20 \% \text { der Pa- } \\
\text { tienten hatten } \\
\text { eine offene Cho- } \\
\text { lezystektomie, }\end{array}$ & & & $\begin{array}{l}\text { europäische } \\
\text { Richtlinie }\end{array}$ & II \\
\hline
\end{tabular}




\begin{tabular}{|c|c|c|c|c|c|c|c|}
\hline Referenz & Studientyp & Intervention & Teilnehmer & $\begin{array}{l}\text { Indextest und } \\
\text { Referenztest }\end{array}$ & $\begin{array}{l}\text { Zielgröße und } \\
\text { Ergebnis }\end{array}$ & Bemerkungen & Evidenzgrad \\
\hline & & & $\begin{array}{l}\text { Subgruppenana- } \\
\text { lyse für die LC- } \\
\text { Gruppe } \\
\text { Englisch oder } \\
\text { Deutsch; syste- } \\
\text { matisches Re- } \\
\text { view, RCT, kon- } \\
\text { trollierte Studie, } \\
\text { Kohortenstudie, } \\
\text { Fallkontrollstu- } \\
\text { die, Fallserie } \geq 6 \\
\text { Patienten }\end{array}$ & & & & \\
\hline $\begin{array}{l}\text { Ford } 2012 \\
\text { [147] }\end{array}$ & $\begin{array}{l}\text { systematisches } \\
\text { Review }\end{array}$ & $\begin{array}{l}\mathrm{N}=1.715 \text { in } 8 \\
\text { Studien }\end{array}$ & $\begin{array}{l}\text { Medline, Emba- } \\
\text { se, Cochrane } \\
\text { und Clinical- } \\
\text { trials.gov } \\
\text { RCT mit Erwach- } \\
\text { senen }\end{array}$ & $\begin{array}{l}\text { Routine-IOCG vs. } \\
\text { keine IOCG bei } \\
\text { Patienten mit } \\
\text { niedriger Wahr- } \\
\text { scheinlichkeit für } \\
\text { Choledocholli- } \\
\text { thiasis (6 Studien) } \\
\text { oder selektive } \\
\text { IOCG (2 Studien) }\end{array}$ & $\begin{array}{l}2 \text { Fälle mit Gal- } \\
\text { lengangverlet- } \\
\text { zung, } 13 \text { mit } \\
\text { Choledocholi- } \\
\text { thiasis } \\
\text { keine der Stu- } \\
\text { dien zeigte ei- } \\
\text { nen Vorteil } \\
\text { beim Nachweis } \\
\text { einer Choledo- } \\
\text { cholithiasis } \\
\text { OP-Dauer } \\
\text { durchschnitt- } \\
\text { lich + } 16 \text { min }\end{array}$ & $\begin{array}{l}\text { unzureichende } \\
\text { Power der Studi- } \\
\text { en, geringe Stu- } \\
\text { dienqualität }\end{array}$ & II \\
\hline $\begin{array}{l}\text { Giger } 2011 \\
\text { [148] }\end{array}$ & $\begin{array}{l}\text { retrospektive } \\
\text { Kohortenstudie }\end{array}$ & $N=31838$ & $\begin{array}{l}\text { Datenbank von } \\
114 \text { Schweizer } \\
\text { Krankenhäusern, } \\
\text { LC wegen akuter } \\
\text { oder chronischer } \\
\text { Cholezystitis }\end{array}$ & $\begin{array}{l}\text { IOCG vs. keien } \\
\text { IOCG }\end{array}$ & $\begin{array}{l}\text { Inzidenz Gal- } \\
\text { lengangverlet- } \\
\text { zung } 0,3 \% \\
\text { (101 Patien- } \\
\text { ten) } \\
\text { kein Unter- } \\
\text { schied zwi- } \\
\text { schen Gruppen } \\
\text { mit und ohne } \\
\text { IOCG }\end{array}$ & retrospektiv & III \\
\hline $\begin{array}{l}\text { Landman } \\
2013 \text { [149] }\end{array}$ & Metaanalyse & 6 Studien & $\begin{array}{l}\text { Studien zur } \\
\text { HRQoL bei Pa- } \\
\text { tienten mit Gal- } \\
\text { lengangverlet- } \\
\text { zungen }\end{array}$ & - & $\begin{array}{l}\text { insbesondere } \\
\text { Effekte auf die } \\
\text { psychische Ge- } \\
\text { sundheit OR } 38 \\
\text { (95\% Cl } 19 \text { - } \\
77)\end{array}$ & & II \\
\hline $\begin{array}{l}\text { Pitt } 2013 \\
\text { [150] }\end{array}$ & $\begin{array}{l}\text { retrospektive } \\
\text { Fallserie }\end{array}$ & $N=528$ & $\begin{array}{l}\text { Gallengangver- } \\
\text { letzung }\end{array}$ & - & $\begin{array}{l}96 \% \text { erfolg- } \\
\text { reich endosko- } \\
\text { pisch versorgt } \\
\text { bessere Ergeb- } \\
\text { nisse der Chi- } \\
\text { rurgie in den } \\
\text { letzten Jahren } \\
\text { Patienten, die } \\
\text { mit Stent über } \\
\text { mehr als } 6 \text { Jah- } \\
\text { re behandelt } \\
\text { wurden }\end{array}$ & & III \\
\hline $\begin{array}{l}\text { Sahajpal } \\
2010 \text { [151] }\end{array}$ & $\begin{array}{l}\text { retrospektive } \\
\text { Fallserie }\end{array}$ & $N=69$ & $\begin{array}{l}\text { Patienten mit } \\
\text { Gallengangver- } \\
\text { letzung nach LC }\end{array}$ & $\begin{array}{l}\text { verschiedene } \\
\text { operative Ein- } \\
\text { griffe }\end{array}$ & $\begin{array}{l}\text { häufiger Strik- } \\
\text { turen bei Repa- } \\
\text { ratur in der in- } \\
\text { termediären } \\
\text { Phase ( } 72 \mathrm{~h} \text { - } 6\end{array}$ & $\begin{array}{l}\text { Strassberg-Klassi- } \\
\text { fikation, nur uni- } \\
\text { variate Analyse }\end{array}$ & III \\
\hline
\end{tabular}




\begin{tabular}{|c|c|c|c|c|c|c|c|}
\hline Referenz & Studientyp & Intervention & Teilnehmer & $\begin{array}{l}\text { Indextest und } \\
\text { Referenztest }\end{array}$ & $\begin{array}{l}\text { Zielgröße und } \\
\text { Ergebnis }\end{array}$ & Bemerkungen & Evidenzgrad \\
\hline & & & & & $\begin{array}{l}\text { Wochen) im } \\
\text { Vergleich zu } \\
\text { akuter oder } \\
\text { später OP }\end{array}$ & & \\
\hline $\begin{array}{l}\text { Sheffield } \\
2013 \text { [152] }\end{array}$ & $\begin{array}{l}\text { retrospektive } \\
\text { Kohortenstudie }\end{array}$ & $N=92932$ & $\begin{array}{l}\text { Texas Medicare } \\
\text { Files }\end{array}$ & $\begin{array}{l}\text { IOCG vs. keine } \\
\text { IOCG }\end{array}$ & $\begin{array}{l}\text { IOCG bei } \\
40,4 \% \text { der Pa- } \\
\text { tienten und } \\
\text { Gallengangver- } \\
\text { letzung bei } \\
0,30 \% \text { der Pa- } \\
\text { tienten, } 0,21 \% \\
\text { bei Patienten } \\
\text { mit IOCG und } \\
0,36 \% \text { bei Pa- } \\
\text { tienten ohne } \\
\text { IOCG } \\
\text { nach der Prü- } \\
\text { fung auf Con- } \\
\text { founder kein } \\
\text { Unterschied } \\
\text { bei Gallen- } \\
\text { gangverletzun- } \\
\text { gen }\end{array}$ & $\begin{array}{l}\text { retrospektiv, nur } \\
\text { Patienten } \geq 66 \\
\text { Jahre, Gallen- } \\
\text { gangverletzung } \\
\text { definiert über } \\
\text { konsekutive } \\
\text { Hepaticojejunos- } \\
\text { tomie, milde } \\
\text { Gallengangver- } \\
\text { letzungen nicht } \\
\text { enthalten }\end{array}$ & III \\
\hline $\begin{array}{l}\text { Törnqvist } \\
2012 \text { [153] }\end{array}$ & $\begin{array}{l}\text { prospektive Ko- } \\
\text { hortenstudie }\end{array}$ & $N=51041$ & $\begin{array}{l}\text { GallRiks: schwe- } \\
\text { disches Gallen- } \\
\text { steinregister, OP } \\
\text { oder ERC }\end{array}$ & IOCG & $\begin{array}{l}\text { Inzidenz 1,5\% } \\
\text { Patienten mit } \\
\text { Gallengangver- } \\
\text { letzung haben } \\
\text { höhere Morta- } \\
\text { lität }\end{array}$ & & $\|$ \\
\hline $\begin{array}{l}\text { Walsh } 2007 \\
{[154]}\end{array}$ & $\begin{array}{l}\text { retrospektive } \\
\text { Fallserie }\end{array}$ & $\begin{array}{l}\mathrm{N}=84 \text { von } 144 \\
\text { Patienten }\end{array}$ & $\begin{array}{l}\text { Patienten mit } \\
\text { Gallengangver- } \\
\text { letzungen, die } \\
\text { einer biliodiges- } \\
\text { tiven Rekons- } \\
\text { truktion unter- } \\
\text { zogen wurden }\end{array}$ & $\begin{array}{l}\text { biliodigestive } \\
\text { Rekonstruktion } \\
\text { einschließlich } \\
\text { Revsionen } \\
\text { vorausgegange- } \\
\text { ner OPs }\end{array}$ & $\begin{array}{l}\text { Verletzungsni- } \\
\text { veau und Zeit- } \\
\text { punkt der } \\
\text { Rekonstruktion } \\
\text { Prädiktoren des } \\
\text { Strikturrisikos }\end{array}$ & $\begin{array}{l}\text { Daten nicht ge- } \\
\text { zeigt, mittleres } \\
\text { Follow-up } 67 \\
\text { Monate }\end{array}$ & III \\
\hline
\end{tabular}


Empfehlung IIIB.16

\begin{tabular}{|c|c|c|c|c|c|c|c|}
\hline Referenz & Studientyp & Intervention & Teilnehmer & $\begin{array}{l}\text { Indextest und } \\
\text { Referenztest }\end{array}$ & $\begin{array}{l}\text { Zielgröße und } \\
\text { Ergebnis }\end{array}$ & Bemerkungen & Evidenzgrad \\
\hline $\begin{array}{l}\text { Kilic } 2013 \\
\text { [155] }\end{array}$ & $\begin{array}{l}\text { Fallserie, retro- } \\
\text { spektiv }\end{array}$ & $\begin{array}{l}\mathrm{N}=1687 \text { herz- } \\
\text { transplantierte } \\
\text { Patienten, USA }\end{array}$ & $\begin{array}{l}\text { herztransplan- } \\
\text { tierte Patienten } \\
\geq 18 \text { Jahre, die } \\
\text { cholezystekto- } \\
\text { miert wurden }\end{array}$ & & $\begin{array}{l}\mathrm{N}=1218 \text { akute } \\
\text { Cholezystitis, } \\
\text { Mortalität } 37 \\
(2,2 \%), \text { Morbi- } \\
\text { dität } 17,1 \text { vs. } \\
6,5 \% \text { bei offe- } \\
\text { ner vs. LC }\end{array}$ & große Fallzahl & III \\
\hline $\begin{array}{l}\text { Sarkio } 2007 \\
\text { [156] }\end{array}$ & $\begin{array}{l}\text { Fallserie, retro- } \\
\text { spektiv }\end{array}$ & $\begin{array}{l}\mathrm{N}=1608 \text { trans- } \\
\text { plantierte Pa- } \\
\text { tienten, mono- } \\
\text { zentrisch, Finn- } \\
\text { land }\end{array}$ & $\begin{array}{l}\text { Patienten mit } \\
\text { Nierentransplan- } \\
\text { tation (NTX) }\end{array}$ & & $\begin{array}{l}\text { Cholezystekto- } \\
\text { mie prä-NTX } \\
\text { bei } 71 \text { Pati- } \\
\text { enten (4\%), } \\
\text { post-NTX } 30 \\
\text { Patienten mit } \\
\text { Cholelithiasis, } 4 \\
\text { Patienten ohne } \\
\text { Gallensteine } \\
\text { entwickelten } \\
\text { Komplikatio- } \\
\text { nen, } 9 \% \text { der } \\
\text { Patienten ent- } \\
\text { wickelten Gal- } \\
\text { lensteine post- } \\
\text { NTX } \\
6,3 \% \text { Gallen- } \\
\text { steine prä- } \\
\text { NTX, } 10,3 \% \\
\text { post-NTX }\end{array}$ & $\begin{array}{l}\text { medianes } \\
\text { Follow-up } 7 \text { Jahre }\end{array}$ & III \\
\hline
\end{tabular}

Empfehlung IIIC.2

\begin{tabular}{|c|c|c|c|c|c|c|c|}
\hline Referenz & Studientyp & Intervention & Teilnehmer & $\begin{array}{l}\text { Indextest und } \\
\text { Referenztest }\end{array}$ & $\begin{array}{l}\text { Zielgröße und } \\
\text { Ergebnis }\end{array}$ & Bemerkungen & Evidenzgrad \\
\hline $\begin{array}{l}\text { Alexakis } 2012 \\
\text { [157] }\end{array}$ & $\begin{array}{l}\text { systematisches } \\
\text { Review mit } \\
\text { Metaanalyse }\end{array}$ & $\begin{array}{l}\text { Medline, SCI } \\
(1990-2011) \text {, } \\
\text { RCT }\end{array}$ & $\begin{array}{l}\mathrm{N}=933 \text { in } 9 \text { Stu- } \\
\text { dien }\end{array}$ & $\begin{array}{l}\text { LC+LCBDE oder } \\
\text { ERC intraoperativ } \\
\text { (einzeitige } \\
\text { Behandlung) vs. } \\
\text { ERC+LC oder LC } \\
\text { +ERC (zweizeiti- } \\
\text { ge Behandlung) }\end{array}$ & $\begin{array}{l}\text { kein Unter- } \\
\text { schied bei CBD- } \\
\text { Clearance (OR } \\
0,89 ; 95 \% \mathrm{Cl} \\
0,65 \text { - } 1,21) \text {, } \\
\text { Mortalität (OR } \\
1,20 ; 95 \% \mathrm{Cl} \\
0,32 \text { - } 4,52 \text { ), } \\
\text { Morbidität (OR } \\
0,75,95 \% \\
0,53 \text { - 1,06) } \\
\text { oder Notwen- } \\
\text { digkeit zusätzli- } \\
\text { cher Prozedu- } \\
\text { ren (OR 1,58, } \\
95 \% \text { Cl 0,76- } \\
\text { 3,30) }\end{array}$ & $\begin{array}{l}\text { Aktualisierung } \\
\text { des Reviews } \\
\text { von Clayton } \\
2006 \text { [158], un- } \\
\text { zureichende } \\
\text { Power der Stu- } \\
\text { dien }\end{array}$ & I \\
\hline $\begin{array}{l}\text { Bansal } 2010 \\
\text { [159] }\end{array}$ & RCT & $\begin{array}{l}\text { Patienten mit } \\
\text { CBD-Steinen }\end{array}$ & $\begin{array}{l}\mathrm{N}=2 \times 15 \text { Pati- } \\
\text { enten mit symp- } \\
\text { tomatischen Gal- } \\
\text { lensteinen und } \\
\mathrm{CBD}>10 \mathrm{~mm}\end{array}$ & $\begin{array}{l}\text { LCBDE vs. ERC } \\
\text { prä-OP }\end{array}$ & $\begin{array}{l}\text { Krankenhaus- } \\
\text { verweildauer } \\
4,2(3-9) \text { bei } \\
\text { LCBDE vs. } 4,0 \\
(2-11) \text { Tage } \\
\text { bei ERC prä-OP } \\
\text { frustrane Gang- } \\
\text { intervention }\end{array}$ & kleine Fallzahl & I \\
\hline
\end{tabular}




\begin{tabular}{|c|c|c|c|c|c|c|c|}
\hline Referenz & Studientyp & Intervention & Teilnehmer & $\begin{array}{l}\text { Indextest und } \\
\text { Referenztest }\end{array}$ & $\begin{array}{l}\text { Zielgröße und } \\
\text { Ergebnis }\end{array}$ & Bemerkungen & Evidenzgrad \\
\hline & & & & & $\begin{array}{l}6,7 \% \text { bei LCBDE } \\
\text { vs. } 26,7 \% \text { bei } \\
\text { ERC prä-OP }\end{array}$ & & \\
\hline $\begin{array}{l}\text { Bansal } 2014 \\
{[160]}\end{array}$ & RCT & $\begin{array}{l}\text { Patienten mit } \\
\text { simultanen Gal- } \\
\text { lenblasenstei- } \\
\text { nen und CBD- } \\
\text { Steinen }\end{array}$ & $\begin{array}{l}\mathrm{N}=168 \text {, jeweils } \\
84 \text { in beiden } \\
\text { Gruppen }\end{array}$ & $\begin{array}{l}\text { LCBDE vs. ERC } \\
\text { prä-OP }\end{array}$ & $\begin{array}{l}\text { keine Unter- } \\
\text { schiede in } \\
\text { Steinfreiheits- } \\
\text { rate und Kom- } \\
\text { plikationsrate } \\
\text { Unterschiede } \\
\text { zugunsten ERC } \\
\text { prä-OP in der } \\
\text { OP-Zeit } 136 \\
\pm 37 \text { min vs. } 72 \\
\pm 28 \text { min } \\
\text { (P<0,001) und } \\
\text { zugunsten } \\
\text { LCBDE in der } \\
\text { Krankenhaus- } \\
\text { verweildauer: } \\
4,6 \pm 2,4 \text { Tage } \\
\text { vs. } 5,3 \pm 6,2 \\
\text { Tage }(P<0,03)\end{array}$ & & 1 \\
\hline $\begin{array}{l}\text { Dasari } 2013 \\
\text { [161] }\end{array}$ & $\begin{array}{l}\text { systematisches } \\
\text { Review mit } \\
\text { Metaanalyse }\end{array}$ & $\begin{array}{l}\text { Patienten mit } \\
\text { CBD-Steinen }\end{array}$ & $\begin{array}{l}16 \text { RCT mit } \\
N=1758\end{array}$ & $\begin{array}{l}\text { offene CBDE } \\
\text { oder } L C B D E \text { vs. } \\
\text { ERC }\end{array}$ & $\begin{array}{l}\text { offene CBDE vs. } \\
\text { ERC: keine Un- } \\
\text { terschiede bei } \\
\text { Mortalität oder } \\
\text { Morbidität, } \\
\text { offene CBDE } \\
\text { weniger } \\
\text { Residualsteine } \\
\text { ( } 6 \text { vs. } 16 \% \text {, OR } \\
0,36,95 \% \text { Cl } \\
0,21 \text { - } 0,62) \\
\text { LCBDE vs. ERC + } \\
\text { LC: keine } \\
\text { Unterschiede } \\
\text { LCBDE vs. LC + } \\
\text { intraoperative } \\
\text { ERC: keine } \\
\text { Unterschiede } \\
\text { LCBDE vs. LC + } \\
\text { postoperativer } \\
\text { ERC: bei LCBDE } \\
\text { weniger Resi- } \\
\text { dualsteine } \\
\text { (9 vs. } 25 \% \text {, OR } \\
0,28,95 \% \text { Cl } \\
0,11 \text { - } 0,72 \text { ) }\end{array}$ & & 1 \\
\hline $\begin{array}{l}\text { Ding } 2014 \\
\text { [162] }\end{array}$ & RCT & $\begin{array}{l}\text { Patienten mit } \\
\text { CBD-Steinen in } \\
\text { der MRCP }\end{array}$ & $\begin{array}{l}\mathrm{N}=110 \text { LCBDE } \\
\text { vs. } \mathrm{N}=111 \mathrm{ERC} \\
\text { prä-OP + LC und }\end{array}$ & $\begin{array}{l}\text { LCBDE vs. ERC } \\
\text { prä-OP }\end{array}$ & $\begin{array}{l}\text { keine Mortalität } \\
\text { Residualsteine } \\
2,1 \% \text { bei LCBDE } \\
\text { vs. } 9,5 \% \text { bei } \\
\text { ERC prä-OP } \\
\text { ( } 8 \text { - } 10 \text { Jahre } \\
\text { später), } \\
\text { P= } 0,037 \\
\text { frustrane Gang- } \\
\text { intervention } \\
6,4 \% \text { bei LCBDE } \\
\text { vs. } 5,4 \% \text { bei } \\
\text { ERC prä-OP }\end{array}$ & $\begin{array}{l}\text { Randomisie- } \\
\text { rung unklar, } \\
\text { ein einziger } \\
\text { Chirurg für alle } \\
\text { Patienten }\end{array}$ & 1 \\
\hline
\end{tabular}




\begin{tabular}{|c|c|c|c|c|c|c|c|}
\hline Referenz & Studientyp & Intervention & Teilnehmer & $\begin{array}{l}\text { Indextest und } \\
\text { Referenztest }\end{array}$ & $\begin{array}{l}\text { Zielgröße und } \\
\text { Ergebnis }\end{array}$ & Bemerkungen & Evidenzgrad \\
\hline $\begin{array}{l}\text { ElGeidie } \\
\text { 2011a [163] }\end{array}$ & RCT & $\begin{array}{l}\text { Patienten mit } \\
\text { CBD-Steinen, } \\
\text { ASA } \leq \text { III }\end{array}$ & $\begin{array}{l}\mathrm{N}=115 \mathrm{LCBDE} \\
\text { vs. } \mathrm{N}=111 \mathrm{ERC} \\
\text { intra-OP + LC }\end{array}$ & $\begin{array}{l}\text { LCBDE vs. ERC in- } \\
\text { tra-OP }\end{array}$ & $\begin{array}{l}\text { Krankenhaus- } \\
\text { verweildauer } \\
2,2(1-9) \text { bei } \\
\text { LCBDE vs. } 3,1 \\
(1-7) \text { Tage bei } \\
\text { ERC intra-OP } \\
\text { Residualsteine } \\
8,0 \% \text { bei LCBDE } \\
\text { vs. } 2,8 \% \text { bei } \\
\text { ERC intra-OP } \\
\text { frustrane Gang- } \\
\text { intervention } \\
5,2 \% \text { bei LCBDE } \\
\text { vs. } 2,7 \% \text { bei } \\
\text { ERC intra-OP }\end{array}$ & & I \\
\hline $\begin{array}{l}\text { ElGeidi 2011b } \\
\text { [164] }\end{array}$ & RCT & $\begin{array}{l}\text { Patienten mit } \\
\text { CBD-Steinen in } \\
\text { der MRCP, ASA } \\
\leq \text { III }\end{array}$ & $\begin{array}{l}N=98 \mathrm{LC}+\mathrm{ERC} \\
\text { intra-OP vs. } \\
\mathrm{N}=100 \mathrm{ERC} \\
\text { prä-OP + LC }\end{array}$ & $\begin{array}{l}\text { ERC intra-OP vs. } \\
\text { ERC prä-OP }\end{array}$ & $\begin{array}{l}\text { Krankenhaus- } \\
\text { verweildauer } \\
1,3(1-4) \text { bei } \\
\text { ERC intra-OP } \\
\text { vs. } 3,0(2-11) \\
\text { bei ERC prä-OP } \\
\text { Residualsteine } \\
2,2 \% \text { bei ERC } \\
\text { intra-OP vs. } \\
4,7 \% \text { bei ERC } \\
\text { prä-OP } \\
\text { frustrane Gang- } \\
\text { intervention } \\
2,0 \% \text { bei ERC } \\
\text { intra-OP vs. } \\
5,0 \% \text { bei ERC } \\
\text { prä-OP }\end{array}$ & $\begin{array}{l}\text { Daten in Text } \\
\text { und Tabellen } \\
\text { stimmen nicht } \\
\text { überein }\end{array}$ & I \\
\hline $\begin{array}{l}\text { Gurusamy } \\
2011 \text { [165] }\end{array}$ & $\begin{array}{l}\text { systematisches } \\
\text { Review mit } \\
\text { Metaanalyse } \\
\text { von } 4 \text { RCT }\end{array}$ & $\begin{array}{l}\text { Patienten mit } \\
\text { CBD-Steinen }\end{array}$ & $\begin{array}{l}\mathrm{N}=532 \text { intraop- } \\
\text { erative endosko- } \\
\text { pische Sphinkte- } \\
\text { rotomie (IOES) } \\
\text { vs. präoperative } \\
\text { endoskopische } \\
\text { Sphinkterotomie } \\
\text { (POES) }\end{array}$ & & $\begin{array}{l}\text { kein Unter- } \\
\text { schied in der } \\
\text { Steinfreiheits- } \\
\text { rate } \\
\text { post-EPT Kom- } \\
\text { plikationen } \\
\text { (Pankreatitis, } \\
\text { Blutung, Perfo- } \\
\text { ration, Cholan- } \\
\text { gitis, Cholezys- } \\
\text { titis) niedriger } \\
\text { in IOES (RR } \\
0,37,95 \% \mathrm{Cl} \\
0,18-0,78 \text {, } \\
\mathrm{P}=0,009 \text { ) }\end{array}$ & & I \\
\hline $\begin{array}{l}\text { Wang } 2013 \\
\text { [166] }\end{array}$ & $\begin{array}{l}\text { systematisches } \\
\text { Review mit } \\
\text { Metaanalyse } \\
\text { von } 5 \text { RCT }\end{array}$ & $\begin{array}{l}\text { Patienten mit } \\
\text { CBD-Steinen }\end{array}$ & $\begin{array}{l}\mathrm{N}=631 \text { intraop- } \\
\text { erative endosko- } \\
\text { pische Sphinkte- } \\
\text { rotomie (IOES) } \\
\text { vs. präoperative } \\
\text { endoskopische } \\
\text { Sphinkterotomie } \\
\text { (POES) }\end{array}$ & & $\begin{array}{l}\text { kein Unter- } \\
\text { schied in der } \\
\text { Steinfreiheits- } \\
\text { rate und Mor- } \\
\text { talität } \\
\text { Komplikationen } \\
\text { häufiger bei } \\
\text { POES (RR } 2,27 \text {, } \\
95 \% \mathrm{Cl} 1,18 \text { - } \\
4,40, \mathrm{P}=0,01 \text { ), } \\
\text { vor allem post- } \\
\text { ERC- Pankreati- } \\
\text { tis (RR } 4,85 \text {, } \\
95 \% \mathrm{Cl} 1,41 \text { - } \\
16,66, \mathrm{P}=0,01 \text { ) }\end{array}$ & & I \\
\hline
\end{tabular}




\begin{tabular}{|c|c|c|c|c|c|c|c|}
\hline Referenz & Studientyp & Intervention & Teilnehmer & $\begin{array}{l}\text { Indextest und } \\
\text { Referenztest }\end{array}$ & $\begin{array}{l}\text { Zielgröße und } \\
\text { Ergebnis }\end{array}$ & Bemerkungen & Evidenzgrad \\
\hline & & & & & $\begin{array}{l}\text { Krankenhaus- } \\
\text { verweildauer } \\
\text { länger bei POES } \\
\text { (RR 2,22, 95\% } \\
\text { Cl 1,98-2,46, } \\
\text { P<0,01) }\end{array}$ & & \\
\hline $\begin{array}{l}\text { Кoc } 2013 \\
{[167]}\end{array}$ & RCT & $\begin{array}{l}\text { Patienten mit } \\
\text { CBD-Steinen } \\
(C B D>8 \mathrm{~mm})\end{array}$ & $\begin{array}{l}N=57 \text { LCBDE vs. } \\
N=54 \text { ERC prä- } \\
\text { OP + LC }\end{array}$ & $\begin{array}{l}\text { LCBDE vs. ERC } \\
\text { prä-OP }\end{array}$ & $\begin{array}{l}\text { Krankenhaus- } \\
\text { verweildauer } 3 \\
\text { Tage bei LCBDE } \\
\text { vs. } 6 \text { Tage bei } \\
\text { ERC prä-OP } \\
\text { Residualsteine } \\
3,5 \% \text { bei LCBDE } \\
\text { vs. } 5,6 \% \text { bei } \\
\text { ERC prä-OP } \\
\text { frustrane Gang- } \\
\text { intervention } \\
3,5 \% \text { bei LCBDE } \\
\text { vs. } 5,6 \% \text { bei } \\
\text { ERC prä-OP }\end{array}$ & $\begin{array}{l}\text { Randomisie- } \\
\text { rung unklar }\end{array}$ & 1 \\
\hline $\begin{array}{l}\text { Noble } 2009 \\
{[168]}\end{array}$ & RCT & $\begin{array}{l}\text { Patienten mit } \\
\text { CBD-Steinen }\end{array}$ & $\begin{array}{l}N=44 \text { LCBDE vs. } \\
N=47 \text { ERC prä- } \\
O P+L C\end{array}$ & $\begin{array}{l}\text { LCBDE vs. ERC } \\
\text { prä-OP }\end{array}$ & $\begin{array}{l}\text { Krankenhaus- } \\
\text { verweildauer } 5 \\
(2-7) \text { bei } \\
\text { LCBDE vs. } 3 \\
(2-7) \text { Tage bei } \\
\text { ERC prä-OP } \\
\text { Residualsteine } \\
\text { postinterven- } \\
\text { tionell } 0 \% \text { bei } \\
\text { LCBDE vs. } \\
38,3 \% \text { bei ERC } \\
\text { prä-OP } \\
\text { Komplikationen } \\
\text { und Konversi- } \\
\text { onraten idem } \\
\text { Residualsteine } \\
2,3 \% \text { bei LCBDE } \\
(1 \times 2,3 \text { Jahre } \\
\text { post-OP) vs. } \\
14,9 \% \text { bei ERC } \\
\text { prä-OP }(6 \times \\
\text { CBDE, } 1 \times 6 \\
\text { Monate post- } \\
\text { OP) } \\
\text { frustrane Gang- } \\
\text { intervention } \\
0 \% \text { bei LCBDE } \\
\text { vs. } 29,8 \% \text { bei } \\
\text { ERC prä-OP }\end{array}$ & $\begin{array}{l}\text { sehr niedrige } \\
\text { primäre Er- } \\
\text { folgsquote in } \\
\text { der ERC prä-OP } \\
\text { + LC -Gruppe }\end{array}$ & 1 \\
\hline $\begin{array}{l}\text { Rogers } 2010 \\
\text { [169] }\end{array}$ & RCT & $\begin{array}{l}\text { Patienten mit } \\
\text { CBD-Steinen } \\
\text { (CBD } \geq 6 \mathrm{~mm}) \text {, } \\
\text { ASA I - II }\end{array}$ & $\begin{array}{l}N=57 \text { LCBDE vs. } \\
N=55 \text { prä-OP } \\
E R C+L C\end{array}$ & $\begin{array}{l}\text { LCBDE vs. ERC } \\
\text { prä-OP }\end{array}$ & $\begin{array}{l}\text { Krankenhaus- } \\
\text { verweildauer } \\
5,3 \pm 3,2 \text { bei } \\
\text { LCBDE vs. } 6,6 \\
\pm 4,0 \text { Tage bei } \\
\text { ERC prä-OP } \\
\text { frustrane Gang- } \\
\text { intervention } \\
6,7 \% \text { bei LCBDE } \\
\text { vs. } 26,7 \% \text { bei } \\
\text { ERC prä-OP }\end{array}$ & $\begin{array}{l}\text { schlechte ERC- } \\
\text { Ergebnisse }\end{array}$ & 1 \\
\hline
\end{tabular}




\begin{tabular}{|c|c|c|c|c|c|c|c|}
\hline Referenz & Studientyp & Intervention & Teilnehmer & $\begin{array}{l}\text { Indextest und } \\
\text { Referenztest }\end{array}$ & $\begin{array}{l}\text { Zielgröße und } \\
\text { Ergebnis }\end{array}$ & Bemerkungen & Evidenzgrad \\
\hline Lu 2012 [170] & $\begin{array}{l}\text { Cochrane- } \\
\text { Review mit } \\
\text { Metaanalyse } \\
\text { von } 7 \text { RCT }\end{array}$ & $\begin{array}{l}\text { Patienten mit } \\
\text { simultanen Gal- } \\
\text { lenblasen- und } \\
\text { CBD-Steinen }\end{array}$ & $\begin{array}{l}\mathrm{N}=621 \text { ( } 5 \text { RCT }) \\
\text { LCBDE vs. prä-OP } \\
\text { ERC + LC und } \\
\mathrm{N}=166(2 \text { RCT }) \\
\text { LCBDE vs. post- } \\
\text { OP ERC + LC }\end{array}$ & & $\begin{array}{l}\text { keine Unter- } \\
\text { schiede bei St } \\
\text { einfreiheitsrate, } \\
\text { postoperativer } \\
\text { Morbidität, } \\
\text { Mortalität, } \\
\text { Konversionsra- } \\
\text { te, Kranken- } \\
\text { hausverweil- } \\
\text { dauer oder } \\
\text { OP-Zeit }\end{array}$ & & I \\
\hline
\end{tabular}

Empfehlung IIIC.6

\begin{tabular}{|c|c|c|c|c|c|c|c|}
\hline Referenz & Studientyp & Intervention & Teilnehmer & $\begin{array}{l}\text { Indextest und } \\
\text { Referenztest }\end{array}$ & $\begin{array}{l}\text { Zielgröße und } \\
\text { Ergebnis }\end{array}$ & Bemerkungen & Evidenzgrad \\
\hline $\begin{array}{l}\text { McAlister } \\
2007 \text { [171] }\end{array}$ & Cochrane-Review & $\begin{array}{l}\mathrm{N}=662 \text { in } 5 \\
\text { Studien }\end{array}$ & $\begin{array}{l}\text { RCT mit Patien- } \\
\text { ten mit Gallen- } \\
\text { blase in situ nach } \\
\text { EPT }\end{array}$ & $\begin{array}{l}\text { Watch-and-wait- } \\
\text { Strategie vs. Cho- } \\
\text { lezystektomie }\end{array}$ & $\begin{array}{l}\text { Mortalität rela- } \\
\text { tiv zur Chole- } \\
\text { zystektomie RR } \\
1,78 \text { (95\% CI } \\
\text { 1,15-2,75); re- } \\
\text { zidivierende bi- } \\
\text { liäre Schmerzen } \\
\text { RR 14,6 (95\% CI } \\
\text { 5,0-42,8); } \\
\text { Gelbsucht oder } \\
\text { Cholangitis RR } \\
2,53 \text { (95\% CI } \\
\text { 1,09-5,87); } \\
\text { Notwendigkeit } \\
\text { einer Re-ERC } \\
\text { oder anderer } \\
\text { Cholangiogra- } \\
\text { fien RR 2,36 } \\
\text { (95\% CI 1,29- } \\
4,32 \text { ) } \\
\text { Cholezystekto- } \\
\text { mie im weite- } \\
\text { ren Verlauf bei } \\
\text { 35\% der } \\
\text { Watch-and- } \\
\text { wait-Gruppe }\end{array}$ & $\begin{array}{l}\text { nicht verblindet, } \\
\text { Randomisierung } \\
\text { adäquat bei } 4 \\
\text { RCT }\end{array}$ & 1 \\
\hline $\begin{array}{l}\text { Reinders } \\
2010 \text { [172] }\end{array}$ & $\mathrm{RCT}$ & $\begin{array}{l}\text { N=96, } 49 \text { in } \\
\text { der frühen LC- } \\
\text { Gruppe und } 47 \\
\text { in der späten } \\
\text { LC-Gruppe }\end{array}$ & $\begin{array}{l}\text { Patienten ( } \geq 18 \\
\text { Jahre, ASA } \leq \text { III) } \\
\text { bei denen nach } \\
\text { einer erfolgrei- } \\
\text { chen EPT und } \\
\text { Steinextraktion } \\
\text { wegen Choledo- } \\
\text { cholithiasis Gal- } \\
\text { lenblasensteine } \\
\text { nachweisbar } \\
\text { waren }\end{array}$ & $\begin{array}{l}\text { LC innerhalb von } \\
72 \text { h nach EPT vs. } \\
\text { LC nach } 6-8 \\
\text { Wochen nach } \\
\text { EPT }\end{array}$ & $\begin{array}{l}\text { kein Unter- } \\
\text { schied bei Kon- } \\
\text { versionsrate, } \\
\text { OP-Dauer, OP- } \\
\text { Komplikationen } \\
\text { oder Kranken- } \\
\text { hausverweil- } \\
\text { dauer } \\
\text { in der späten } \\
\text { LC-Gruppe ent- } \\
\text { wickelten } 36 \% \\
\text { Rezidivbe- } \\
\text { schwerden in } \\
\text { vs. } 2 \% \text { in der } \\
\text { frühen LC- } \\
\text { Gruppe }\end{array}$ & $\begin{array}{l}\text { Multicenterstu- } \\
\text { die }\end{array}$ & 1 \\
\hline
\end{tabular}


Empfehlungen IIIC.7

\begin{tabular}{|c|c|c|c|c|c|c|c|}
\hline Referenz & Studientyp & Intervention & Teilnehmer & $\begin{array}{l}\text { Index- und } \\
\text { Referenztest }\end{array}$ & $\begin{array}{l}\text { Zielgröße und } \\
\text { Ergebnis }\end{array}$ & Bemerkungen & Evidenzgrad \\
\hline $\begin{array}{l}\text { Aboulian } \\
2010 \text { [173] }\end{array}$ & RCT & $N=50$ & $\begin{array}{l}\text { Patienten } 18 \text { - } \\
100 \text { Jahre mit } \\
\text { milder biliärer } \\
\text { Pankreatitis }\end{array}$ & $\begin{array}{l}\text { frühe Cholezyst- } \\
\text { ektomie }(<48 \mathrm{~h} \\
\text { nach Aufnahme) } \\
(\mathrm{N}=25) \text { vs. späte } \\
\text { Cholezystekto- } \\
\text { mie }(\mathrm{N}=25)\end{array}$ & $\begin{array}{l}\text { Krankenhaus- } \\
\text { verweildauer } \\
\text { 3,5 Tage (95\% } \\
\text { Cl 2,7-4,3) vs. } \\
\text { 5,8 Tage }(95 \% \\
\text { Cl 3,8-7,9) } \\
\text { kein Unter- } \\
\text { schied bei } \\
\text { Komplikatio- } \\
\text { nen }\end{array}$ & $\begin{array}{l}\text { monozentrisch, } \\
\text { kleine Patienten- } \\
\text { zahl, überwie- } \\
\text { gend spanische } \\
\text { Patienten }\end{array}$ & 1 \\
\hline $\begin{array}{l}\text { Da Costa } \\
2015 \text { [19] }\end{array}$ & RCT & $N=266$ & $\begin{array}{l}\text { Patienten (38 - } \\
68 \text { Jahre, ASA } \leq \\
\text { III) mit milder } \\
\text { biliärer Pankeati- } \\
\text { tis (kein Organ- } \\
\text { versagen > } 48 \mathrm{~h} \text {, } \\
\text { keine Nekrosen, } \\
\text { kein peripan- } \\
\text { kreatischer Flüs- } \\
\text { sigkeitsverhalt, } \\
\text { CRP < } 100 \text { mg/l) }\end{array}$ & $\begin{array}{l}\text { Same-admission } \\
\text { Cholezystekto- } \\
\text { mie innerhalb } \\
\text { von } 3 \text { Tagen } \\
\text { nach Randomi- } \\
\text { sierung } \\
\text { ( } \mathrm{N}=128 \text { ) vs. In- } \\
\text { tervallcholezyst- } \\
\text { ektomie (nach } \\
25-30 \text { Tagen) } \\
(\mathrm{N}=136)\end{array}$ & $\begin{array}{l}\text { primärer End- } \\
\text { punkt Wieder- } \\
\text { aufnahme/Tod } \\
5 \% \text { vs. } 17 \% \text { (RR } \\
0,28,95 \% \text { Cl } \\
0,12-0,66 \text { ) } \\
\text { Pankreatitis } 2 \% \\
\text { vs. } 9 \% \text { (RR } \\
0,27,95 \% \text { Cl } \\
0,08-0,92 \text { ), } \\
\text { biliäre Koliken } \\
\text { (RR 0,30, 95\% } \\
\text { CI 0,06-1,43), } \\
\text { Cholezystitis } 0 \\
\text { vs. } 2 \% \\
\text { Konversionsra- } \\
\text { te, Komplika- } \\
\text { tionen und } \\
\text { Krankenhaus- } \\
\text { verweildauer } \\
\text { idem }\end{array}$ & $\begin{array}{l}183 \text { Patienten } \\
\text { wegen Nekrosen } \\
\text { ausgeschlossen }\end{array}$ & 1 \\
\hline $\begin{array}{l}\text { van Baal } \\
2012 \text { [174] }\end{array}$ & $\begin{array}{l}\text { systematisches } \\
\text { Review mit } \\
\text { Metaanalyse }\end{array}$ & $\begin{array}{l}\mathrm{N}=998 \text { aus } 8 \\
\text { Kohortenstu- } \\
\text { dien, } 1 \mathrm{RCT}\end{array}$ & $\begin{array}{l}\text { Medline, Embase } \\
\text { und Cochrane } \\
\text { Kohortenpatien- } \\
\text { ten, die nach } \\
\text { einer milden } \\
\text { bilïren Pankrea- } \\
\text { titis eine Chole- } \\
\text { zystektomie } \\
\text { erhielten } \\
\text { Endpunkte: Zeit } \\
\text { zwischen Gene- } \\
\text { sung und Chole- } \\
\text { zystektomie, } \\
\text { Anzahl rezidivie- } \\
\text { render biliärer } \\
\text { Ereignisse vor } \\
\text { Cholezystekto- } \\
\text { mie, Komplika- } \\
\text { tionen bei der } \\
\text { Cholezystektomie }\end{array}$ & $\begin{array}{l}\text { Intervall-Chole- } \\
\text { zystektomie vs. } \\
\text { Index-Cholezyst- } \\
\text { ektomie }\end{array}$ & $\begin{array}{l}\mathrm{N}=483(48 \%) \\
\text { Index-Chole- } \\
\text { zystektomie, } \\
515(52 \%) \text { In- } \\
\text { tervall- Chole- } \\
\text { zystektomie } \\
\text { nach im Medi- } \\
\text { an } 40 \text { Tagen } \\
\text { (19-58 Tage) } \\
\text { bei Intervall- } \\
\text { Cholezytsekto- } \\
\text { mie } \mathrm{N}=95 \\
\text { ( } 18 \% \text { ) Wieder- } \\
\text { aufnahme we- } \\
\text { gen rezidivie- } \\
\text { render biliären } \\
\text { Beschwerden } \\
\text { (0 vs. } 18 \%, \\
\mathrm{P}<0,0001), \\
\text { einschließlich } \\
\text { rezidivierender } \\
\text { biliärer Pankre- } \\
\text { atitis ( } \mathrm{N}=43) \text {, } \\
\text { akuter Chole- } \\
\text { zystitis ( } \mathrm{N}=17 \text { ) } \\
\text { und biliärer }\end{array}$ & $\begin{array}{l}\text { nur } 1 \text { RCT und } 8 \\
\text { Kohortenstudien } \\
\text { kein Vergleich } \\
\text { der Baseline- } \\
\text { Charakteristika } \\
\text { bei } 74 \% \text { der } \\
\text { Patienten }\end{array}$ & $\|$ \\
\hline
\end{tabular}




\begin{tabular}{|c|c|c|c|c|c|c|c|}
\hline Referenz & Studientyp & Intervention & Teilnehmer & $\begin{array}{l}\text { Index- und } \\
\text { Referenztest }\end{array}$ & $\begin{array}{l}\text { Zielgröße und } \\
\text { Ergebnis }\end{array}$ & Bemerkungen & Evidenzgrad \\
\hline & & & & & $\begin{array}{l}\text { Koliken } \\
(\mathrm{N}=35) \\
\text { Patienten nach } \\
\text { ERC hatten we- } \\
\text { niger Rezidive } \\
(10 \text { vs. } 24 \%, \\
\mathrm{P}=0,001), \text { v. a. } \\
\text { seltener eine } \\
\text { erneute biliäre } \\
\text { Pankreatitis } \\
\text { kein Unter- } \\
\text { schied bei } \\
\text { Komplikatio- } \\
\text { nen, Konversi- } \\
\text { onsrate und } \\
\text { Mortalität }\end{array}$ & & \\
\hline
\end{tabular}

Empfehlungen IIIC.8

\begin{tabular}{|c|c|c|c|c|c|c|c|}
\hline Referenz & Studientyp & $\begin{array}{l}\text { Interventi- } \\
\text { on }\end{array}$ & Teilnehmer & $\begin{array}{l}\text { Index- und } \\
\text { Referenztest }\end{array}$ & $\begin{array}{l}\text { Zielgröße und } \\
\text { Ergebnis }\end{array}$ & Bemerkungen & Evidenzgrad \\
\hline $\begin{array}{l}\text { Petrov } 2008 \\
{[175]}\end{array}$ & $\begin{array}{l}\text { systemati- } \\
\text { sches Review } \\
\text { mit Metaana- } \\
\text { lyse }\end{array}$ & $\begin{array}{l}\mathrm{N}=450 \text { aus } 3 \\
\mathrm{RCT}\end{array}$ & $\begin{array}{l}\text { RCT, akute biliäre } \\
\text { Pankreatitis ohne } \\
\text { Zeichen einer } \\
\text { akuten Cholangi- } \\
\text { tis }\end{array}$ & $\begin{array}{l}\text { frühe ERC }(<72 \mathrm{~h}) \\
\text { mit oder ohne EPT } \\
\text { vs. konservative } \\
\text { Behandlung mit } \\
\text { selektiver ERC mit } \\
\text { oder ohne EPT }\end{array}$ & $\begin{array}{l}\text { kein Unter- } \\
\text { schied bei Kom- } \\
\text { plikationen (RR } \\
0,76,95 \% \mathrm{Cl} \\
0,41-1,04 \text {, } \\
\mathrm{P}=0,38 \text { ) und } \\
\text { Mortalität (RR } \\
1,13,95 \% \mathrm{Cl} \\
0,23-5,63 \text {, } \\
\mathrm{P}=0,88 \text { ) } \\
\text { Schweregrad } \\
\text { der Pankreatitis } \\
\text { ohne Einfluss }\end{array}$ & & II \\
\hline $\begin{array}{l}\text { van Santvoort } \\
2009 \text { [176] }\end{array}$ & $\begin{array}{l}\text { prospektive } \\
\text { multizentri- } \\
\text { sche Kohorte }\end{array}$ & $N=153$ & $\begin{array}{l}\text { akute, voraussicht- } \\
\text { lich schwere biliäre } \\
\text { Pankreatitis }\end{array}$ & $\begin{array}{l}\text { frühe ERC }(72 \mathrm{~h}) \\
(\mathrm{N}=81) \text { vs. kon- } \\
\text { servative Behand- } \\
\text { lung }(\mathrm{N}=72)\end{array}$ & $\begin{array}{l}\text { ERC reduzierte } \\
\text { Komplikationen } \\
\text { bei Patienten } \\
\text { mit Cholestase } \\
\text { ( } 25 \text { vs. } 54 \% \text {, } \\
\text { P=0,020, OR } \\
0,35,95 \% \mathrm{Cl} \\
0,13-0,99 \text { ) } \\
\text { kein Unter- } \\
\text { schied bei } \\
\text { Patienten ohne } \\
\text { Cholestase } \\
\text { ( } 45 \text { vs. } 41 \%, \\
\text { P=0,814, OR } \\
1,36,95 \% \text { Cl } \\
0,49-3,76 \text { ) } \\
\text { kein Mortalitäts- } \\
\text { unterschied bei } \\
\text { beiden }\end{array}$ & & II \\
\hline Tse 2012 [177] & $\begin{array}{l}\text { systemati- } \\
\text { sches Review } \\
\text { mit Metaana- } \\
\text { lyse }\end{array}$ & $\begin{array}{l}\mathrm{N}=664 \text { aus } 5 \\
\mathrm{RCT}\end{array}$ & $\begin{array}{l}\text { akute biliäre } \\
\text { Pankreatitis, } \\
\text { Subgruppe mit } \\
\text { schwerer Pan- } \\
\text { kreatitis ( } 2 \text { RCT) }\end{array}$ & $\begin{array}{l}\text { frühe routinemä- } \\
\text { ßige ERC }(<72 \mathrm{~h}) \\
\text { vs. frühe konser- } \\
\text { vative Behandlung } \\
\text { mit oder oder }\end{array}$ & $\begin{array}{l}\text { ohne begleiten- } \\
\text { de Cholestase } \\
\text { oder Cholangitis } \\
\text { kein Unter- } \\
\text { schied bei Mor- }\end{array}$ & & I \\
\hline
\end{tabular}




\begin{tabular}{|c|c|c|c|c|c|c|c|}
\hline Referenz & Studientyp & $\begin{array}{l}\text { Interventi- } \\
\text { on }\end{array}$ & Teilnehmer & $\begin{array}{l}\text { Index- und } \\
\text { Referenztest }\end{array}$ & $\begin{array}{l}\text { Zielgröße und } \\
\text { Ergebnis }\end{array}$ & Bemerkungen & Evidenzgrad \\
\hline & & & & $\begin{array}{l}\text { selektive ERC-Stra- } \\
\text { tegie }\end{array}$ & $\begin{array}{l}\text { talität (RR 0,74, } \\
95 \% \text { Cl 0,18- } \\
3,03 \text { ), lokalen } \\
\text { und systemi- } \\
\text { schen Komplika- } \\
\text { tionen (RR 0,86, } \\
95 \% \text { Cl 0,52- } \\
1,43 ; \text { RR 0,59, } \\
95 \% \text { Cl 0,31- } \\
1,11 \text { ) } \\
\text { Schweregrad } \\
\text { der Pankreatitis } \\
\text { ohne Einfluss } \\
\text { Pankreatitis mit } \\
\text { Cholangitis: } \\
\text { Unterschied bei } \\
\text { Mortalität (RR } \\
0,20,95 \% \text { Cl } \\
0,06 \text { - 0,68) } \\
\text { sowie lokalen } \\
\text { und systemi- } \\
\text { schen Komplika- } \\
\text { tionen (RR 0,45, } \\
95 \% \text { Cl 0,20- } \\
0,99 ; \text { RR 0,37, } \\
95 \% \text { Cl 0,18- } \\
0,78 \text { ) }\end{array}$ & & \\
\hline
\end{tabular}

Empfehlung III.C10

\begin{tabular}{|c|c|c|c|c|c|c|c|}
\hline $\begin{array}{l}\text { Refe- } \\
\text { renz }\end{array}$ & Studientyp & Intervention & Teilnehmer & $\begin{array}{l}\text { Index- und } \\
\text { Referenztest }\end{array}$ & $\begin{array}{l}\text { Zielgröße und } \\
\text { Ergebnis }\end{array}$ & Bemerkungen & $\begin{array}{l}\text { Evidenz- } \\
\text { grad }\end{array}$ \\
\hline $\begin{array}{l}\text { Sharaiha } \\
2017 \\
{[178]}\end{array}$ & $\begin{array}{l}\text { systematischer } \\
\text { Review und } \\
\text { Metaanalyse }\end{array}$ & $\begin{array}{l}\mathrm{N}=483 \text { Patienten } \\
\text { aus } 9 \text { vergleichen- } \\
\text { den Studien (davon } \\
3 \text { RCT) PTCD vs. } \\
\text { EUS-gestützte Gal- } \\
\text { lengangdrainage }\end{array}$ & $\begin{array}{l}\text { Medline, Embase, } \\
\text { Cochrane, Web of } \\
\text { Science und Scopus } \\
\text { Januar } 2001 \text { - Sep- } \\
\text { tember } 2016\end{array}$ & $\begin{array}{l}\text { PTCD vs. EUS-ge- } \\
\text { stützte Gallengang- } \\
\text { drainage: techni- } \\
\text { scher und klinischer } \\
\text { Erfolg, Komplikatio- } \\
\text { nen, Re-Interventio- } \\
\text { nen }\end{array}$ & $\begin{array}{l}\text { identischer techni- } \\
\text { scher Erfolg, bes- } \\
\text { serer klinischer Er- } \\
\text { folg (OR 0,45), } \\
\text { weniger Komplika- } \\
\text { tionen (OR 0,23) } \\
\text { und weniger } \\
\text { Re-Interventionen } \\
\text { (OR 0,13) bei EUS- } \\
\text { gestützter Gallen- } \\
\text { gangdrainage vs. } \\
\text { PTCD }\end{array}$ & $\begin{array}{l}\text { Heterogenität } \\
\text { der Studien, } \\
\text { keine Aussage } \\
\text { zur Anzahl be- } \\
\text { nigner Indika- } \\
\text { tionen }\end{array}$ & III \\
\hline $\begin{array}{l}\text { Khan } \\
2016 \\
{[179]}\end{array}$ & $\begin{array}{l}\text { systematischer } \\
\text { Review und } \\
\text { Metaanalyse }\end{array}$ & $\begin{array}{l}\mathrm{N}=1186 \text { Patienten } \\
\text { aus } 19 \text { Beobach- } \\
\text { tungsstudien und } \\
\text { einem RCT, davon } \\
10 \text { Studien mit } \\
\text { Einschluss beni- } \\
\text { gner Indikationen }\end{array}$ & $\begin{array}{l}\text { Medline, Embase, } \\
\text { Cochrane, Web of } \\
\text { Science und Scopus } \\
\text { Januar } 2001 \text { - Janu- } \\
\text { ar } 2015\end{array}$ & $\begin{array}{l}\text { Beurteilung von } \\
\text { technischem und } \\
\text { klinischem Erfolg } \\
\text { sowie Komplikatio- } \\
\text { nen endosonografi- } \\
\text { scher Gallengang- } \\
\text { drainagen } \\
\text { Analyse von Ein- } \\
\text { flussfaktoren }\end{array}$ & $\begin{array}{l}90 \% \text { gepoolter } \\
\text { technischer Erfolg } \\
\text { und } 17 \% \text { Kompli- } \\
\text { kationsrate, höhe- } \\
\text { rer technischer Er- } \\
\text { folg bei distaler } \\
\text { Gallengangstrik- } \\
\text { tur und transpa- } \\
\text { pillärer Drainage } \\
\text { höhere Sicherheit } \\
\text { des extrahepati- } \\
\text { schen gegenüber } \\
\text { dem intrahepati- } \\
\text { schen Zugang }\end{array}$ & $\begin{array}{l}\text { nur } 14 \% \text { der in } \\
\text { die Metaana- } \\
\text { lyse einge- } \\
\text { schlossenen } \\
\text { Patienten hat- } \\
\text { ten benigne } \\
\text { Indikationen }\end{array}$ & III \\
\hline
\end{tabular}




\begin{tabular}{|c|c|c|c|c|c|c|c|}
\hline Referenz & Studientyp & Intervention & Teilnehmer & $\begin{array}{l}\text { Index- und } \\
\text { Referenztest }\end{array}$ & $\begin{array}{l}\text { Zielgröße und } \\
\text { Ergebnis }\end{array}$ & Bemerkungen & Evidenzgrad \\
\hline $\begin{array}{l}\text { Gurusamy } \\
2013 \text { [180] }\end{array}$ & $\begin{array}{l}\text { systematisches Re- } \\
\text { view mit } 2 \text { RCT }\end{array}$ & $N=70+86=156$ & $\begin{array}{l}\text { Patienten, } \\
\text { mit perkuta- } \\
\text { ner Cholezys- } \\
\text { tostomie }\end{array}$ & $\begin{array}{l}\text { Cholezystosto- } \\
\text { mie ( } 1 \text { Studie mit } \\
\text { früher } L C \text { ) vs. } \\
\text { verzögerte LC } \\
\text { oder konservati- } \\
\text { ve Behandlung }\end{array}$ & $\begin{array}{l}\text { Cholezystosto- } \\
\text { mie mit früher LC } \\
\text { vs. später LC: kei- } \\
\text { ne Unterschiede } \\
\text { bei Mortalität } \\
\text { und Morbidität } \\
\text { Frühe LC: kürzere } \\
\text { Krankenhausver- } \\
\text { weildauer, nied- } \\
\text { rigere Kosten } \\
\text { Cholezystosto- } \\
\text { mie vs. konser- } \\
\text { vative Behand- } \\
\text { lung: keine } \\
\text { Unterschiede bei } \\
\text { Mortalität und } \\
\text { Morbidität }\end{array}$ & & II \\
\hline $\begin{array}{l}\text { Winbladh } \\
2009 \text { [181] }\end{array}$ & $\begin{array}{l}\text { systematisches Re- } \\
\text { view von } \\
\text { Kohortenstudien }\end{array}$ & $\begin{array}{l}\text { Patienten mit } \\
\text { akuter Cholezys- } \\
\text { titis } \\
\mathrm{N}=1918 \text { aus } 53 \\
\text { Studien }\end{array}$ & $\begin{array}{l}\text { Medline, Cl- } \\
\text { NAHL, Emba- } \\
\text { se und Coch- } \\
\text { rane } \\
\text { Studien in } \\
\text { Englisch oder } \\
\text { Schwedisch } \\
\text { mit mindes- } \\
\text { tens } 6 \text { Patien- } \\
\text { ten, die einer } \\
\text { ultraschallge- } \\
\text { steuerten } \\
\text { oder CT-ge- } \\
\text { führten per- } \\
\text { kutanen Cho- } \\
\text { lezystostomie } \\
\text { unterzogen } \\
\text { wurden }\end{array}$ & $\begin{array}{l}\text { perkutane Cho- } \\
\text { lezystostomie }\end{array}$ & $\begin{array}{l}\text { primäre Erfolgs- } \\
\text { rate } 86 \% \\
\text { Cholezystekto- } \\
\text { mie im Verlauf } \\
\text { bei } 40 \% \text { der Pa- } \\
\text { tienten mit einer } \\
\text { Mortalität von } \\
1,96 \% \\
\text { prozedurbezoge- } \\
\text { ne Mortalität } \\
0,36 \%, 30-T a- \\
\text { ges-Mortalität } \\
15,4 \% \text { bei mit } \\
\text { perkutaner Cho- } \\
\text { lezystostomie } \\
\text { behandelten Pa- } \\
\text { tienten und } 4,5 \% \\
\text { bei akuter Chole- } \\
\text { zystektomie }\end{array}$ & $\begin{array}{l}\text { keine RCT, } \\
\text { stark variieren- } \\
\text { de Einschluss- } \\
\text { kriterien, be- } \\
\text { grenztes Fol- } \\
\text { low-up }\end{array}$ & $\|$ \\
\hline $\begin{array}{l}\text { Khan } 2017 \\
{[182]}\end{array}$ & $\begin{array}{l}\text { systematisches Re- } \\
\text { view und Metaana- } \\
\text { lyse }\end{array}$ & $\begin{array}{l}\mathrm{N}=809 \\
\text { Patienten in } 23 \\
\text { Studien, davon } 2 \\
\text { RCT }\end{array}$ & $\begin{array}{l}\text { Medline, Em- } \\
\text { base, Cochra- } \\
\text { ne und Scopus } \\
\text { bis Dezember } \\
2015\end{array}$ & $\begin{array}{l}\text { perkutane vs. } \\
\text { endoskopisch } \\
\text { transpapilläre } \\
\text { und EUS-ge- } \\
\text { stützte Gallen- } \\
\text { blasendrainagen: } \\
\text { technischer und } \\
\text { klinischer Erfolg, } \\
\text { postinterventio- } \\
\text { nelle Komplika- } \\
\text { tionen, Re-inter- } \\
\text { ventionen }\end{array}$ & $\begin{array}{l}\text { gepoolte Daten } \\
\text { für ERC mit } \\
\text { transpapillärer } \\
\text { Drainage: tech- } \\
\text { nischer Erfolg } \\
83 \% \text { (95\% CI } 78 \\
87 \% \text { ), klinischer } \\
\text { Erfolg } 93 \% \text { (95\% } \\
\text { Cl 89-96\%), } \\
\text { Komplikationsra- } \\
\text { te } 10 \% \\
\text { (95\% CI 7- } \\
13 \%), \text { Rezidiv } \\
\text { Cholecystitis: } 3 \% \\
\text { (95\% CI 1-5\%) } \\
\text { gepoolte Daten } \\
\text { für EUS-gestützte } \\
\text { Gallenblasendrai- } \\
\text { nage: technischer } \\
\text { Erfolg } 93 \% \text { (95\% } \\
\text { Cl 87-96\%), kli- } \\
\text { nischer Erfolg } \\
97 \% \text { (95\% CI } 93 \text { - } \\
99 \% \text { ), Komplikati- } \\
\text { onsrate } 13 \%\end{array}$ & & \\
\hline
\end{tabular}




\begin{tabular}{|c|c|c|c|c|c|c|c|}
\hline Referenz & Studientyp & Intervention & Teilnehmer & $\begin{array}{l}\text { Index- und } \\
\text { Referenztest }\end{array}$ & $\begin{array}{l}\text { Zielgröße und } \\
\text { Ergebnis }\end{array}$ & Bemerkungen & Evidenzgrad \\
\hline & & & & & $\begin{array}{l}\text { (95\% Cl } 8 \text { - 19\%), } \\
\text { Rezidiv Cholecys- } \\
\text { titis } 4 \% \text { ( } 95 \% \text { Cl } \\
2-9 \% \text { ) } \\
\text { gepoolte OR für } \\
\text { technischen Er- } \\
\text { folg der endosko- } \\
\text { pischen vs. per- } \\
\text { kutanen Gallen- } \\
\text { blasendrainage } \\
\text { war 0,51 (95\% Cl } \\
0,09-2,88) \text { und } \\
\text { für Komplikatio- } \\
\text { nen 0,33 (95\% Cl } \\
0,14-0,88)\end{array}$ & & \\
\hline
\end{tabular}

Empfehlungen IIIC.15

\begin{tabular}{|c|c|c|c|c|c|c|c|}
\hline Referenz & Studientyp & Intervention & Teilnehmer & $\begin{array}{l}\text { Index- und } \\
\text { Referenztest }\end{array}$ & $\begin{array}{l}\text { Zielgröße und } \\
\text { Ergebnis }\end{array}$ & Bemerkungen & Evidenzgrad \\
\hline $\begin{array}{l}\text { Date } 2008 \\
\text { [183] }\end{array}$ & $\begin{array}{l}\text { systematisches } \\
\text { Review von } \\
\text { Studien mäßi- } \\
\text { ger Qualität }\end{array}$ & $\begin{array}{l}\text { konservative } \\
\text { vs. chirurgi- } \\
\text { sche Therapie } \\
\text { bei Cholezysti- } \\
\text { tis: } 6 \text { Studien } \\
\text { Sicherheit der } \\
\text { LC: } 20 \text { Berichte } \\
\text { ERC: } 9 \text { Berichte } \\
\text { biliäre Pankrea- } \\
\text { titis: } 12 \text { Berich- } \\
\text { te }\end{array}$ & $\begin{array}{l}\text { Management } \\
\text { der Cholezysto- } \\
\text { und Choledo- } \\
\text { cholithiasis } \\
\text { sowie der akuten } \\
\text { Pankreatitis } \\
\text { LC vs. offene } \\
\text { Cholezystekto- } \\
\text { mie }\end{array}$ & $\begin{array}{l}\text { OP, MRCP, LC vs. } \\
\text { konservativ, ERC, } \\
\text { IOC, CBD-Explora- } \\
\text { tion, offene Cho- } \\
\text { lezystektomie }\end{array}$ & $\begin{array}{l}\text { kein Unterschied } \\
\text { bei Frühgeburten- } \\
\text { rate oder fetaler } \\
\text { Mortalität zwi- } \\
\text { schen konservati- } \\
\text { ver und operativer } \\
\text { Therapie } \\
\text { keine maternale } \\
\text { oder fetale Morta- } \\
\text { lität nach LC oder } \\
\text { ERC } \\
\text { LC in allen Trimes- } \\
\text { tern unbedenklich } \\
\text { kein Unterschied } \\
\text { bei fetaler Morta- } \\
\text { lität zwischen } \\
\text { konservativer und } \\
\text { chirurgischer The- } \\
\text { rapie bei biliärer } \\
\text { Pankreatitis ( } 8,0 \% \\
\text { bei konservativer } \\
\text { vs. } 2,6 \% \text { bei chi- } \\
\text { rurgischer Thera- } \\
\text { pie, P = } 0,28 \text { ) }\end{array}$ & $\begin{array}{l}\text { mäßige Quali- } \\
\text { tät der Studien }\end{array}$ & II \\
\hline $\begin{array}{l}\text { Dhupar } \\
2010[184]\end{array}$ & $\begin{array}{l}\text { retrospektive } \\
\text { Fall-Kontroll- } \\
\text { Studie }\end{array}$ & $\begin{array}{l}\mathrm{N}=58 \text { Schwan- } \\
\text { gere mit symp- } \\
\text { tomatischer } \\
\text { Cholelithiasis }\end{array}$ & $\begin{array}{l}\text { symptomatische } \\
\text { Cholelithiasis } \\
\text { während der } \\
\text { Schwanger- } \\
\text { schaft }\end{array}$ & $\begin{array}{l}\mathrm{LC}(\mathrm{N}=19) \text { vs. } \\
\text { konservative } \\
\text { Behandlung } \\
(\mathrm{N}=39)\end{array}$ & $\begin{array}{l}\text { höhere Morbidität } \\
\text { bei konservativem } \\
\text { Vorgehen ( } 36 \text { vs. } \\
5 \% \text { ) }\end{array}$ & $\begin{array}{l}\text { kleine Fallzahl } \\
\text { und } 56 \% \text { Loss } \\
\text { to follow-up }\end{array}$ & III \\
\hline $\begin{array}{l}\text { Othman } \\
2012 \text { [185] }\end{array}$ & $\begin{array}{l}\text { retrospektive } \\
\text { Fall-Kontroll- } \\
\text { Kohorte }\end{array}$ & $\begin{array}{l}\mathrm{N}=112 \\
\text { Schwangere } \\
\text { mit sympto- } \\
\text { matischer Cho- } \\
\text { lelithiasis }\end{array}$ & $\begin{array}{l}\text { symptomatische } \\
\text { Cholelithiasis } \\
\text { während der } \\
\text { Schwanger- } \\
\text { schaft }\end{array}$ & $\begin{array}{l}\text { LC/ERC }(\mathrm{N}=27 / \\
13,4 \text { Patienten } \\
\text { beides) vs. kon- } \\
\text { servative Behand- } \\
\text { lung }(\mathrm{N}=68)\end{array}$ & $\begin{array}{l}\text { in der konservati- } \\
\text { ven Gruppe mehr } \\
\text { biliäre Symptome } \\
\text { sowie häufiger } \\
\text { Notaufnahme, sta- } \\
\text { tionäre Aufnahme } \\
\text { und Sectio kein } \\
\text { Unterschied bei } \\
\text { Geburtsgewicht }\end{array}$ & $\begin{array}{l}\text { retrospektiv, } \\
\text { monozen- } \\
\text { trisch, tertiäres } \\
\text { Zentrum }\end{array}$ & III \\
\hline
\end{tabular}


Empfehlung IV.6

\begin{tabular}{|c|c|c|c|c|c|c|c|}
\hline Referenz & Studientyp & Intervention & Teilnehmer & $\begin{array}{l}\text { Index- und } \\
\text { Referenztest }\end{array}$ & $\begin{array}{l}\text { Zielgröße und } \\
\text { Ergebnis }\end{array}$ & Bemerkungen & Evidenzgrad \\
\hline $\begin{array}{l}\text { Barthels- } \\
\text { son } 2008 \\
{[186]}\end{array}$ & $\mathrm{RCT}$ & $\begin{array}{l}\text { ambulante vs. } \\
\text { stationäre } \\
\text { Cholezystek- } \\
\text { tomie }\end{array}$ & $\begin{array}{l}\mathrm{N}=34 \text { ambulant } \\
\text { vs. } \mathrm{N}=39 \text { stationär, } \\
\text { ASA I - II, } 20-70 \\
\text { Jahre }\end{array}$ & $\begin{array}{l}\text { elektive LC in 4-Tro- } \\
\text { kartechnik, ambulant } \\
\text { vor 11:00 Uhr mit Ent- } \\
\text { lasssung nach } 5-6 \mathrm{~h} \\
\text { vs. stationär mit Ent- } \\
\text { lassung am Folgetag }\end{array}$ & $\begin{array}{l}\text { Wiederaufnahme } \\
1 / 34 \text { ambulanten } \\
\text { Patienten } \\
\text { QoL und Schmer- } \\
\text { zen idem }\end{array}$ & $\begin{array}{l}\text { Randomisie- } \\
\text { rung unklar }\end{array}$ & II \\
\hline $\begin{array}{l}\text { Vaughan } \\
2013 \\
{[187]}\end{array}$ & $\begin{array}{l}\text { systemati- } \\
\text { sches Review } \\
\text { mit Meta- } \\
\text { analyse }\end{array}$ & $\begin{array}{l}\text { Cochrane, } \\
\text { Medline, Em- } \\
\text { base und SCI }\end{array}$ & $\begin{array}{l}6 \mathrm{RCT} \text { mit } \mathrm{N}=492 \\
(\mathrm{~N}=239 \text { ambulant } \\
\text { und } \mathrm{N}=253 \text { mit } \\
\text { Fast track) }\end{array}$ & $\begin{array}{l}\text { ambulante Cholezyst- } \\
\text { ektomie vs. Fast track }\end{array}$ & $\begin{array}{l}\text { keine signifikan- } \\
\text { ten Unterschiede }\end{array}$ & $\begin{array}{l}\text { weitere Studi- } \\
\text { en zu QoL und } \\
\text { Outcome } \\
\text { erforderlich }\end{array}$ & II \\
\hline
\end{tabular}




\section{Anhang IV: Schema zur Graduierung der Evidenzstärke}

OCEBM Levels of Evidence Working Group. Oxford Centre for Evidence-Based Medicine 2011 Levels of Evidence (http://www.cebm.net/ index.aspx?o=5653)

Oxford Centre for Evidence-Based Medicine 2011 Levels of Evidence

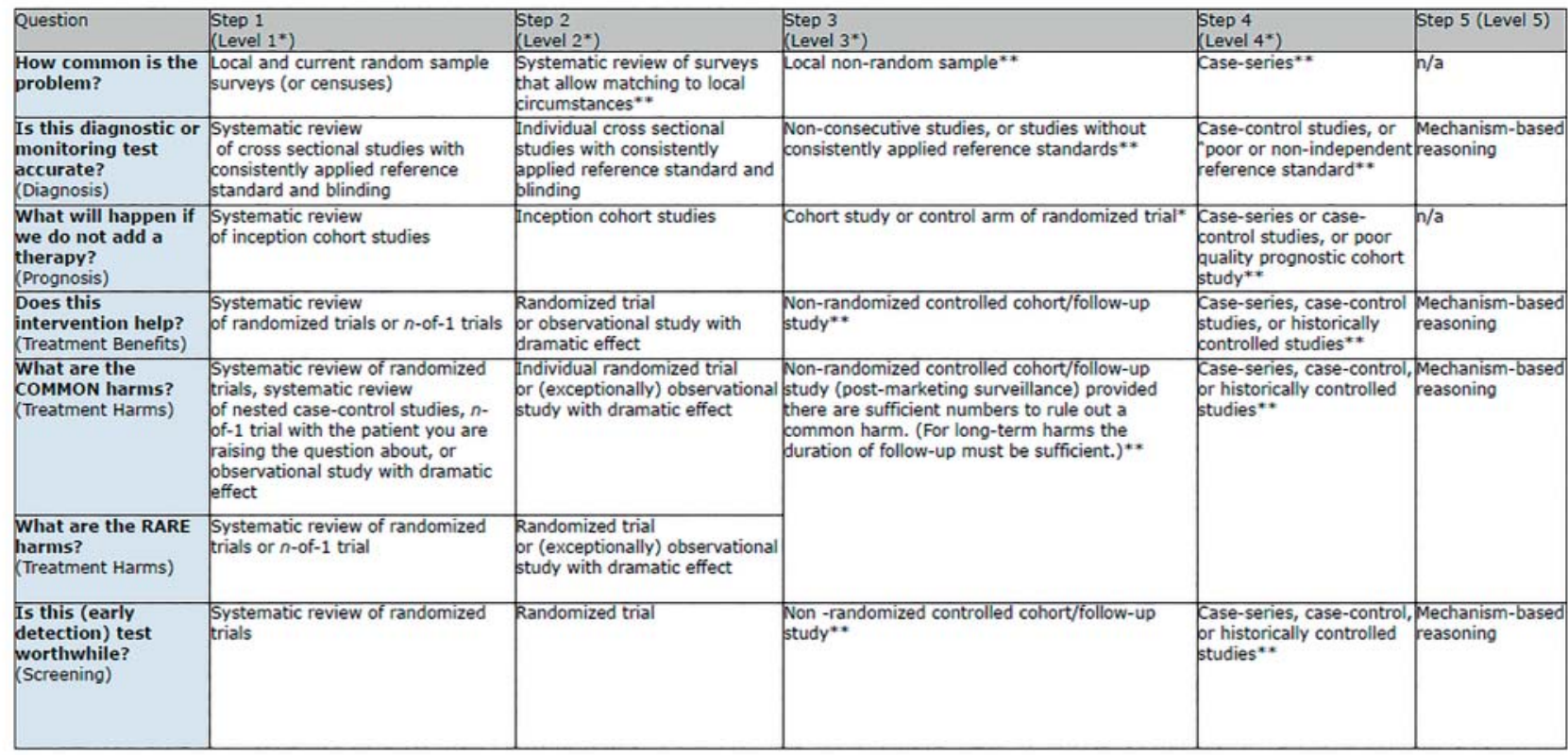

* Level may be graded down on the basis of study quality, imprecision, indirectness (study PIcO does not match questions PICO), because of inconsistency between studies, or because the absolute effect size is very small; Level may be graded up if there is a large or very large effect size.

** As always, a systematic review is generally better than an individual study.

How to cite the Levels of Evidence Table

OCEBM Levels of Evidence Working Group*. "The Oxford 2011 Levels of Evidence".

Oxford Centre for Evidence-Based Medicine. htto://www.cebm.net/index.aspx?0=5653

* OCEBM Table of Evidence Working Group - Jeremy Howick, Iain Chaimers (James Lind Library), Paul Glasziou, Trish Greenhalgh, Carl Heneghan, Alessandro Liberati, Ivan Moschetti, Bob Phillips, Hazel Thomton, Olive Goddard and Mary Hodgkinson

- Abb. 1 OCEBM Levels of Evidence Working Group. Oxford Centre for Evidence-Based Medicine 2011 Levels of Evidence (http://www.cebm.net/ index.aspx?0 $=5653$ ) 


\section{Anhang V: Schema zur Graduierung der Empfehlungsstärke}

Graduierung von Empfehlungen nach: Bundesärztekammer, AWMF, Kassenärztliche Bundesvereinigung (Hrsg). Programm für Nationale Versorgungsleitlinien - Methodenreport. ÄZQ, Berlin (http://www.methodik.n-v-l.de/).

\section{Von der Evidenz zur Empfehlung: \\ Visualisierung der klinischen Beurteilung \\ als Prozess der Kriteriengestützten Konsensusentscheidung}

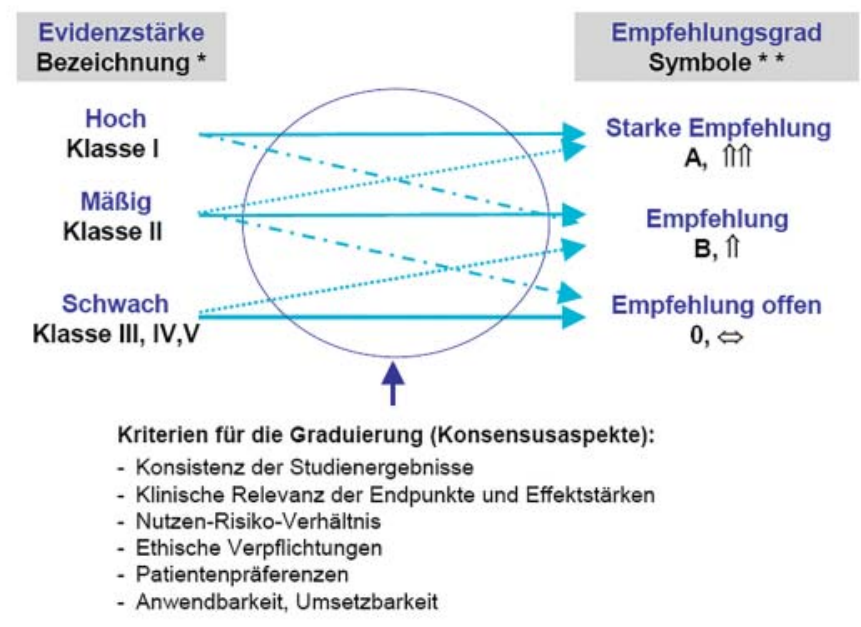

- Abb.2 Kopp I, Lelgemann M, Ollenschläeger G. EbM und Leitlinien. In: Kunz R et al. (Hrsg.). Lehrbuch Evidenzbasierte Medizin in Klinik und Praxis. Deutscher Ärzteverlag, Köln 2007. *Nach Oxford Centre of Evidence based Medicine. ${ }^{* *}$ Symbole der Empfehlungsgraduierung im Programm für Nationale Versorgungsleitlinien.

Die Empfehlungen wurden analog formuliert:

Starke Empfehlung: „soll“; Empfehlung: „sollte“; Empfehlung offen: „kann“ (Handlungsoption). Negativ-Empfehlungen wurden sprachlich ausgedrückt („nicht“) bei gleichen Symbolen.

\section{Literatur}

[1] Berndt H, Nürnberg D, Pannwitz H. Prävalenz der Cholelithiasis. Ergebnisse einer epidemiologischen Studie mittels Sonographie in der DDR. Z Gastroenterol 1989; 27: 662-666

[2] Kratzer W, Mason RA, Kachele V. Prevalence of gallstones in sonographic surveys worldwide. J Clin Ultrasound 1999; 27: 1-7

[3] Lammert F, Sauerbruch T. Mechanisms of disease: the genetic epidemiology of gallbladder stones. Nat Clin Pract Gastroenterol Hepatol 2005; 2 : 423-433

[4] Völzke H, Baumeister SE, Alte D et al. Independent risk factors for gallstone formation in a region with high cholelithiasis prevalence. Digestion 2005; 71: 97-105

[5] Spindler J. Fallpauschalenbezogene Krankenhausstatistik: Diagnosen und Prozeduren der Krankenhauspatienten auf Basis der Daten nach §21 Krankenhausentgeltgesetz. In: Klauber J, Geraedts M, Friedrich J eds, et al., Hrsg Krankenhaus-Report 2017 Schwerpunkt: Zukunft gestalten. Stuttgart: Schattauer; 2017: $321-353$

[6] Wittenburg H. Pathoegnese der Gallensteine. Gastroenterologe 2018; 13: $6-14$

[7] Sandler RS, Everhart JE, Donowitz M et al. The burden of selected digestive diseases in the United States. Gastroenterology 2002; 122: 1500 1511
[8] Encke A, Kopp I, Selbmann HK et al. Arbeitsgemeinschaft der Wissenschaftlichen Medizinischen Fachgesellschaften (AWMF), Ärztliches Zentrum für Qualität in der Medizin (ÄZQ), and (Hrsg). Deutsches Instrument zur methodischen Bewertung von Leitlinien: DELBI. DtÄrzteblø, 102: A1912-A1913 www.delbi.de

[9] Lynen JansenP, Preiss JC, Muche-Borowski C et al. Das Leitlinienprogramm der DGVS. Z Gastroenterol 2013; 51: 643-650

[10] Muche BorowskiM. http://www.awmf.org/leitlinien/awmf-regelwerk/ awmf-regelwerk-offline.html

[11] Gechter D et al. http://www.cochrane.de/sites/cochrane.de/files/uploads/20130523_Manual_Literaturrecherche_Final.pdfGechter

[12] Neubrand M, Sackmann M, Caspary WF et al. Guidelines by the German Society of Digestive and Metabolic Diseases for treatment of gallstones. German Society of Digestive and Metabolic Diseases. Z Gastroenterol 2000; 38: 449-468

[13] Lammert F, Neubrand MW, Bittner R et al. S3-Leitlinie der Deutschen Gesellschaft für Verdauungs- und Stoffwechselkrankheiten und der Deutschen Gesellschaft für Viszeralchirurgie zur Diagnostik und Behandlung von Gallensteinen. Z Gastroenterol 2007; 45: 971 - 1001

[14] Takada T, Strasberg SM, Solomkin JS et al. TG13: updated Tokyo guidelines for the management of acute cholangitis and cholecystitis. J Hepatobiliary Pancreat Sci 2013; 20: 1 -7

[15] Warttig S, Ward S, Rogers $G$ et al. Diagnosis and management of gallstone disease: summary of NICE guidance. BMJ 2014; 349: g6241 
[16] Neederlandse richtlijnGalsteenlijden. 2016 https://richtlijnendatabase. nl/richtlijn/galsteenlijden/galsteenlijden_-_startpagina.html

[17] European Association for theStudy of the Liver. EASL Clinical Practice Guidelines on the prevention, diagnosis and treatment of gallstones. J Hepatol 2016; 65: 146-181

[18] Williams E, Beckingham I, El SayedG et al. Updated guideline on the management of common bile duct stones (CBDS). Gut 2017; 66: 765 782

[19] da Costa DW, Bouwense SA, Schepers NJ et al. Same-admission versus interval cholecystectomy for mild gallstone pancreatitis (PONCHO): a multicentre randomised controlled trial. Lancet 2015; 386: 1261 - 1268

[20] Medizinischer Fakultätentag. Nationaler Kompetenzbasierter Lernzielkatalog Medizin (NKLM) 2015. Berlin, 2015

[21] Leese T, Neoptolemos JP, Baker AR et al. Management of acute cholangitis and the impact of endoscopic sphincterotomy. Br J Surg 1986; 73 988-992

[22] Lai EC, Mok FP, Tan ES et al. Endoscopic biliary drainage for severe acute cholangitis. N Engl J Med 1992; 326: $1582-1586$

[23] Leung JW, Ling TK, Chan RC et al. Antibiotics, biliary sepsis, and bile duct stones. Gastrointest Endosc 1994; 40: 716-721

[24] Sharma BC, Agarwal DK, Baijal SS et al. Endoscopic management of acute calculous cholangitis. J Gastroenterol Hepatol 1997; 12: 874-876

[25] Csendes A, Diaz JC, Burdiles P et al. Risk factors and classification of acute suppurative cholangitis. Br J Surg 1992; 79: 655-658

[26] Boey JH, Way LW. Acute cholangitis. Ann Surg 1980; 191: 264-270

[27] Reynolds BM, Dargan EL. Acute obstructive cholangitis; a distinct clinical syndrome. Ann Surg 1959; 150: 299-303

[28] Shea JA, Berlin JA, Escarce J] et al. Revised estimates of diagnostic test sensitivity and specificity in suspected biliary tract disease. Arch Intern Med 1994; 154: $2573-2581$

[29] Trowbridge RL, Rutkowski NK, Shojania KG. Does this patient have acute cholecystitis? JAMA 2003; 289: 80-86

[30] Tenner S, Dubner $\mathrm{H}$, Steinberg W. Predicting gallstone pancreatitis with laboratory parameters: a meta-analysis. Am J Gastroenterol 1994; 89 : $1863-1866$

[31] Ammori B], Boreham B, Lewis P et al. The biochemical detection of biliary etiology of acute pancreatitis on admission: a revisit in the modern era of biliary imaging. Pancreas 2003; 26: e32-35

[32] Lévy P, Boruchowicz A, Hastier P et al. Diagnostic criteria in predicting a biliary origin of acute pancreatitis in the era of endoscopic ultrasound: multicentre prospective evaluation of 213 patients. Pancreatology 2005; 5: $450-456$

[33] Liu CL, Fan ST, Lo CM et al. Clinico-biochemical prediction of biliary cause of acute pancreatitis in the era of endoscopic ultrasonography. Aliment Pharmacol Ther 2005; 22: 423-431

[34] Sackmann M. Behandlung der biliären Kolik. Dtsch Med Wochenschr 1998; 123: $945-947$

[35] Festi D, Sottili S, Colecchia A et al. Clinical manifestations of gallstone disease: evidence from the multicenter Italian study on cholelithiasis (MICOL). Hepatology 1999; 30: 839-846

[36] Neubrand M, Sackmann M, Caspary W et al. Leitlinien der Deutschen Gesellschaft für Verdauungs- und Stoffwechselkrankheiten zur Behandlung von Gallensteinen. Z Gastroenterol 2000; 38: 449-468

[37] Lorenz W, Ollenschläger G, Geraedts M et al. Das Leitlinien-Manual. Entwicklung und Implementierung von Leitlinien in der Medizin. Z Ärztl Fortbild Qual Gesundheitswes 2001; 95: 1-84

[38] Beyer M, Geraedts M, Gerlach FM et al. Deutsches Instrument zur methodischen Leitlinien-Bewertung (DELBI). Z Ärztl Fortbild Qual Gesundheitswes 2006; 99: 468-492

[39] Rünzi M, Layer P, Büchler MW et al. Therapie der akuten Pankreatitis. Gemeinsame Leitlinien. Z Gastroenterol 2000; 38: 571-581
[40] Singer M, Deutschman CS, Seymour CW et al. The third international consensus definitions for sepsis and septic shock (sepsis-3). JAMA 2016; 315: $801-810$

[41] Misciagna G, Centonze S, Leoci C et al. Diet, physical activity, and gallstones - a population-based, case-control study in southern Italy. Am J Clin Nutr 1999; 69: 120-126

[42] Tsai C], Leitzmann MF, Willett WC et al. Long-term intake of dietary fiber and decreased risk of cholecystectomy in women. Am J Gastroenterol 2004; 99: 1364 - 1370

[43] Tsai C], Leitzmann MF, Willett WC et al. Dietary carbohydrates and glycaemic load and the incidence of symptomatic gall stone disease in men. Gut 2005; 54: 823-828

[44] Tsai C], Leitzmann MF, Willett WC et al. Glycemic load, glycemic index, and carbohydrate intake in relation to risk of cholecystectomy in women. Gastroenterology 2005; 129: 105-112

[45] Tsai C], Leitzmann MF, Willett WC et al. Fruit and vegetable consumption and risk of cholecystectomy in women. Am J Med 2006; 119: 760 - 767

[46] Nordenvall C, Oskarsson V, Wolk A. Fruit and vegetable consumption and risk of cholecystectomy: a prospective cohort study of women and men. Eur J Nutr 2018; 57: 75-81

[47] Pixley F, Wilson D, McPherson $\mathrm{K}$ et al. Effect of vegetarianism on development of gall stones in women. Br Med J (Clin Res Ed) 1985; 291: 11 - 12

[48] Pixley F, Mann J. Dietary factors in the aetiology of gall stones: a case control study. Gut 1988; 29: 1511-1515

[49] Walcher T, Haenle MM, Mason RA et al. The effect of alcohol, tobacco and caffeine consumption and vegetarian diet on gallstone prevalence. Eur ] Gastroenterol Hepatol 2010; 22: 1345 - 1351

[50] Lander EM, Wertheim BC, Koch SM et al. Vegetable protein intake is associated with lower gallbladder disease risk: Findings from the Women's Health Initiative prospective cohort. Prev Med 2016; 88: 20-26

[51] Barre A, Gusto G, Cadeau C et al. Diet and risk of cholecystectomy: a prospective study based on the French E3N cohort. Am J Gastroenterol 2017; $112: 1448-1456$

[52] McConnell T], Appleby PN, Key T]. Vegetarian diet as a risk factor for symptomatic gallstone disease. Eur ] Clin Nutr 2017; 71: 731 - 735

[53] Tsai C], Leitzmann MF, Hu FB et al. Frequent nut consumption and decreased risk of cholecystectomy in women. Am J Clin Nutr 2004; 80: 76-81

[54] Tsai C], Leitzmann MF, Willett WC et al. The effect of long-term intake of cis unsaturated fats on the risk for gallstone disease in men: a prospective cohort study. Ann Intern Med 2004; 141: 514-522

[55] Tsai C], Leitzmann MF, Willett WC et al. Long-term intake of trans-fatty acids and risk of gallstone disease in men. Arch Intern Med 2005; 165: $1011-1015$

[56] Tsai C], Leitzmann MF, Willett WC et al. Long-chain saturated fatty acids consumption and risk of gallstone disease among men. Ann Surg 2008; 247: $95-103$

[57] Simon JA, Hudes ES. Serum ascorbic acid and other correlates of gallbladder disease among US adults. Am J Public Health 1998; 88: 1208 1212

[58] Simon JA, Grady D, Snabes MC et al. Ascorbic acid supplement use and the prevalence of gallbladder disease. Heart \& Estrogen-Progestin Replacement Study (HERS) Research Group. J Clin Epidemiol 1998; 51: $257-265$

[59] Simon JA, Hudes ES. Serum ascorbic acid and gallbladder disease prevalence among US adults: the Third National Health and Nutrition Examination Survey (NHANES III). Arch Intern Med 2000; 160: 931 - 936

[60] Walcher T, Haenle MM, Kron M et al. Vitamin C supplement use may protect against gallstones: an observational study on a randomly selected population. BMC Gastroenterol 2009; 9: 74

[61] Tsai C], Leitzmann MF, Willett WC et al. Long-term effect of magnesium consumption on the risk of symptomatic gallstone disease among men. Am J Gastroenterol 2008; 103: 375-382 
[62] Jørgensen T. Gall stones in a Danish population. Relation to weight, physical activity, smoking, coffee consumption, and diabetes mellitus. Gut 1989; 30: 528-534

[63] Misciagna G, Leoci C, Guerra V et al. Epidemiology of cholelithiasis in southern Italy. Part II: Risk factors. Eur J Gastroenterol Hepatol 1996; 8: $585-593$

[64] Leitzmann MF, Willett WC, Rimm EB et al. A prospective study of coffee consumption and the risk of symptomatic gallstone disease in men. Jama 1999; 281: 2106-2112

[65] Ruhl CE, Everhart JE. Association of coffee consumption with gallbladder disease. Am J Epidemiol 2000; 152: $1034-1038$

[66] Leitzmann MF, Stampfer M], Willett WC et al. Coffee intake is associated with lower risk of symptomatic gallstone disease in women. Gastroenterology 2002; 123: $1823-1830$

[67] Ishizuk H, Eguchi H, Oda T et al. Relation of coffee, green tea, and caffeine intake to gallstone disease in middle-aged Japanese men. Eur J Epidemiol 2003; 18: 401 - 405

[68] Nordenvall C, Oskarsson V, Wolk A. Inverse association between coffee consumption and risk of cholecystectomy in women but not in men. Clin Gastroenterol Hepatol 2015; 13: 1096 - 1102

[69] Zhang YP, Li WQ, Sun YL et al. Systematic review with meta-analysis: coffee consumption and the risk of gallstone disease. Aliment Pharmacol Ther 2015; 42: 637-648

[70] Gebhard RL, Prigge WF, Ansel H] et al. The role of gallbladder emptying in gallstone formation during diet-induced rapid weight loss. Hepatology 1996; 24: $544-548$

[71] Festi D, Colecchia A, Orsini M et al. Gallbladder motility and gallstone formation in obese patients following very low calorie diets. Use it (fat) to lose it (well). Int J Obes Relat Metab Disord 1998; 22: 592 - 600

[72] Mendez-Sanchez N, Gonzalez V, Aguayo P et al. Fish oil ( $n-3)$ polyunsaturated fatty acids beneficially affect biliary cholesterol nucleation time in obese women losing weight. J Nutr 2001; 131: $2300-2303$

[73] Moran S, Milke P, Rodriguez-Leal G et al. Ref: Gallstone formation in obese subjects undergoing a weight reduction diet. Int J Obes Relat Metab Disord 1998; 22: 282-284

[74] Utter AC, Whitcomb DC, Nieman DC et al. Effects of exercise training on gallbladder function in an obese female population. Med Sci Sports Exerc 2000; 32: $41-45$

[75] Ko CW, Napolitano PG, Lee SP et al. Physical activity, maternal metabolic measures, and the incidence of gallbladder sludge or stones during pregnancy: a randomized trial. Am J Perinatol 2014; 31: 39-48

[76] Ahmed M, Diggory R. The correlation between ultrasonography and histology in the search for gallstones. Ann R Coll Surg Engl 2011; 93 : $81-83$

[77] Ahvenjarvi L, Koivukangas V, Jartti A et al. Diagnostic accuracy of computed tomography imaging of surgically treated acute acalculous cholecystitis in critically ill patients. J Trauma 2011; 70: 183-188

[78] Altun E, Semelka RC, Elias J et al. Acute cholecystitis: MR findings and differentiation from chronic cholecystitis. . Radiology 2007; 244: 174- 183

[79] Kiewiet J, Leeuwenburgh MM, Bipat S et al. A systematic review and meta-analysis of diagnostic performance of imaging in acute cholecystitis. Radiology 2012; 264: $708-720$

[80] Gurusamy KS, Giljaca V, Takwoingi Y et al. Ultrasound versus liver function tests for diagnosis of common bile duct stones. Cochrane Database Syst Rev 2015; 2: CD011548

[81] Garrow D, Miller S, Sinha D et al. Endoscopic ultrasound: a meta-analysis of test performance in suspected biliary obstruction. Clin Gastroenterol Hepatol 2007; 5: 616-623

[82] Jovanovic P, Salkic NN, Zerem E et al. Biochemical and ultrasound parameters may help predict the need for therapeutic endoscopic retrograde cholangiopancreatography $(E R C P)$ in patients with a firm cli- nical and biochemical suspicion for choledocholithiasis. Eur ] Intern Med 2011; 22: e110-e114

[83] Karki S, Joshi KS, Regmi S et al. Role of ultrasound as compared with ERCP in patient with obstructive jaundice. Kathmandu Univ Med J (KUMJ) 2013; 11: 237-240

[84] Tse F, Liu L, Barkun AN et al. EUS: a meta-analysis of test performance in suspected choledocholithiasis. Gastrointest Endosc 2008; 67: 235 - 244

[85] Tseng CW, Chen CC, Chen TS et al. Can computed tomography with coronal reconstruction improve the diagnosis of choledocholithiasis? J Gastroenterol Hepatol 2008; 23: 1586-1589

[86] Patel R, Ingle M, Choksi D et al. Endoscopic ultrasonography can prevent unnecessary aiagnostic endoscopic retrograde cholangiopancreatography even in patients with high likelihood of choledocholithiasis and inconclusive ultrasonography: results of a prospective study. Clin Endosc 2017; 50: $592-597$

[87] Narvaez RiveraRM, Gonzalez GonzalezJA, Monreal RoblesR et al. Accuracy of ASGE criteria for the prediction of choledocholithiasis. Rev Esp Enferm Dig 2016; 108: 309-314

[88] Sharma R, Menachery J, Choudhary NS et al. Routine endoscopic ultrasound in moderate and indeterminate risk patients of suspected choledocholithiasis to avoid unwarranted ERCP: A prospective randomized blinded study. Indian J Gastroenterol 2015; 34: 300-304

[89] Giljaca V, Gurusamy KS, Takwoingi Y et al. Endoscopic ultrasound versus magnetic resonance cholangiopancreatography for common bile duct stones. Cochrane Database Syst Rev 2015; 2: CD011549

[90] De Castro VL, Moura EG, Chaves DM et al. Endoscopic ultrasound versus magnetic resonance cholangiopancreatography in suspected choledocholithiasis: A systematic review. Endosc Ultrasound 2016; 5: 118-128

[91] Chen W, Mo JJ, Lin L et al. Diagnostic value of magnetic resonance cholangiopancreatography in choledocholithiasis. World J Gastroenterol 2015; $21: 3351-3360$

[92] Meeralam Y, Al-Shammari K, Yaghoobi M. Diagnostic accuracy of EUS compared with MRCP in detecting choledocholithiasis: a meta-analysis of diagnostic test accuracy in head-to-head studies. Gastrointest Endosc 2017; 86: $986-993$

[93] Smith I, Ramesh J, Kyanam KabirBaig KR et al. Emerging role of endoscopic ultrasound in the diagnostic evaluation of idiopathic pancreatitis. Am J Med Sci 2015; 350: 229-234

[94] Wilcox CM, Seay T, Kim H et al. Prospective endoscopic ultrasoundbased approach to the evaluation of idiopathic pancreatitis: causes, response to therapy, and long-term outcome. Am J Gastroenterol 2016; 111: $1339-1348$

[95] Mazeh H, Mizrahi I, Dior U et al. Role of antibiotic therapy in mild acute calculus cholecystitis: a prospective randomized controlled trial. World J Surg 2012; 36: 1750 - 1759

[96] Schmidt M, Sondenaa K, Vetrhus M et al. A randomized controlled study of uncomplicated gallstone disease with a 14-year follow-up showed that operation was the preferred treatment. Dig Surg 2011; 28: 270-276

[97] Festi D, Dormi A, Capodicasa S et al. Incidence of gallstone disease in Italy: results from a multicenter, population-based Italian study (the MICOL project). World J Gastroenterol 2008; 14: 5282-5289

[98] Festi D, Reggiani ML, Attili AF et al. Natural history of gallstone disease: Expectant management or active treatment? Results from a populationbased cohort study. J Gastroenterol Hepatol 2010; 25: 719-724

[99] Khan ZS, Livingston EH, Huerta S. Reassessing the need for prophylactic surgery in patients with porcelain gallbladder: case series and systematic review of the literature. Arch Surg 2011; 146: 1143-1147

[100] Cha BH, Hwang $\mathrm{JH}$, Lee $\mathrm{SH}$ et al. Pre-operative factors that can predict neoplastic polypoid lesions of the gallbladder. World J Gastroenterol 2011; 17: 2216-2222 
[101] Colecchia A, Larocca A, Scaioli E et al. Natural history of small gallbladder polyps is benign: evidence from a clinical and pathogenetic study. Am J Gastroenterol 2009; 104: 624-629

[102] French DG, Allen PD, Ellsmere JC. The diagnostic accuracy of transabdominal ultrasonography needs to be considered when managing gallbladder polyps. Surg Endosc 2013; 27: 4021-4025

[103] Ito H, Hann LE, D'Angelica $M$ et al. Polypoid lesions of the gallbladder: diagnosis and followup. J Am Coll Surg 2009; 208: 570-575

[104] Elmasry M, Lindop D, Dunne DF et al. The risk of malignancy in ultrasound detected gallbladder polyps: A systematic review. Int J Surg 2016; 33: $28-35$

[105] Bhatt NR, Gillis A, Smoothey CO et al. Evidence based management of polyps of the gall bladder: A systematic review of the risk factors of malignancy. Surgeon 2016; 14: 278-286

[106] Wiles R, Varadpande M, Muly S et al. Growth rate and malignant potential of small gallbladder polyps-systematic review of evidence. Surgeon 2014; 12: $221-226$

[107] Li VK, Pulido N, Martinez-Suartez P et al. Symptomatic gallstones after sleeve gastrectomy. Surg Endosc 2009; 23: 2488-2492

[108] Moon RC, Teixeira AF, DuCoin C et al. Comparison of cholecystectomy cases after Roux-en-Y gastric bypass, sleeve gastrectomy, and gastric banding. Surg Obes Relat Dis 2014; 10: 64-68

[109] Plecka OstlundM, Wenger U, Mattsson F et al. Population-based study of the need for cholecystectomy after obesity surgery. Br J Surg 2012; 99: $864-869$

[110] Stokes CS, Gluud LL, Casper M et al. Ursodeoxycholic acid and diets higher in fat prevent gallbladder stones during weight loss: a metaanalysis of randomized controlled trials. Clin Gastroenterol Hepatol 2014; 12: $1090-1100$

[111] Tsirline VB, Keilani ZM, El DjouziS et al. How frequently and when do patients undergo cholecystectomy after bariatric surgery? Surg Obes Relat Dis 2014; 10: 313-321

[112] Warschkow R, Tarantino I, Ukegjini K et al. Concomitant cholecystectomy during laparoscopic Roux-en-Y gastric bypass in obese patients is not justified: a meta-analysis. Obes Surg 2013; 23: 397-407

[113] Gelbard R, Karamanos E, Teixeira PG et al. Effect of delaying sameadmission cholecystectomy on outcomes in patients with diabetes. Br J Surg 2014; 101: 74-78

[114] Gul R, Dar RA, Sheikh RA et al. Comparison of early and delayed laparoscopic cholecystectomy for acute cholecystitis: experience from a single center. N Am J Med Sci 2013; 5: 414-418

[115] Gurusamy KS, Davidson C, Gluud C et al. Early versus delayed laparoscopic cholecystectomy for people with acute cholecystitis. Cochrane Database Syst Rev 2013; 6: CD005440

[116] Gutt CN, Encke J, Koninger J et al. Acute cholecystitis: early versus delayed cholecystectomy, a multicenter randomized trial (ACDC study, NCT00447304). Ann Surg 2013; 258: 385-393

[117] de Mestral C, Rotstein OD, Laupacis A et al. A population-based analysis of the clinical course of 10,304 patients with acute cholecystitis, discharged without cholecystectomy. J Trauma Acute Care Surg 2013; 74: $26-30$

[118] Macafee DA, Humes DJ, Bouliotis G et al. Prospective randomized trial using cost-utility analysis of early versus delayed laparoscopic cholecystectomy for acute gallbladder disease. Br J Surg 2009; 96: 1031 - 1040

[119] Regimbeau JM, Fuks D, Pautrat $K$ et al. Effect of postoperative antibiotic administration on postoperative infection following cholecystectomy for acute calculous cholecystitis: a randomized clinical trial. JAMA 2014; 312: 145-154

[120] Roulin D, Saadi A, Di Mare L et al. Early versus delayed cholecystectomy for acute cholecystitis, are the 72 hours still the rule? A randomized trial. Ann Surg 2016; 264: 717-722
[121] Schmidt M, Sondenaa K, Vetrhus M et al. Long-term follow-up of a randomized controlled trial of observation versus surgery for acute cholecystitis: non-operative management is an option in some patients. Scand J Gastroenterol 2011; 46: 1257-1262

[122] Yadav RP, Adhikary S, Agrawal CS et al. A comparative study of early vs. delayed laparoscopic cholecystectomy in acute cholecystitis. Kathmandu Univ Med J (KUMJ) 2009; 7: 16-20

[123] Deng YL, Xiong XZ, Zhou Y et al. Selective histology of cholecystectomy specimens-is it justified? J Surg Res 2015; 193: 196-201

[124] Glauser PM, Strub D, Kaser SA et al. Incidence, management, and outcome of incidental gallbladder carcinoma: analysis of the database of the Swiss association of laparoscopic and thoracoscopic surgery. Surg Endosc 2010; 24: 2281-2286

[125] Götze TO, Paolucci V. Immediate re-resection of T1 incidental gallbladder carcinomas: a survival analysis of the German Registry. Surg Endosc 2008; 22: 2462-2465

[126] Hari DM, Howard JH, Leung AM et al. A 21-year analysis of stage I gallbladder carcinoma: is cholecystectomy alone adequate? HPB (Oxford) 2013; $15: 40-48$

[127] Lee SE, Jang JY, Lim CS et al. Systematic review on the surgical treatment for T1 gallbladder cancer. World J Gastroenterol 2011; 17: 174-180

[128] Swank HA, Mulder IM, Hop WC et al. Routine histopathology for carcinoma in cholecystectomy specimens not evidence based: a systematic review. Surg Endosc 2013; 27: 4439-4448

[129] Tantia O, Jain M, Khanna S et al. Incidental carcinoma gall bladder during laparoscopic cholecystectomy for symptomatic gall stone disease. Surg Endosc 2009; 23: 2041-2046

[130] van Vliet JL, van Gulik TM, Verbeek PC. Is it necessary to send gallbladder specimens for routine histopathological examination after cholecystectomy? The use of macroscopic examination. Dig Surg 2013; 30: $472-475$

[131] Yoon JH, Lee Y], Kim SC et al. What is the better choice for T1b gallbladder cancer: simple versus extended cholecystectomy. World I Surg 2014; 38: 3222-3227

[132] You DD, Lee HG, Paik KY et al. What is an adequate extent of resection for T1 gallbladder cancers? Ann Surg 2008; 247: 835-838

[133] Zhang WJ, Xu GF, Zou XP et al. Incidental gallbladder carcinoma diagnosed during or after laparoscopic cholecystectomy. World J Surg 2009; 33: $2651-2656$

[134] Fuks D, Regimbeau JM, Le TreutYP et al. Incidental gallbladder cancer by the AFC-GBC-2009 Study Group. World J Surg 2011; 35: 1887-1897

[135] Fuks D, Regimbeau JM, Pessaux P et al. Is port-site resection necessary in the surgical management of gallbladder cancer? J Visc Surg 2013; 150: $277-284$

[136] Götze TO, Paolucci V. Benefits of reoperation of T2 and more advanced incidental gallbladder carcinoma: analysis of the German registry. Ann Surg 2008; 247: 104-108

[137] Maker AV, Butte JM, Oxenberg J et al. Is port site resection necessary in the surgical management of gallbladder cancer? Ann Surg Oncol 2012; 19: $409-417$

[138] Gurusamy KS, Vaughan J, Ramamoorthy R et al. Miniports versus standard ports for laparoscopic cholecystectomy. Cochrane Database Syst Rev 2013; 8: CD006804

[139] Milas M, Devedija S, Trkulja V. Single incision versus standard multiport laparoscopic cholecystectomy: up-dated systematic review and metaanalysis of randomized trials. Surgeon 2014; 12: 271-289

[140] Keizman D, Ish-Shalom M, Konikoff FM. The clinical significance of bile duct sludge: is it different from bile duct stones? Surg Endosc 2007; 21: $769-773$

[141] Lee YS, Kang BK, Hwang IK et al. Long-term outcomes of symptomatic gallbladder sludge. J Clin Gastroenterol 2015; 49: 594-598 
[142] Alvarez FA, de Santibanes M, Palavecino M et al. Impact of routine intraoperative cholangiography during laparoscopic cholecystectomy on bile duct injury. Br J Surg 2014; 101: 677-684

[143] de Reuver PR, Rauws EA, Bruno MJ et al. Survival in bile duct injury patients after laparoscopic cholecystectomy: a multidisciplinary approach of gastroenterologists, radiologists, and surgeons. Surgery 2007; 142: 1 -9

[144] de Reuver PR, Grossmann I, Busch OR et al. Referral pattern and timing of repair are risk factors for complications after reconstructive surgery for bile duct injury. Ann Surg 2007; 245: 763 - 770

[145] Ejaz A, Spolverato G, Kim Y et al. Long-term health-related quality of life after iatrogenic bile duct injury repair. J Am Coll Surg 2014; 219: $923-932$

[146] Eikermann M, Siegel R, Broeders I et al. Prevention and treatment of bile duct injuries during laparoscopic cholecystectomy: the clinical practice guidelines of the European Association for Endoscopic Surgery (EAES). Surg Endosc 2012; 26: 3003 - 3039

[147] Ford JA, Soop M, Du J et al. Systematic review of intraoperative cholangiography in cholecystectomy. Br J Surg 2012; 99: 160-167

[148] Giger U, Ouaissi M, Schmitz SF et al. Bile duct injury and use of cholangiography during laparoscopic cholecystectomy. Br J Surg 2011; 98: $391-396$

[149] Landman MP, Feurer ID, Moore DE et al. The long-term effect of bile duct injuries on health-related quality of life: a meta-analysis. HPB (Oxford) 2013; 15: 252-259

[150] Pitt HA, Sherman S, Johnson MS et al. Improved outcomes of bile duct injuries in the 21st century. Ann Surg 2013; 258: 490-499

[151] Sahajpal AK, Chow SC, Dixon E et al. Bile duct injuries associated with laparoscopic cholecystectomy: timing of repair and long-term outcomes. Arch Surg 2010; 145: 757-763

[152] Sheffield KM, Riall TS, Han Y et al. Association between cholecystectomy with vs without intraoperative cholangiography and risk of common duct injury. JAMA 2013; 310: 812-820

[153] Tornqvist B, Stromberg C, Persson G et al. Effect of intended intraoperative cholangiography and early detection of bile duct injury on survival after cholecystectomy: population based cohort study. BMJ 2012; 345: e6457

[154] Walsh RM, Henderson JM, Vogt DP et al. Long-term outcome of biliary reconstruction for bile duct injuries from laparoscopic cholecystectomies. Surgery 2007; 142: 450-456

[155] Kilic A, Sheer A, Shah AS et al. Outcomes of cholecystectomy in US heart transplant recipients. Ann Surg 2013; 258: 312-317

[156] Sarkio S, Salmela K, Kyllonen L et al. Complications of gallstone disease in kidney transplantation patients. Nephrol Dial Transplant 2007; 22: $886-890$

[157] Alexakis N, Connor S. Meta-analysis of one- vs. two-stage laparoscopic/endoscopic management of common bile duct stones. HPB (Oxford) 2012; 14: 254-259

[158] Clayton ES, Connor S, Alexakis N et al. Meta-analysis of endoscopy and surgery versus surgery alone for common bile duct stones with the gallbladder in situ. Br J Surg 2006; 93: 1185-1191

[159] Bansal VK, Misra MC, Garg P et al. A prospective randomized trial comparing two-stage versus single-stage management of patients with gallstone disease and common bile duct stones. Surg Endosc 2010; 24: 1986 - 1989

[160] Bansal VK, Misra MC, Rajan K et al. Single-stage laparoscopic common bile duct exploration and cholecystectomy versus two-stage endoscopic stone extraction followed by laparoscopic cholecystectomy for patients with concomitant gallbladder stones and common bile duct stones: a randomized controlled trial. Surg Endosc 2014; 28: 875-885
[161] Dasari BV, Tan C], Gurusamy KS et al. Surgical versus endoscopic treatment of bile duct stones. Cochrane Database Syst Rev 2013; 12 : CD003327

[162] Ding G, Cai W, Qin M. Single-stage vs. two-stage management for concomitant gallstones and common bile duct stones: a prospective randomized trial with long-term follow-up. J Gastrointest Surg 2014; 18: $947-951$

[163] ElGeidie AA, ElShobary MM, Naeem YM. Laparoscopic exploration versus intraoperative endoscopic sphincterotomy for common bile duct stones: a prospective randomized trial. Dig Surg 2011; 28: 424-431

[164] ElGeidie AA, ElEbidy GK, Naeem YM. Preoperative versus intraoperative endoscopic sphincterotomy for management of common bile duct stones. Surg Endosc 2011; 25: 1230 - 1237

[165] Gurusamy K, Sahay SJ, Burroughs AK et al. Systematic review and meta-analysis of intraoperative versus preoperative endoscopic sphincterotomy in patients with gallbladder and suspected common bile duct stones. Br J Surg 2011; 98: 908-916

[166] Wang B, Guo Z, Liu Z et al. Preoperative versus intraoperative endoscopic sphincterotomy in patients with gallbladder and suspected common bile duct stones: system review and meta-analysis. Surg Endosc 2013; 27: 2454-2465

[167] Koc B, Karahan S, Adas G et al. Comparison of laparoscopic common bile duct exploration and endoscopic retrograde cholangiopancreatography plus laparoscopic cholecystectomy for choledocholithiasis: a prospective randomized study. Am J Surg 2013; 206: 457-463

[168] Noble H, Tranter S, Chesworth T et al. A randomized, clinical trial to compare endoscopic sphincterotomy and subsequent laparoscopic cholecystectomy with primary laparoscopic bile duct exploration during cholecystectomy in higher risk patients with choledocholithiasis. J Laparoendosc Adv Surg Tech A 2009; 19: 713-720

[169] Rogers SJ, Cello JP, Horn JK et al. Prospective randomized trial of LC $+\mathrm{LCBDE}$ vs ERCP/S+LC for common bile duct stone disease. Arch Surg 2010; 145: $28-33$

[170] Lu J, Cheng Y, Xiong XZ et al. Two-stage vs single-stage management for concomitant gallstones and common bile duct stones. World J Gastroenterol 2012; 18: 3156-3166

[171] McAlister VC, Davenport E, Renouf E. Cholecystectomy deferral in patients with endoscopic sphincterotomy. Cochrane Database Syst Rev 2007; 4: CD006233

[172] Reinders JS, Goud A, Timmer R et al. Early laparoscopic cholecystectomy improves outcomes after endoscopic sphincterotomy for choledochocystolithiasis. Gastroenterology 2010; 138: 2315-2320

[173] Aboulian A, Chan T, Yaghoubian A et al. Early cholecystectomy safely decreases hospital stay in patients with mild gallstone pancreatitis: a randomized prospective study. Ann Surg 2010; 251: 615-619

[174] van Baal MC, Besselink MG, Bakker OJ et al. Timing of cholecystectomy after mild biliary pancreatitis: a systematic review. Ann Surg 2012; 255: $860-866$

[175] Petrov MS, van Santvoort HC, Besselink MG et al. Early endoscopic retrograde cholangiopancreatography versus conservative management in acute biliary pancreatitis without cholangitis: a meta-analysis of randomized trials. Ann Surg 2008; 247: 250-257

[176] van Santvoort HC, Besselink MG, de Vries AC et al. Early endoscopic retrograde cholangiopancreatography in predicted severe acute biliary pancreatitis: a prospective multicenter study. Ann Surg 2009; 250: $68-75$

[177] Tse F, Yuan Y. Early routine endoscopic retrograde cholangiopancreatography strategy versus early conservative management strategy in acute gallstone pancreatitis. Cochrane Database Syst Rev 2012; 5 : CD009779

[178] Sharaiha RZ, Khan MA, Kamal F et al. Efficacy and safety of EUS-guided biliary drainage in comparison with percutaneous biliary drainage 
when ERCP fails: a systematic review and meta-analysis. Gastrointest Endosc 2017; 85: $904-914$

[179] Khan MA, Akbar A, Baron TH et al. Endoscopic ultrasound-guided biliary drainage: a systematic review and meta-analysis. Dig Dis Sci 2016; 61: 684-703

[180] Gurusamy KS, Rossi M, Davidson BR. Percutaneous cholecystostomy for high-risk surgical patients with acute calculous cholecystitis. Cochrane Database Syst Rev 2013; 8: CD007088

[181] Winbladh A, Gullstrand P, Svanvik J et al. Systematic review of cholecystostomy as a treatment option in acute cholecystitis. HPB (Oxford) 2009; 11: 183-193

[182] Khan MA, Atiq O, Kubiliun N et al. Efficacy and safety of endoscopic gallbladder drainage in acute cholecystitis: Is it better than percutaneous gallbladder drainage? Gastrointest Endosc 2017; 85: 76- 87 e73

[183] Date RS, Kaushal M, Ramesh A. A review of the management of gallstone disease and its complications in pregnancy. Am J Surg 2008; 196: $599-608$
[184] Dhupar R, Smaldone GM, Hamad GG. Is there a benefit to delaying cholecystectomy for symptomatic gallbladder disease during pregnancy? Surg Endosc 2010; 24: 108 -112

[185] Othman MO, Stone E, Hashimi M et al. Conservative management of cholelithiasis and its complications in pregnancy is associated with recurrent symptoms and more emergency department visits. Gastrointest Endosc 2012; 76: $564-569$

[186] Barthelsson C, Anderberg B, Ramel S et al. Outpatient versus inpatient laparoscopic cholecystectomy: a prospective randomized study of symptom occurrence, symptom distress and general state of health during the first post-operative week. J Eval Clin Pract 2008; 14: 577 - 584

[187] Vaughan J, Gurusamy KS, Davidson BR. Day-surgery versus overnight stay surgery for laparoscopic cholecystectomy. Cochrane Database Syst Rev 2013; 7: CD006798 